Conference Proceedings Paper

\title{
Analysis of Spatial and Temporal Variation of Criteria Air Pollutants in Bangkok Metropolitan Region (BMR) during 2000-2015
}

\author{
Towqir A. Aziz 1,2, Ruozhang Xu 1,2, Chengliang Fan 1,2, Mansi K. Shah 1,2, \\ Thanonphat Boonman ${ }^{2}$, Pham Thi Bich Thao ${ }^{2}$, Sébastien Bonnet ${ }^{2}$ and Savitri Garivait ${ }^{2, *}$ \\ Published: 19 July 2016 \\ 1 UNC Institute for the Environment, University of North Carolina, 100 Europa Drive, \\ Suite 490 Campus Box 1105 Chapel Hill, NC 27517, USA \\ 2 The Joint Graduate School for Energy and Environment (JGSEE), Centre for Energy Technology and \\ Environment (CEE-PERDO), King Mongkut's University of Technology Thonburi (KMUTT), \\ 126 Pracha-Uthit Road, Bangmod, Tungkru, Bangkok 10140, Thailand \\ * Correspondence: savitri_g@jgsee.kmutt.ac.th or savitri.jgsee@gmail.com; Tel.: +66-247-083-09-10 (ext. 4134)
}

\begin{abstract}
Bangkok Metropolitan Region - Thailand (BMR), one of the major metropolitan areas in the world, is a bustling upper-middle class megacity composed of Bangkok city proper and five surrounding provinces. With an actual population of approximately 15 million, it is the central hub for commerce and tourism in the Southeast Asian (SEA) region. In the past decades, Bangkok has experienced extraordinary economic development and urban expansion, all the while displaying notable concern regarding the ambient air pollution and its adverse effects on human health. In this study, 16-years of air quality monitoring data were collected from 25 stations in BMR, which are operated by the Thailand's Pollution Control Department. Data for $\mathrm{O}_{3}, \mathrm{PM}_{10}, \mathrm{NOx}, \mathrm{CO}$ and $\mathrm{SO}_{2}$ were analyzed temporally with a particular focus on long-term, seasonal and diurnal variations. The data were also analyzed spatially to identify the hotspots and flow of air pollution in the region. These investigations were performed to assess the evolution of air quality in BMR over the past 16 years and identify areas of potential concern. Analysis of the data indicated that $\mathrm{PM}_{10}, \mathrm{NOx}, \mathrm{CO}$ and $\mathrm{SO}_{2}$ were in a moderate decline over the 16 years, while $\mathrm{O}_{3}$ concentration has risen steadily throughout this time period. The results and findings of these investigations are discussed with a perspective to provide policy recommendations for air quality improvements in BMR.
\end{abstract}

Keywords: Bangkok Metropolitan Region (BMR); air quality; monitoring; criteria air pollutants; seasonal variation

\section{Introduction}

There has been a rising concern reguarding ambient air pollution throughout the past two decades, especially for "megacities", a term defined as a metropolitan area with a total population exceeding ten million people [1]. Recent studies have clearly demonstrated adverse health impacts related to pollutants such as ozone $\left(\mathrm{O}_{3}\right)$, particulate matter $(\mathrm{PM})$, carbon monoxide $(\mathrm{CO})$, nitrogen oxides (NOx) and sulfur dioxide $\left(\mathrm{SO}_{2}\right)$ [2]. Exposure to such pollutants will lead to increased incidence of pulmonary, cardiovascular and respiratory diseases [3]. The consequent rising mortality and hospitalization rate will also bring about economic burdens to the society [4]. As a result, monitoring and regulating the air quality are urgent and imperative, especially for megacities and metropolises with high population density. Bangkok Metropolitan Region (BMR) in Thailand, is one of the major 
The 1st International Electronic Conference on Atmospheric Sciences (ECAS 2016), 16-31 July 2016;

Sciforum Electronic Conference Series, Vol. 1, 2016

metropolitan areas and in the world that face nascent health impacts due to air quality issues.

This study mainly focused on five of the major criteria air pollutants: $\mathrm{O}_{3}, \mathrm{PM}_{10}, \mathrm{CO}, \mathrm{NO}_{x}$ and $\mathrm{SO}_{2}$. Tropospheric ozone is a secondary air pollutant resulted from the emission of $\mathrm{NO}_{x}$ (mostly from fossil fuel use), VOCs (mostly from biogenic sources) and CO in the presence of sunlight [5]. The background ozone concentration is determined by a set of three reactions together called the "nitrogen cycle":

$$
\begin{gathered}
\mathrm{NO}+\mathrm{O}_{3} \rightarrow \mathrm{NO}_{2}+\mathrm{O}_{2} \\
\mathrm{NO}_{2}+\mathrm{hv} \rightarrow \mathrm{NO}+\mathrm{O} \\
\mathrm{O}+\mathrm{O}_{2} \rightarrow \mathrm{O}_{3}
\end{gathered}
$$

Reaction 1 and Reaction 3 are relatively fast while Reaction 2 is the rate-limiting step [6]. The photochemical oxidation of VOCs provides another pathway to convert $\mathrm{NO}$ to $\mathrm{NO}_{2}$ while not eating up ozone: hydroxyl radicals $(\mathrm{OH})$ oxidize the organic compounds and then form peroxy radicals $\left(\mathrm{HO}_{2}\right.$ and $\left.\mathrm{RO}_{2}\right)$ which can react with $\mathrm{NO}$ as demonstrated in Reaction 4:

$$
\mathrm{NO}+\mathrm{HO}_{2} \rightarrow \mathrm{NO}_{2}+\mathrm{OH}
$$

PM10, defined as particulate matter with a diameter equal to or less than 10 micrometers, is a mixture of solid and liquid particles suspended in the air [3]. PM10 can be directly released to the atmosphere from road dusts, uncovered soil, and mining and agricultural processes as a primary pollutant; meanwhile, it can also be formed by the reactions of the precursors including $\mathrm{NH}_{3}, \mathrm{NO}_{x}$ and $\mathrm{SO}_{2}$ as a secondary pollutant [7]. $\mathrm{CO}, \mathrm{NO}_{x}$ and $\mathrm{SO}_{2}$ are all common primary pollutants resulted from the incomplete or high temperature combustion of fossil fuels such as coal and oil [8].

The study utilized monitoring data of 25 stations on the five criteria pollutants in BMR over 2000 to 2015 from the Pollution Control Department of Thailand (PCD), and by analyzing the yearly, monthly and diurnal trends of the five pollutants, as well as their spatial distribution variations throughout the city center and suburbs, documented the air quality in BMR. This study aims to build on and update previous air quality research in the BMR $[9,10]$. Furthermore, this paper aims to elucidate the relationship between recent policy changes and the resultant air quality impacts. Finally, this paper aims to make recommendations regarding pollution control for the public and policy makers.

\section{Materials and Methods}

\subsection{Study Area}

Bangkok, the capital city of Thailand, is located in the Chao Phraya River delta in the country's central plain and is next to the Gulf of Thailand. Bangkok city proper and its five surrounding provinces, Samut Prakan, Samut Sakhon, Pathum Thani, Pathum Nakhon and Nonthaburi, form a large metropolis, BMR, which covers an area of $7761.6 \mathrm{~km}^{2}$ and home to more than 15 million people [11]. Furthermore, within the BMR lies the Bangkok Metropolitan Administration (BMA), which, in 2010, covered an area of $2100 \mathrm{~km}^{2}$ and was home to 9.6 million people [12].

Figure 1 details the location of the BMR in Thailand. Figures 2 and 3 map the BMR and the BMA, respectively, with their registered populations. This information can be helpful in understanding the health risks posed by various criteria pollutant concentrations throughout the region. 


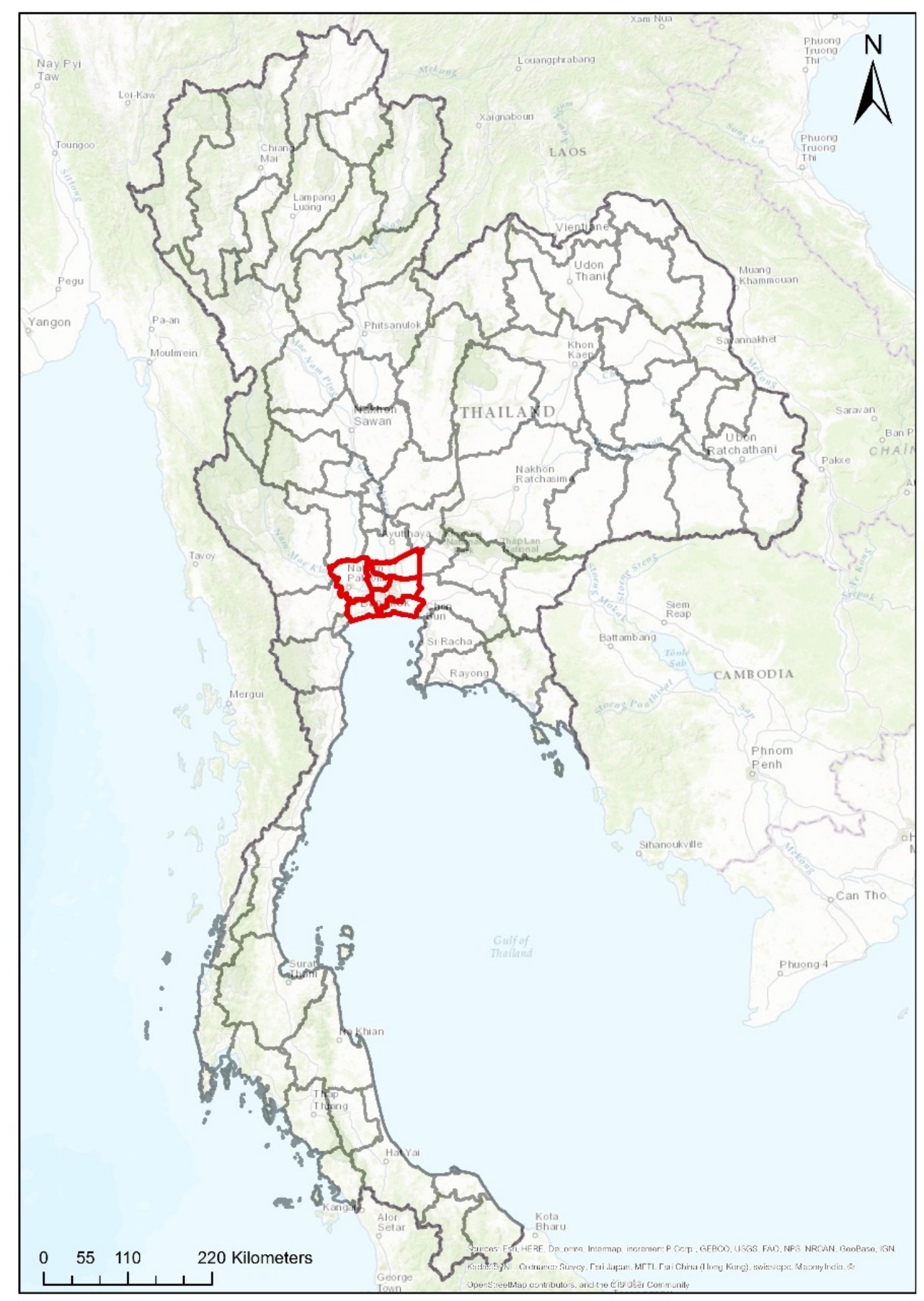

Figure 1. This figure highlights the BMR in red, to show the location in regards to the nation of Thailand.

The BMR has a climate that varies seasonally according to the typical monsoon regime with two main seasons in each year-a wet season from mid-May to mid-October due to monsoon rains, and a dry season from mid-October to mid-May. The dry season can further be divided into two periods, a mild local winter season from October to February that brings slightly cooler temperatures, and an extremely hot local summer season from February until May. Thailand experiences a high relative humidity year round [13].

The population data used in this study was obtained from the National Statistics Office of Thailand. The data, which was in spreadsheet form, was sorted and formatted so that it could be input into ArcGIS for the creation of population maps, Figures 2 and 3. 
The 1st International Electronic Conference on Atmospheric Sciences (ECAS 2016), 16-31 July 2016; Sciforum Electronic Conference Series, Vol. 1, 2016

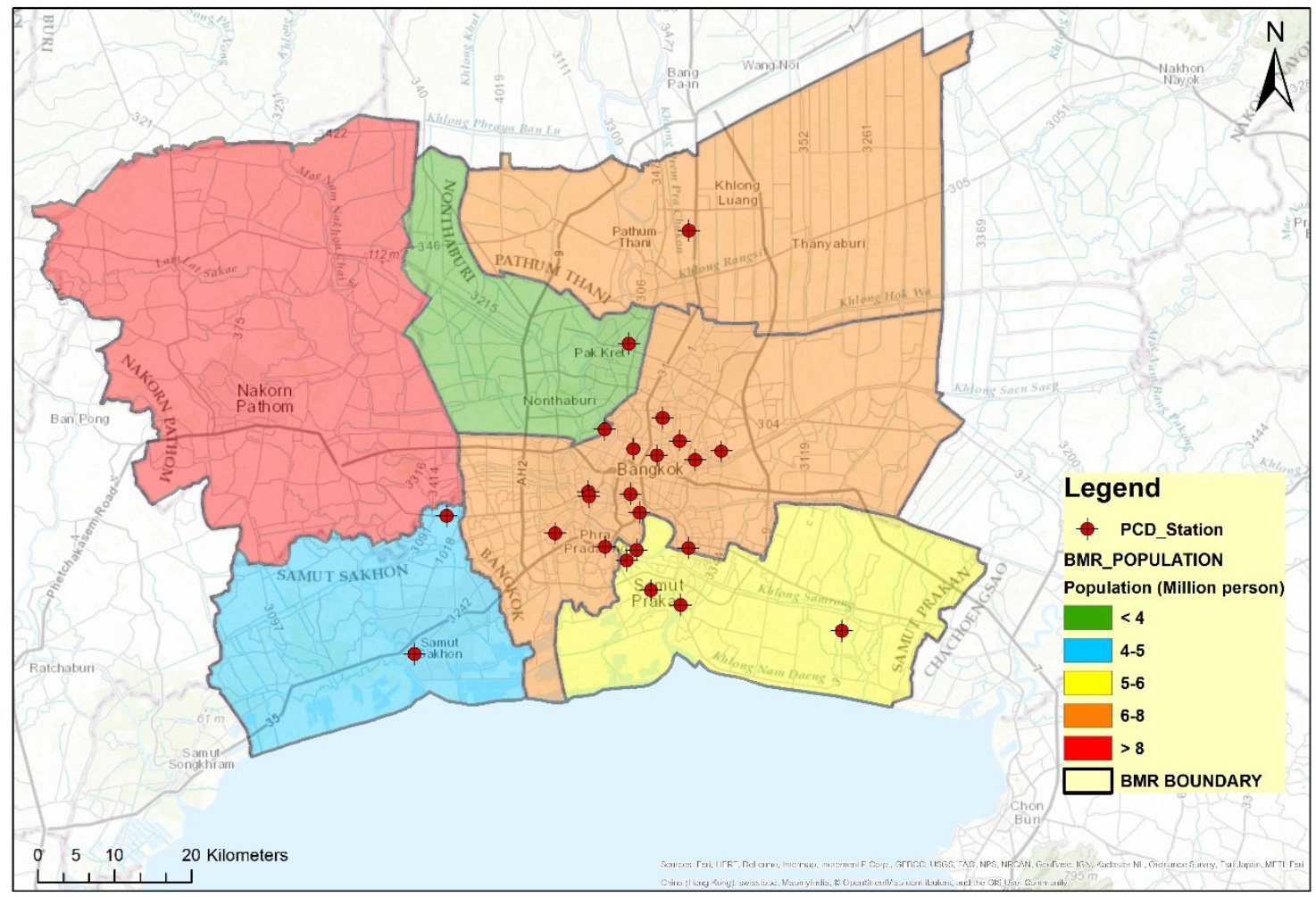

Figure 2. This map displays the districts within the BMR and their total populations, along with the location of every PCD air quality monitoring station within the BMR.



Figure 3. This map displays the districts within BMA and their total populations, along with the location of every PCD air quality monitoring station within the BMA. 


\subsection{PCD Monitoring Stations}

The PCD stations pictured in Figures 2 and 3 are all listed in numerical order in Table 1, along with the district they are in and their designation as being either a general area ambient air quality measurement station or a roadside ambient air quality measurement station. There were 20 general stations and 5 roadside stations in the BMR. The general stations are representative for ambient air quality in surrounding areas, and are usually located at least $100 \mathrm{~m}$ away from major road. The roadside sites are located approximately 10-50 m away from a major roadway.

Table 1. This table lists all of the PCD Stations within the BMR.

\begin{tabular}{cccc}
\hline $\begin{array}{c}\text { Station ID } \\
\text { Number }\end{array}$ & Station Name & District Name & Type of Station \\
\hline 2 & Bansomdejchaopraya Rajabhatá & Thonburi & General Area \\
3 & Rat Burana & Ratburana & General Area \\
5 & TMD & Bangna & General Area \\
7 & Chandrakasem & JJ & General Area \\
8 & Prabadang Rehabitation for the Disable & Shongkanong & General Area \\
10 & Klongjun NHA & Bangkapi & General Area \\
11 & Huaykwang NHA Stadium & HuayKwang & General Area \\
12 & ShongNonsi & Yannawa & General Area \\
13 & EGAT & Bangkruai & General Area \\
14 & Samutsakhon Highway District & Kratoomban & General Area \\
15 & Bangkhuntien & Bang Khun Tien & General Area \\
16 & South Bangkok Thermal Power Plants & Muang & General Area \\
17 & Samut Prakan City Hall & Phraphradeang & General Area \\
18 & Bangplee NHA & Muang & General Area \\
19 & Pathumthani & Bangple & General Area \\
20 & STOU & Klongluang & General Area \\
22 & Residence for Dept of Primary Industries and Mines & Pakkret & General Area \\
27 & Muang & General Area \\
49 & Samutsakhon Subdistrict Administrative Organization & Moadside \\
50 & Department of Land traspotation & JJ & Roadside \\
52 & Rama 4 Road & Pathum Wan & Roadside \\
53 & Thonburi Power Substation & Thonburi & Roadside \\
54 & Chokchai 4 Police Station & Bangkapi & Roadside \\
59 & Dindaeng & Dindaeng & Roadside \\
61 & Public Relations Department & Phayathai & General Area \\
& Badindecha School & Wangtonglang & General Area \\
\hline
\end{tabular}

The BMR air quality data used in this study were collected by Thailand's Pollution Control Department of the Ministry of Natural Resources and Environment between the years 2000 to 2015. Hourly data air pollution and meteorological data were collected at 27 air-monitoring stations spread throughout the BMR. Of these stations, two were disregarded as they did not have enough data. Each station records data for for $\mathrm{O}_{3}, \mathrm{PM}_{10}, \mathrm{NO}_{x}, \mathrm{CO}$ and $\mathrm{SO}_{2}$, and some stations take additional meteorological and air quality measurements which were not analysed in this study, such as temperature, relative humidy, wind speed and wind direction, and solar radiation.

\subsection{Pollutant Data Collection and Processing}

Each of the stations collected data using the respective instruments, as listed in Table 2, and transmitted the hourly average values for the measurements to a central computer situated in the building of each station via a data logger and modem. The instruments are calibrated regularly. 
The 1st International Electronic Conference on Atmospheric Sciences (ECAS 2016), 16-31 July 2016; Sciforum Electronic Conference Series, Vol. 1, 2016

Table 2. This table lists the methods of pollutant concentration monitoring and measurement at the PCD Stations within the BMR.

\begin{tabular}{cc}
\hline Pollutants & Method \\
\hline $\mathrm{CO}$ & Non-dispersive IR \\
$\mathrm{NO}_{2}$ & Chemiluminescence \\
$\mathrm{SO}_{2}$ & Pararosalinine/UV Fluorescence \\
$\mathrm{PM}_{10}$ & Gravimetric High volume \\
$\mathrm{O}_{3}$ & Chemiluminescence \\
\hline
\end{tabular}

\subsection{Statistical Methods Used to Analyze Collected Data}

Hourly data was collected for the five criteria pollutants and saved in spreadsheet from over 16 years. This data was sorted and analyzed using Microsoft Excel's pivot table function, sorting each pollutant into several different time groupings, in order to calculate yearly (overall), monthly (seasonal), and hourly (diurnal) trends. Each individual station varied in the number of data points collected, and sporadically had incomplete data over certain time spans. Two stations did not have sufficient data, and thus were discontinued from the analysis. For the other stations, all recorded data were included in the calculations and for the analysis. If there were any breaks in the recorded data, or any missing dates, such as from before a specific station started collecting data, these hours were considered as having null values and thus did not affect the averages or any percentages. The yearly average was a comprehensive average of each hourly data point for each individual pollutant over the course of one calendar year, at each specific station, which was then averaged together to give the BMR average. The monthly data was similarly averaged across each month, at each station, for each individual pollutant. The diurnal data consisted of the average pollutant level at each specific hour, across the time span of one year. For example, one average would include the specific pollutant level every day at 1:00 am, for 365 days. This value was then averaged over the 16 years' worth of data to show the diurnal trend that each of these pollutants exhibit.

$\mathrm{PM}_{10}$ and $\mathrm{O}_{3}$ were found to have exceeded PCD standards in some of their measurements. These standards, yearly for the PM10 measurements and hourly for $\mathrm{O}_{3}$, were obtained from the PCD's Notification of National Environmental Board No. 24, in 2004, and Notification of National Environmental Board No. 28, in 2007, respectively. To calculate the exceedance percentage, the number of data collections were counted, and of these, the number of exceedances were counted. The resulting fraction was then turned into a percentage.

\section{Results}

\subsection{Ozone}

Figure 4 shows the overall trend of ozone levels in the BMR, which has almost doubled since the year 2000. The mean ozone level in the BMR was found to increase approximately 79.2\% over the last 16 years, each year showing an average annual increase of about $4.2 \%$ from the previous year. Also important to note is the fact that even the minimum average levels of ozone more than doubled, as can be seen by the lower whisker in the box and whisker plot of Figure 4. These minimum levels of ozone are usually found in the city center, as these are the locations where there is an increased concentration of $\mathrm{NO}_{x}$, primarily due to $\mathrm{NO}$ emitted from vehicular transport. The effect of ozone is felt most strongly in the outskirts of the city, or in less urbanized areas with lower vehicular emissions, as these locations have lower concentrations of NOx. Alarmingly, the maximum of the 1 hour averages of the ozone levels increased approximately $76 \%$, which reflects an increasing risk of photochemical smog occurrences. The overall increase in ozone levels in the BMR is of concern for the future, and this trend is expected to continue to grow, as ozone production in the BMR seems to be a function mainly dependent on VOCs, as there was not a strong relationship observed between $\mathrm{NO}_{x}$, the other major anthropogenic precursor to $\mathrm{O}_{3}$. VOCs were not included in this study as they 
The 1st International Electronic Conference on Atmospheric Sciences (ECAS 2016), 16-31 July 2016; Sciforum Electronic Conference Series, Vol. 1, 2016

were not monitored by most stations in the BMR until recent years, but play an integral role in the environmental chemistry surrounding tropospheric ozone formation. VOCs may be increasing due to the Thai government initiative to produce more of its fuel and energy from biofuels, rather than fossil fuels. This would further explain the trend in increasing $\mathrm{O}_{3}$ that has been observed.

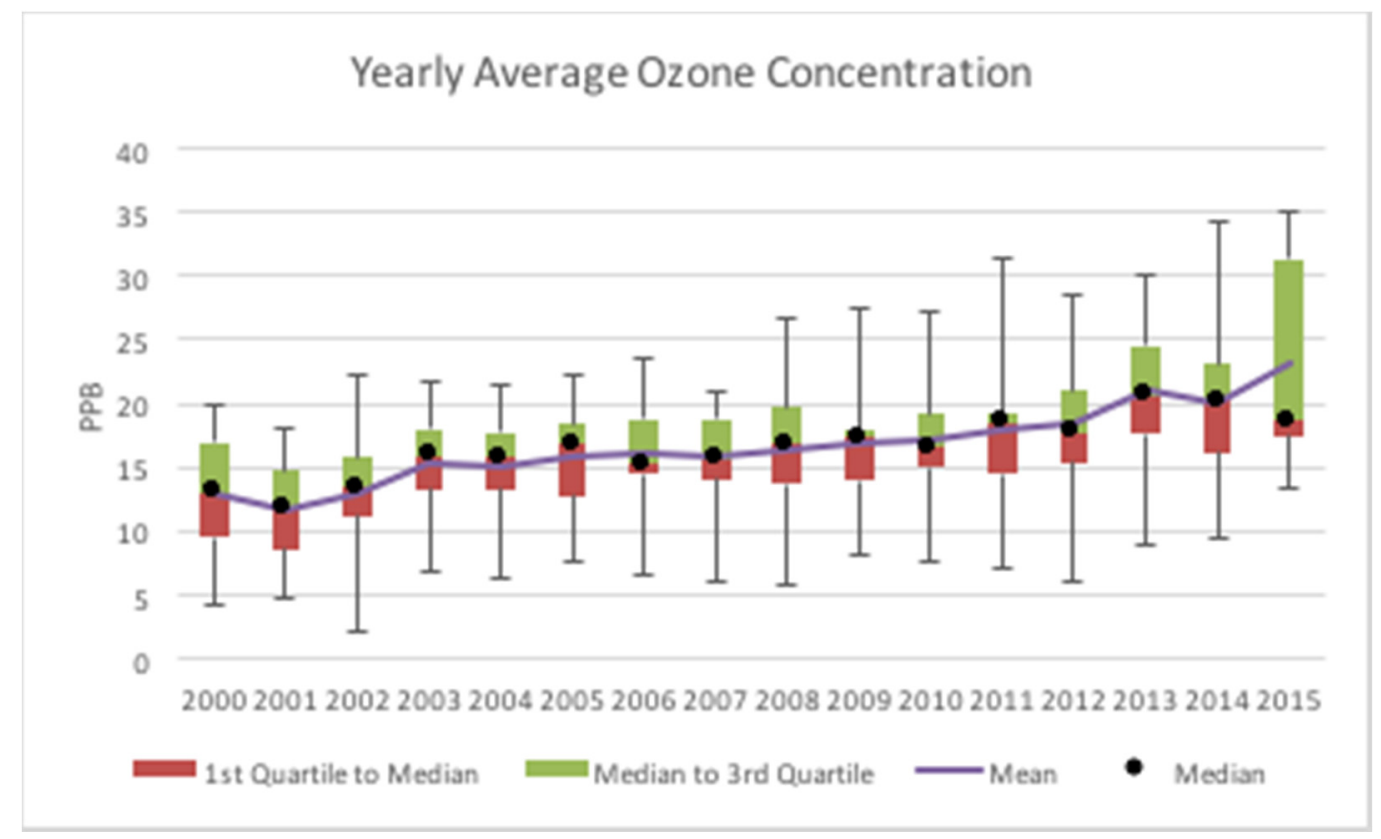

Figure 4. Long Term Average $\mathrm{O}_{3}$ Trend.

Figure 5 shows the seasonal trends for $\mathrm{O}_{3}$, which rises during the dry season, reaching a maximum during the mild portion of the dry season, while experiencing a minimum level in the midst of the wet season. This can be explained by the meteorological conditions during these seasons, as the mild season has favorable conditions for $\mathrm{O}_{3}$ production involving the $\mathrm{NO}_{x}$ chain reaction, the aforementioned VOCs, and hydroxide radicals. In the wet season, cloud cover inhibits tropospheric solar radiation, which in turn suppresses the photolysis of $\mathrm{NO}_{2}$ which produces $\mathrm{O}_{3}$.

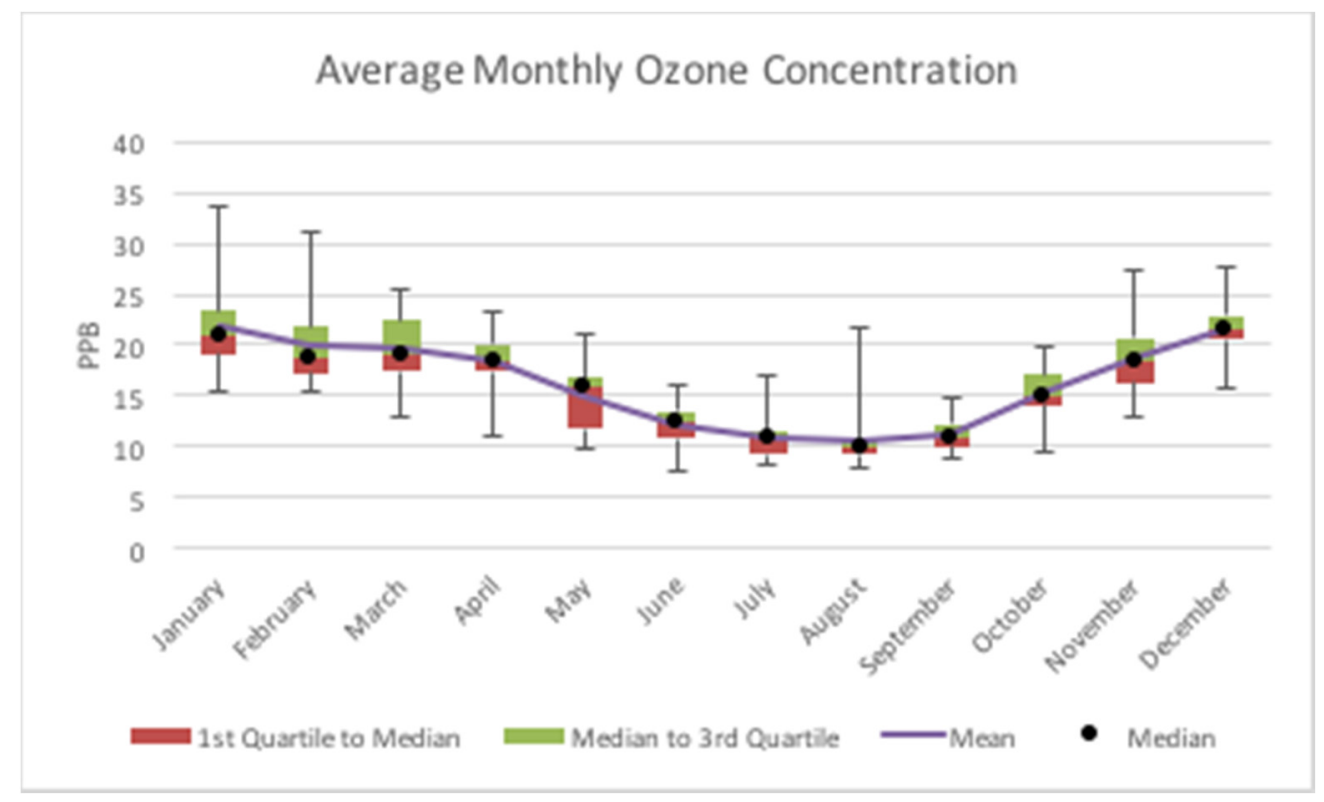

Figure 5. Seasonal Average $\mathrm{O}_{3}$ Trend Graph. 
The 1st International Electronic Conference on Atmospheric Sciences (ECAS 2016), 16-31 July 2016; Sciforum Electronic Conference Series, Vol. 1, 2016

Figure 6 shows the diurnal behavior of $\mathrm{O}_{3}$, which exhibits a minimum in the early morning, due to enhanced $\mathrm{O}_{3}$ depletion associated with $\mathrm{NO}$ emissions from vehicles during the morning rush hour. During the day time, an increased concentration of $\mathrm{NO}_{2}$, an assumed increase in VOC emissions, and an increase in solar radiation all contribute to the net increase of $\mathrm{O}_{3}$. This ozone was then once again destroyed due to NO emissions during the evening rush hour. A maximum value for ozone levels was thus seen in the early afternoon.

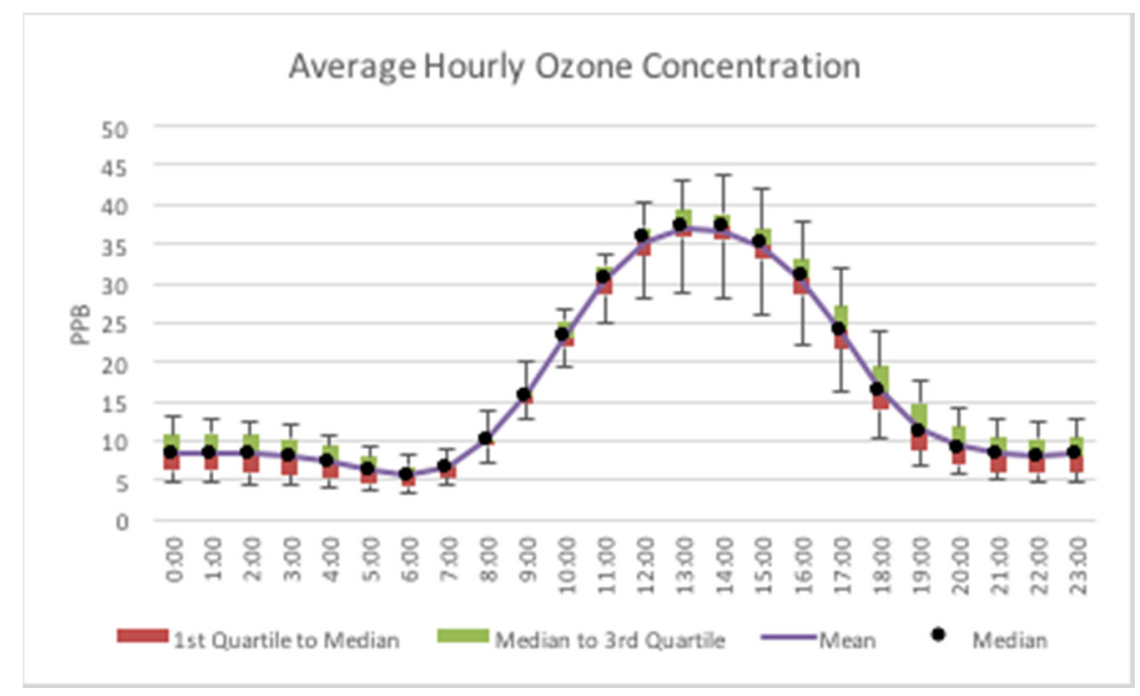

Figure 6. Average Diurnal $\mathrm{O}_{3}$ Trend Graph.

Figure 7 shows the spatial distribution of $\mathrm{O}_{3}$, which can be seen to have a higher concentration in the outskirts of the city and away from major roadways. This is due to the high levels of NO emissions from anthropogenic sources in the city center and along the roadways, which scavenge $\mathrm{O}_{3}$ and bring these levels down. Even in the inner city where the $\mathrm{O}_{3}$ is at its minimum, there has been an increase in $\mathrm{O}_{3}$ levels, which again is a sign of the possible impact of the integration of biofuels or alternative fuels such as natural gas for vehicles (NGV) into the transportation sector.

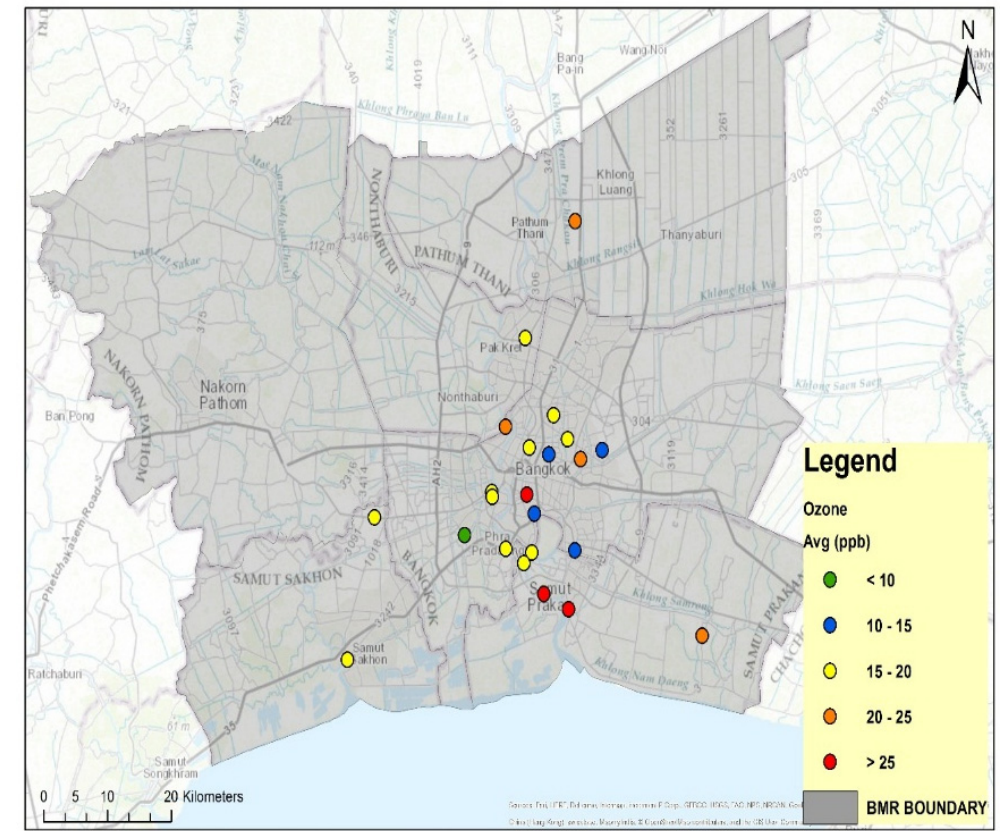

Figure 7. Spatial Distribution of Ozone Concentration in BMR. 
The $\mathrm{O}_{3}$ standard set by the PCD states that the hourly concentration of $\mathrm{O}_{3}$ should not exceed $0.10 \mathrm{ppm}$ [14] Exceedances of the hourly $\mathrm{O}_{3}$ standard were rare, but as the levels rise over time, will become more prevalent. Figure 8 is a representation of the percentage of hourly measurements at each station that exceeded the air quality standard concentration. The standard exceedances were found mostly in the outskirts, away from sources of $\mathrm{NO}$, and during the peak hours of $\mathrm{O}_{3}$ in the daytime. These exceedances may pose a health risk in the future, if levels continue to rise and exceedances become more frequent [15].

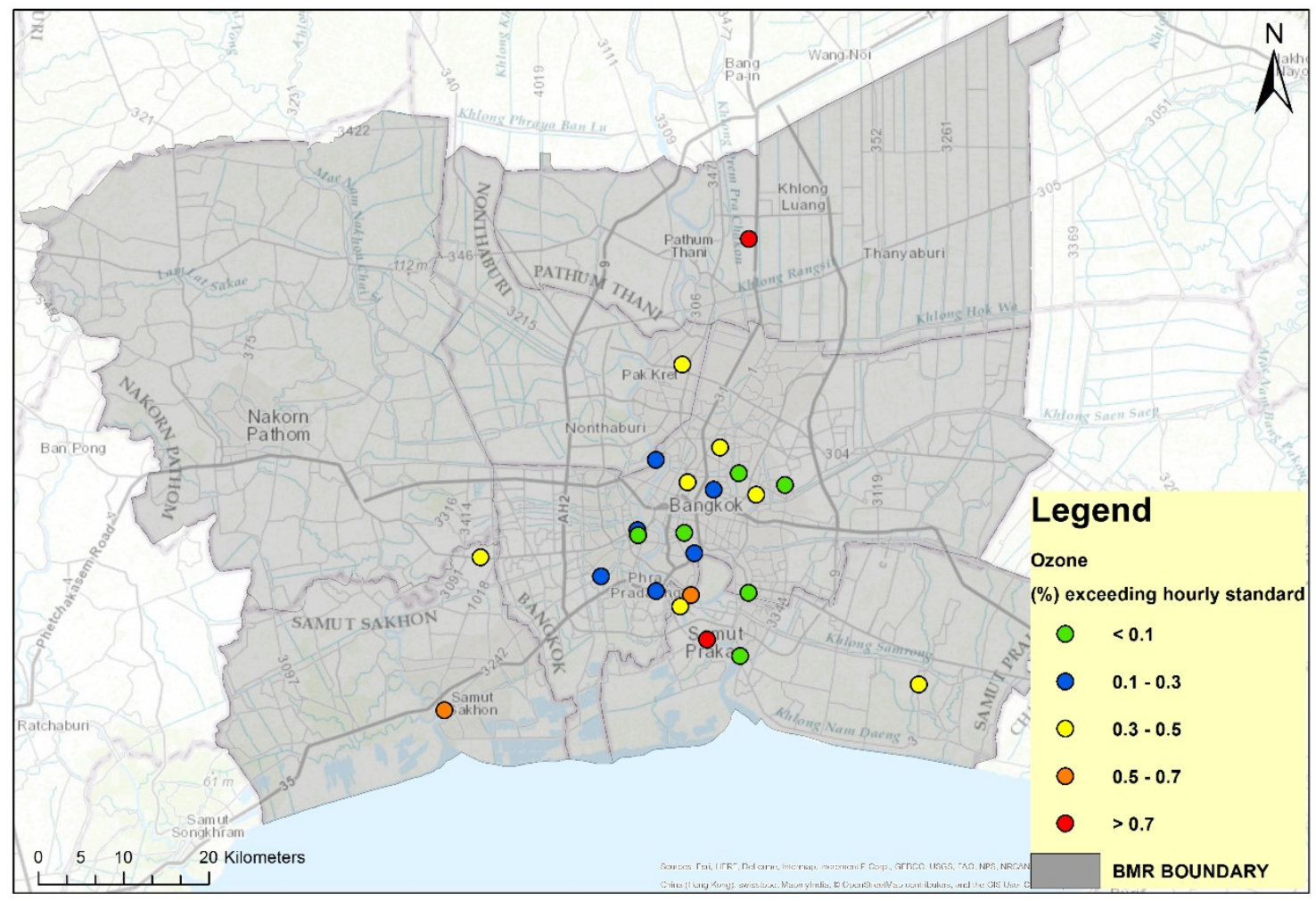

Figure 8. Exceedence Percentages of $\mathrm{O}_{3}$ Hourly Standard.

\section{2. $P M_{10}$}

Figure 9 shows the overall trend of PM10 levels in the BMR, which has almost decreased sharply since the year 2000. The mean PM10 level in the BMR was found to decrease approximately $48 \%$ over the last 16 years, each year showing an average annual decrease of about $13 \%$ from each previous year. From this yearly average of the hourly PM10 data, we can also observe an impressive $48.6 \%$ decrease of the maximum PM10 levels. This data set is also intriguing due to the fact that there is an obvious statistical anomaly skewing the annual averages in the first half of the decade. The intrigue of this phenomenon was compounded when it was discovered that the data skewing the averages were all exceptionally high levels of $\mathrm{PM}_{10}$ coming from the same province of the BMR, Samut Prakan. This province is an industrial and trade hub, as well as being home to the major international airport of the country, Suvarnabhumi International Airport. Construction of this airport may have contributed to the increased levels of $\mathrm{PM}_{10}$ in the early 2000s, and the construction activity corresponds very closely with the PM10 levels. Adding weight to this thesis is the fact that the ozone levels for these stations were also found to be high, suggesting that the PM10 was not from vehicular emissions, since increased traffic would result in higher $\mathrm{NO}_{x}$ levels, and, in turn, a generally lowered ozone level. Looking at the overall trend for PM10, the decrease, which seems promising upon first glance, is actually an inconclusive statistic. At best, it signals an improvement in transportation and industry technologies and practices, through which there is less partial combustion of fuels, and at 
The 1st International Electronic Conference on Atmospheric Sciences (ECAS 2016), 16-31 July 2016;

Sciforum Electronic Conference Series, Vol. 1, 2016

worst it could have been replaced with the finer $\mathrm{PM}_{2.5}$, which is much more dangerous to human health. What the data do show, however, is that the PM10 levels, although still at or exceeding the annual standards set by the PCD in some locations, has shown a marked improvement, especially since 2009. Before 2009 the mean PM10 concentration was at or above the annual PCD standards, but since then the average has remained below the standard.

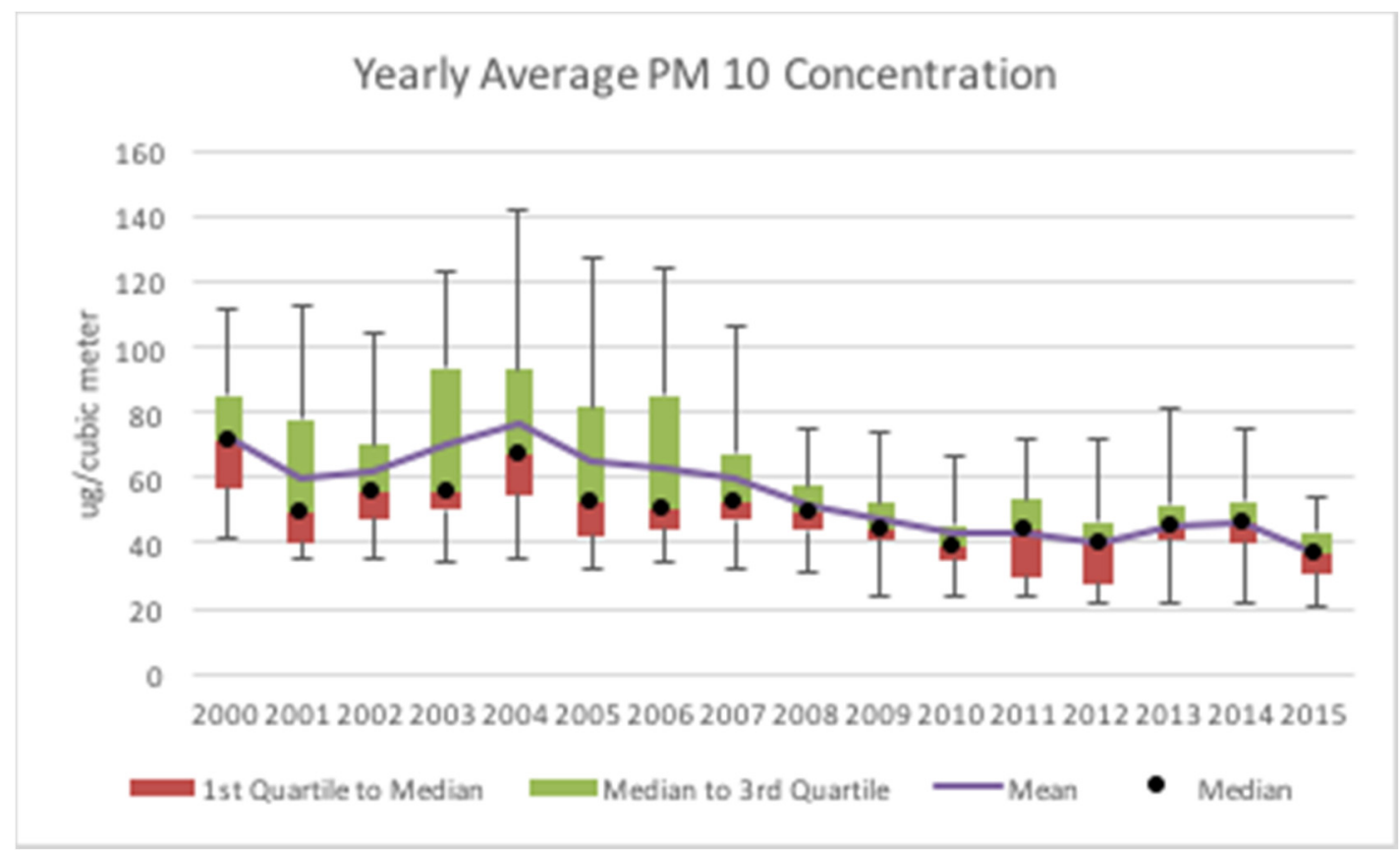

Figure 9. Long Term Average PM10 Trend.

Seasonal variations in $\mathrm{PM}_{10}$ are seen in Figure 10. PM10 levels increased during the dry season, and experienced lower values during the rainy months. This follows intuition, as particulate matter can be washed out of the atmosphere, and confirms precipitation scavenging effects on the removal of $\mathrm{PM}_{10}$ as demonstrated in previous studies [16].

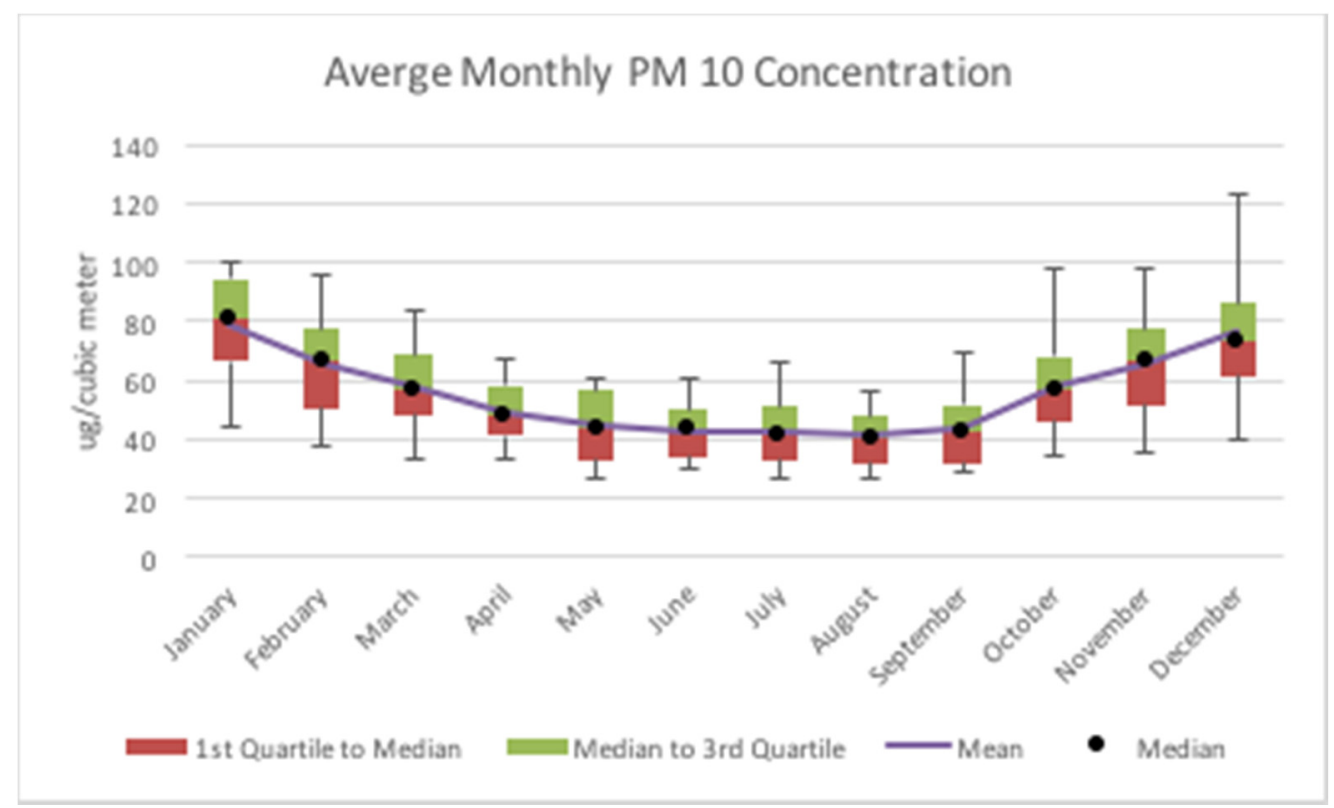

Figure 10. Seasonal Average PM10 Trend. 
The 1st International Electronic Conference on Atmospheric Sciences (ECAS 2016), 16-31 July 2016; Sciforum Electronic Conference Series, Vol. 1, 2016

Diurnal variations of PM10 are seen in Figure 11. PM10 levels displayed two separate peaks, which can be attributed to anthropogenic sources, specifically vehicular emissions from rush hour traffic. A morning peak is observed at $7 \mathrm{am}$, and an evening peak is seen at $8 \mathrm{pm}$.

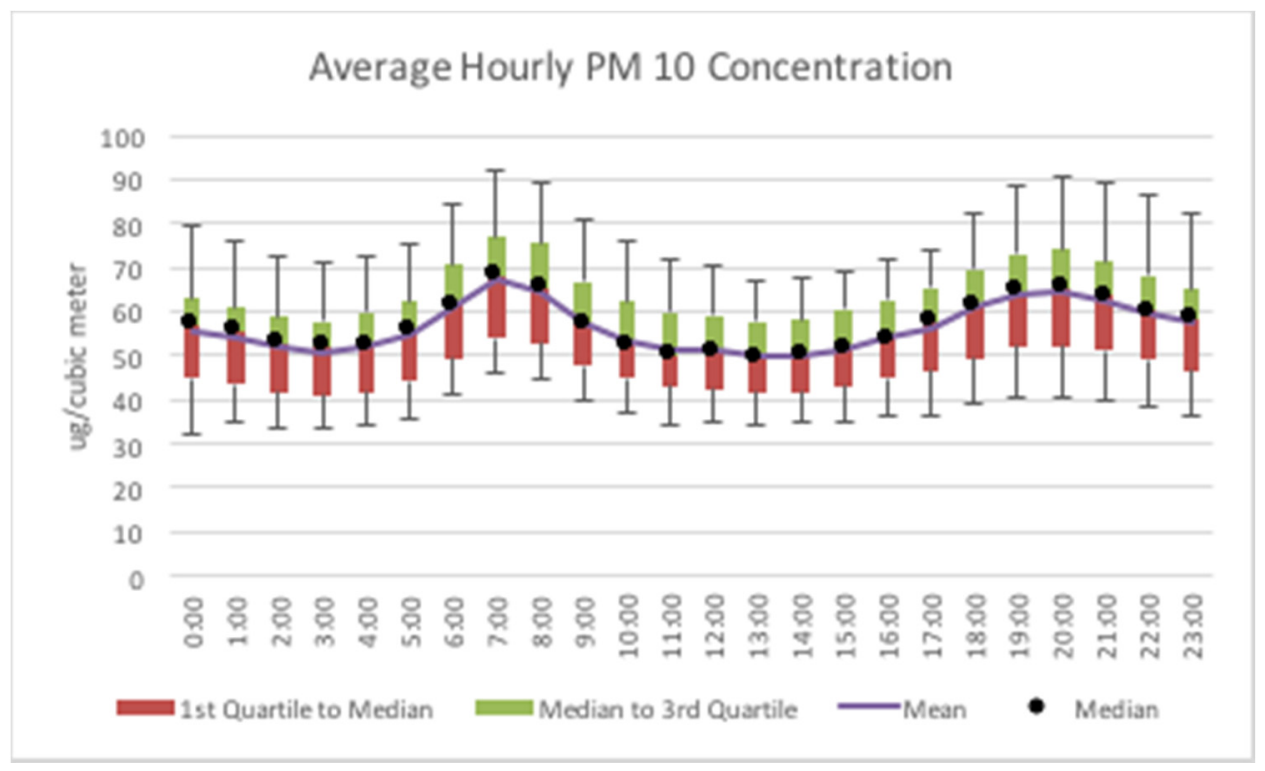

Figure 11. Average Diurnal PM10 Trend.

Spatially, PM10 was found to be highest at roadside monitoring stations, in the city center, and, as mentioned earlier, around industrial regions of Samut Prakan. Figure 12 shows the spatial distribution of the PM10 levels. This area was also of particular interest in that it was the site of massive construction in terms of the development of the new major international airport of Bangkok. Since the years of construction of the airport, the PM10 levels at Samut Prakan have since declined drastically.

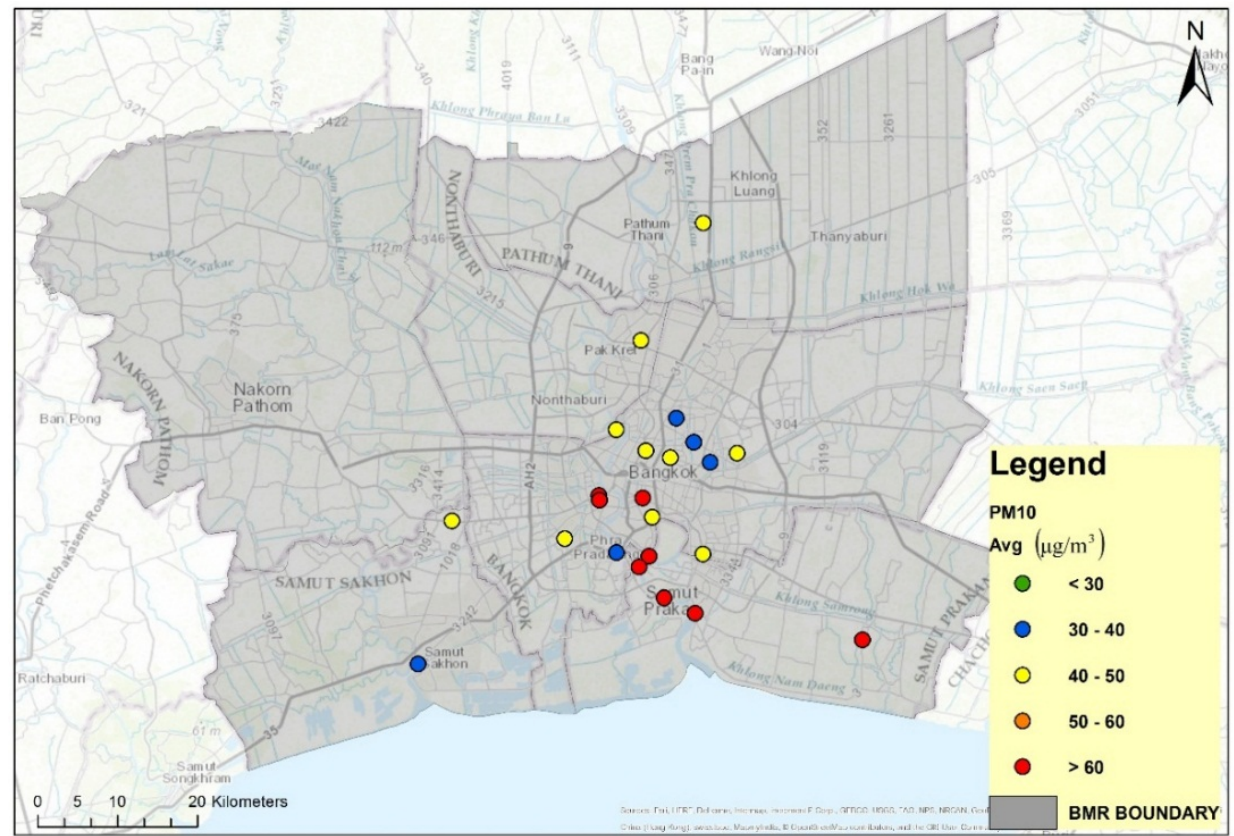

Figure 12. Spatial Distribution of $\mathrm{PM}_{10}$ Concentration in BMR. 
Overall there has been a decline in $\mathrm{PM}_{10}$ concentration levels throughout the BMR, although it still exceeds standards more than any other criteria pollutant. The yearly standard for PM10 is that a concentration should not exceed $0.05 \mathrm{mg} / \mathrm{m}^{3}$ [14]. PM10 is thus seen as one of the most urgent air quality issues to be addressed, and continue to pose a human health risk as well as an environmental risk. Figure 13 shows the areas that have the highest PM10 yearly standard exceedance levels, and thus pose the highest risk to individuals.

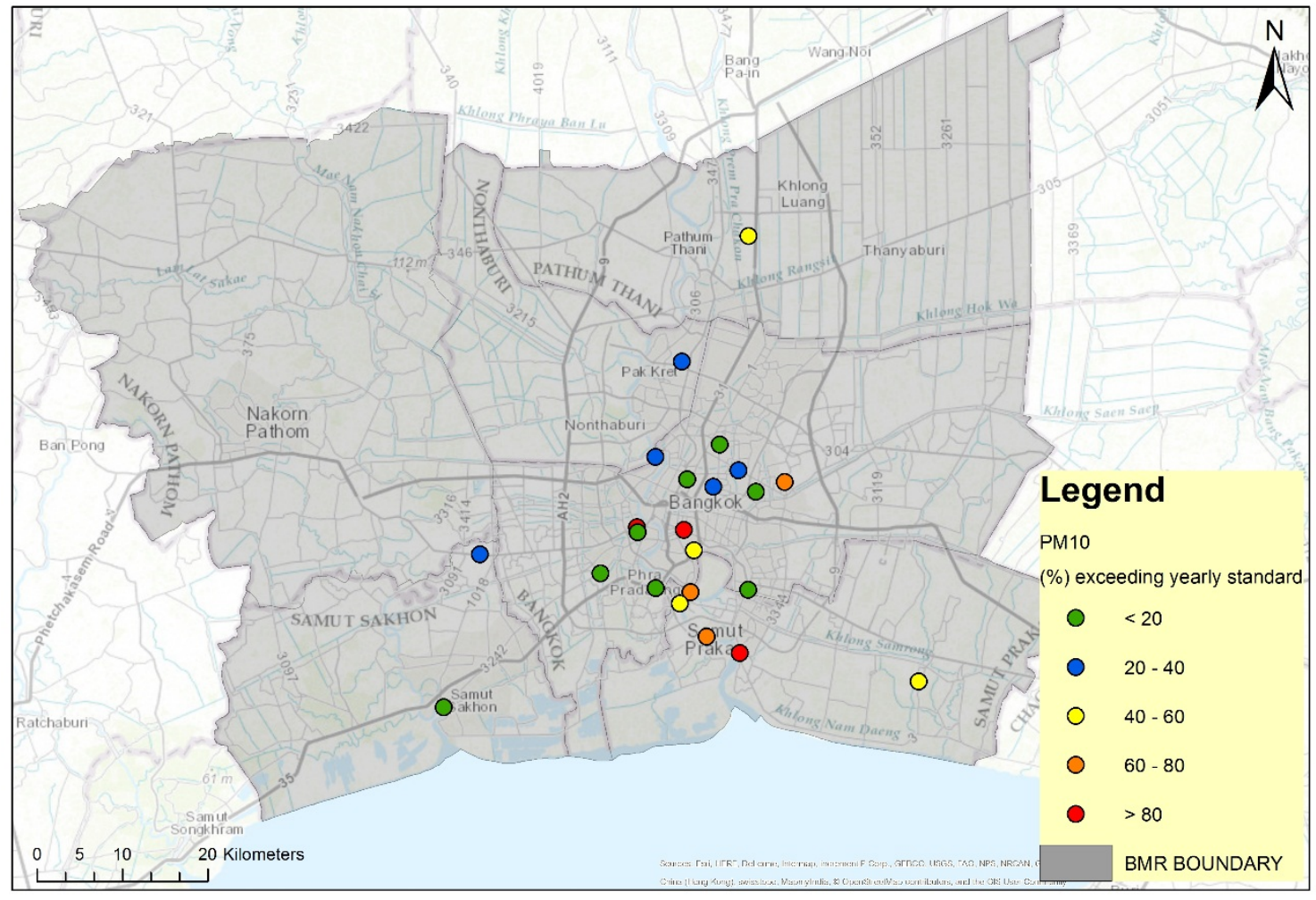

Figure 13. Exceedence Percentages of PM10 Yearly Standard.

\section{3. $N O_{x}$}

$\mathrm{NO}_{x}$ is composed of nitric oxide $(\mathrm{NO})$ and nitrogen dioxide $\left(\mathrm{NO}_{2}\right)$, which have important roles in ozone formation and depletion as well as in secondary particle formation. Figure 14 shows the overall trend of $\mathrm{NO}_{x}$ levels in the BMR, which has decreased by approximately $38.9 \%$ since the year 2000. This data were also skewed by outliers that pulled the mean up, which were primarily from roadside monitoring stations. These stations recorded higher $\mathrm{NO}_{x}$ levels due to increased vehicular emissions from traffic. As mentioned earlier, these sites also exhibited the inverse relationship with ozone, having the lowest tropospheric ozone levels of all the stations. The overall decrease in $\mathrm{NO}_{x}$ levels is promising, but may exacerbate the rise of ozone levels throughout the BMR.

The seasonal variation in $\mathrm{NO}_{x}$ is seen in Figure 15. NOx levels are observed to have been the lowest during the latter, hot portion of the dry months, and were observed to remain relatively low throughout the rainy months. The $\mathrm{NO}_{x}$ levels were highest during the mild dry season. This may be because of meteorological conditions not allowing for NOx formation. 
The 1st International Electronic Conference on Atmospheric Sciences (ECAS 2016), 16-31 July 2016;

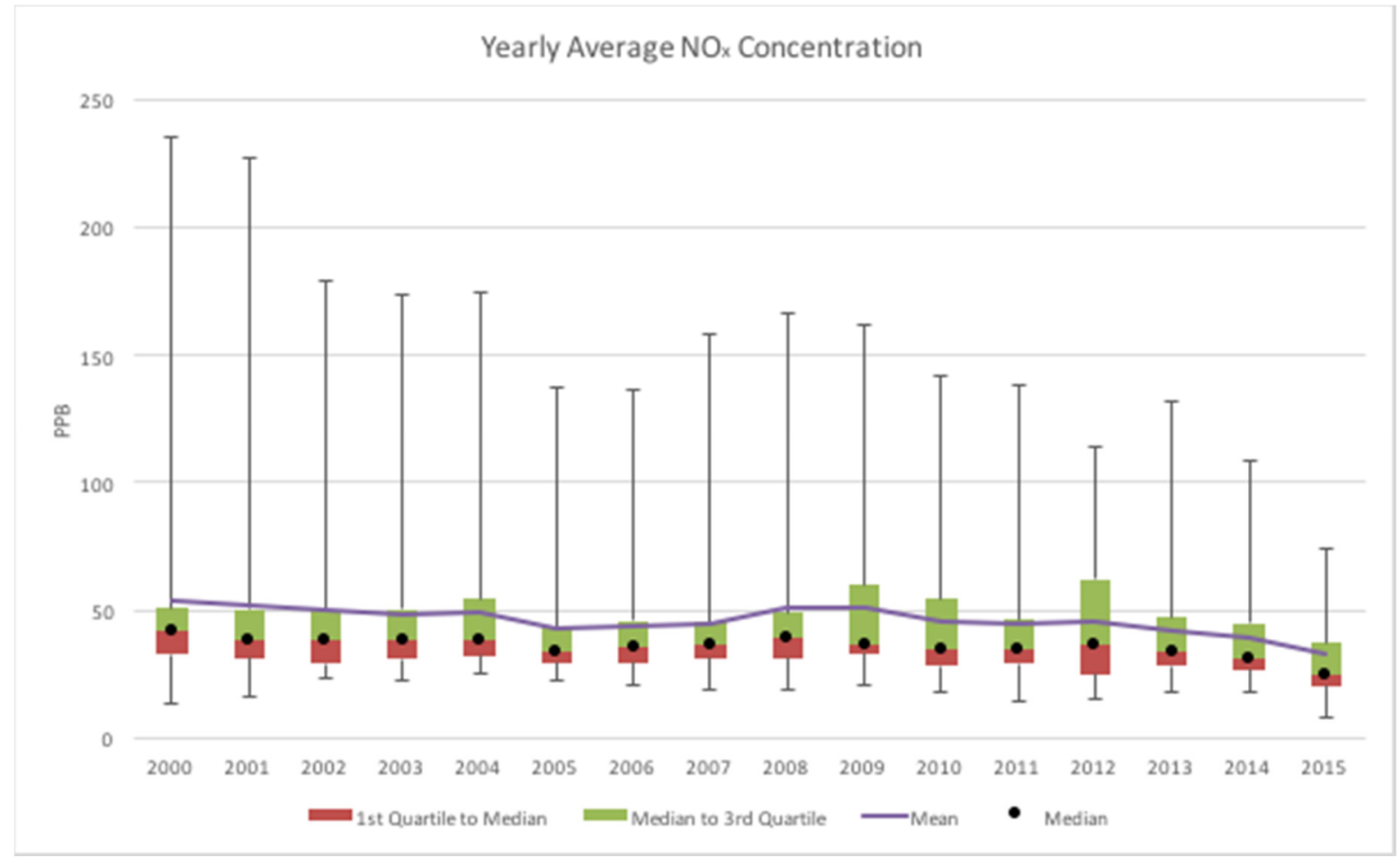

Figure 14. Long Term Average $\mathrm{NO}_{x}$ Trend.

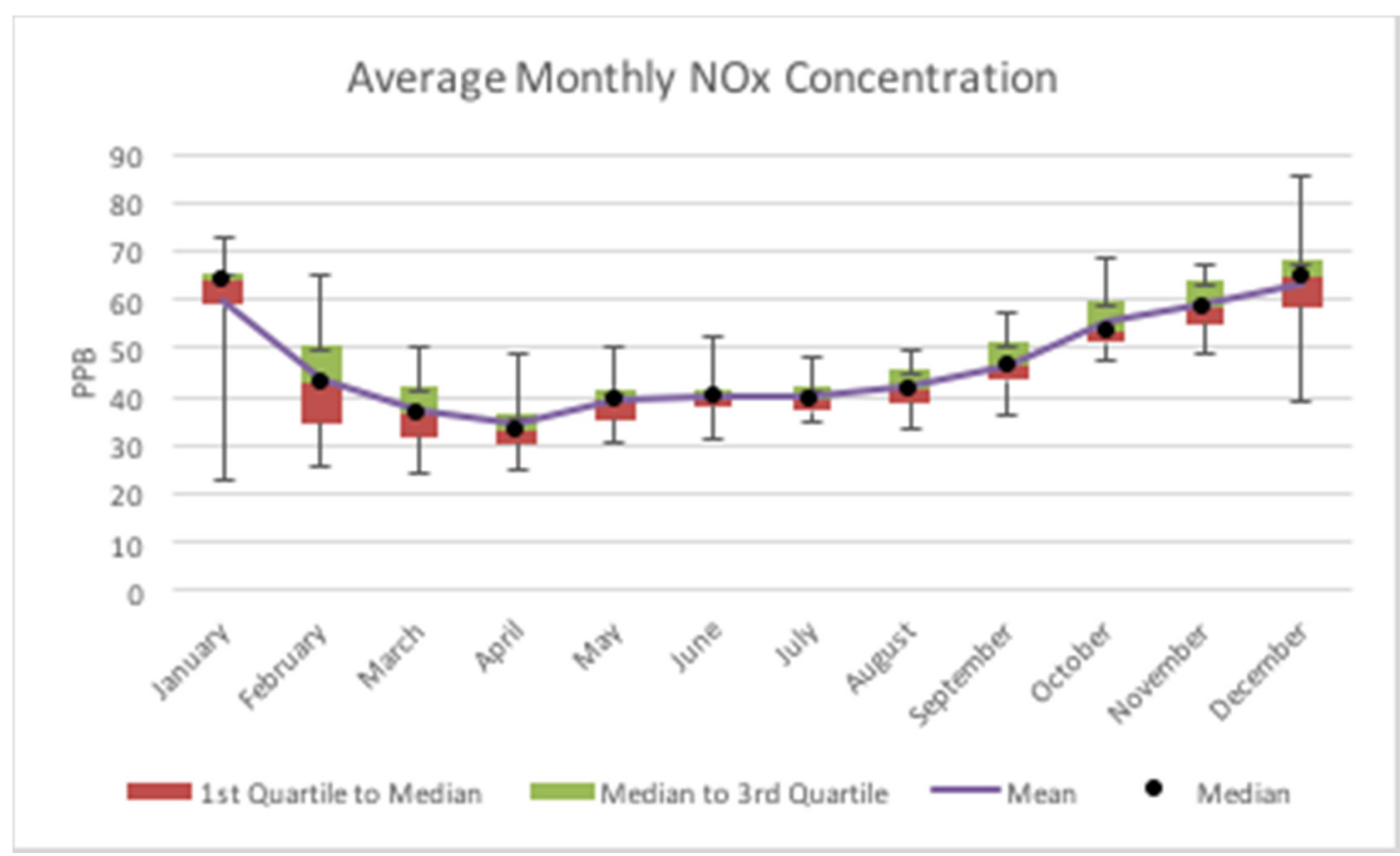

Figure 15. Seasonal NOx Trend Graph.

$\mathrm{NO}_{x}$ also experienced two separate peaks throughout the day, once in the morning and once in the evening, as seen in Figure 16. As mentioned earlier, $\mathrm{NO}_{\mathrm{x}}$ is highly dependent on anthropogenic production, and thus may correspond with times of high traffic volume. The diurnal trend seen with $\mathrm{PM}_{10}$ is reflected in the daily $\mathrm{NO}_{x}$ trend. It is interesting to note how dependent these levels are on anthropogenic sources, and how the trends can offer a peek into the lives of BMR residents. For example, there is a steep morning peak as residents begin their daily activities and go to work or 
The 1st International Electronic Conference on Atmospheric Sciences (ECAS 2016), 16-31 July 2016;

Sciforum Electronic Conference Series, Vol. 1, 2016

school, but in the afternoon the peak is lower and more spread out as individuals vary in their late afternoon and evening activities.



Figure 16. Diurnal NOx Trend Graph.

Spatially, $\mathrm{NO}_{\mathrm{x}}$ is generally higher within the city and along major roads, and has low ambient levels when further away from major roadways. Figure 17 displays the spatial distribution of $\mathrm{NO}_{\mathrm{x}}$ as measured by the monitoring stations in the BMR.

There was no PCD standards for $\mathrm{NO}_{x}$ concentration, although there were standards for $\mathrm{NO}_{2}$. As the data we had collected combined both $\mathrm{NO}$ and $\mathrm{NO}_{2}$, we could not determine if there were any exceedences of the $\mathrm{NO}_{2}$ standard. The $\mathrm{NO}_{2}$ yearly standard is not to exceed $0.03 \mathrm{ppm}$ [14].

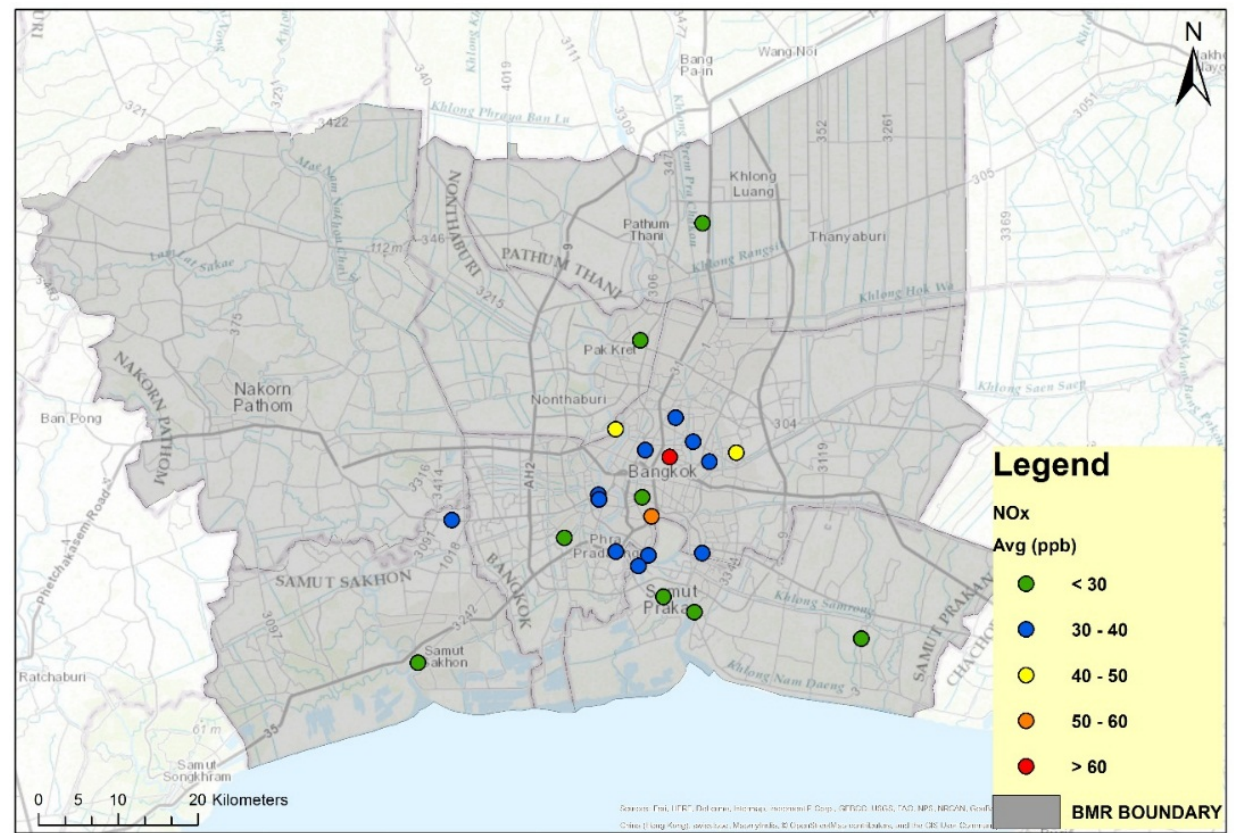

Figure 17. Spatial Distribution of $\mathrm{NO}_{x}$ Concentration in BMR. 
The 1st International Electronic Conference on Atmospheric Sciences (ECAS 2016), 16-31 July 2016; Sciforum Electronic Conference Series, Vol. 1, 2016

\section{4. $\mathrm{CO}$}

Figure 18 shows the overall trend of $\mathrm{CO}$ levels in the BMR, which has decreased since the year 2000. There has been approximately a $32 \%$ decrease in CO monoxide levels measured in the BMR, with an average annual decrease of almost $5 \%$ each year. Carbon monoxide is produced by the combustion of hydrocarbons in limited supplies of oxygen, and is thus highly dependent on traffic emissions. As expected, roadside monitoring stations pulled the average up, but even amongst these stations, the aveage fell approximately $45 \%$ over the analyzed time period. This is an encouraging sign, as the number of vehicles greatly increased over the same time period. Thus the decreased CO may be due to the switch from fossil fuel to biofuel (gasohol and biodiesel) that has been implemented by the Thai government, and especially to the implementation of more efficient engine technology and standards in the national on-road transport sector.

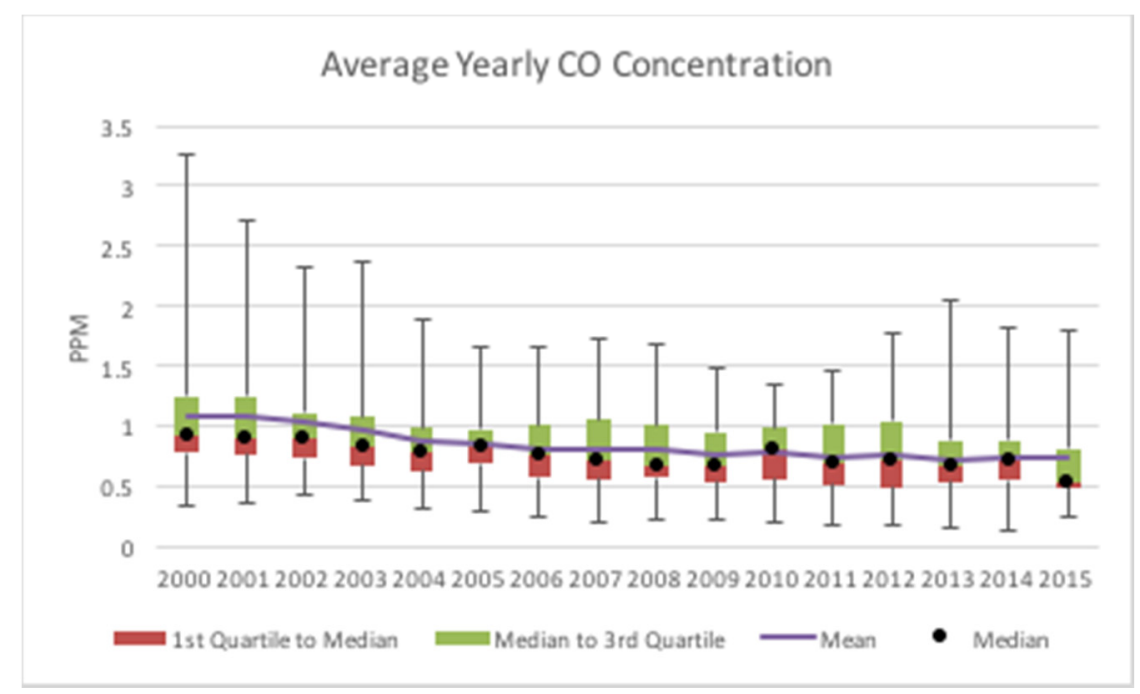

Figure 18. Long Term Average CO Trend.

Seasonal trends of $\mathrm{CO}$ show that there were high concentrations present during the dry season, and low concentrations during the wet season, as seen in Figure 19. This may be attributed to the strong atmospheric stability during the dry season, which suppresses dilution of pollutants, especially during the times of high traffic volume. The rainy season experienced lesser levels of $\mathrm{CO}$ due to vigorous mixing in the boundary layer of the troposphere, and to washout by rainfall.

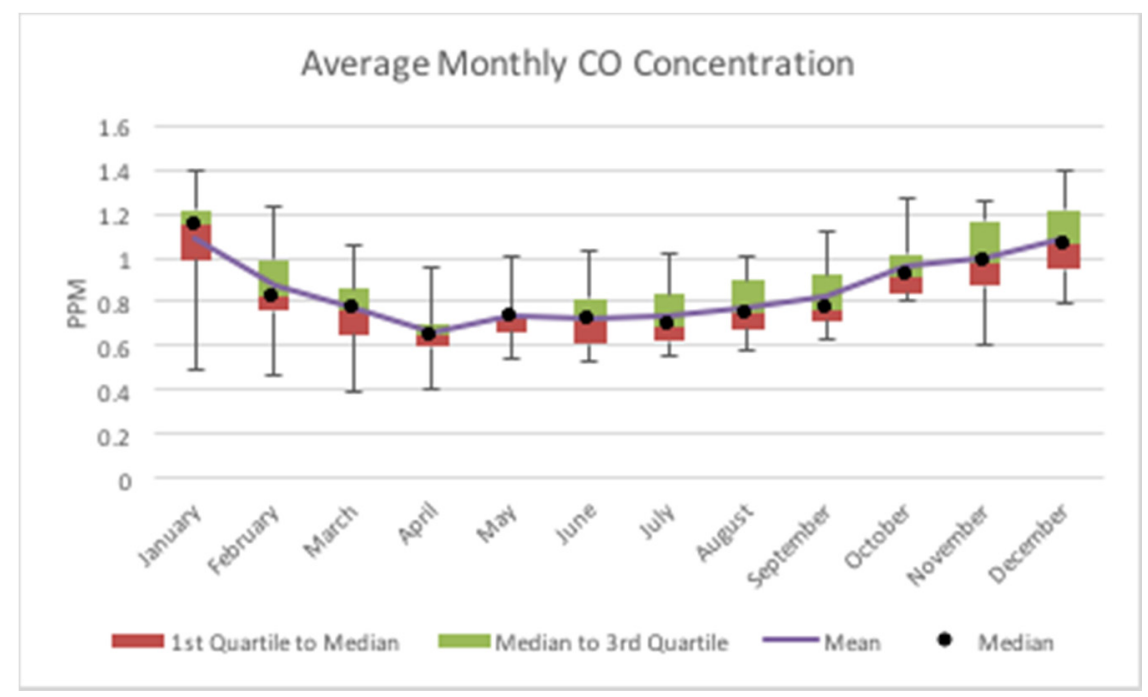

Figure 19. Seasonal CO Trend. 
The 1st International Electronic Conference on Atmospheric Sciences (ECAS 2016), 16-31 July 2016; Sciforum Electronic Conference Series, Vol. 1, 2016

$\mathrm{CO}$ experienced diurnal trends similar to those of $\mathrm{PM}_{10}$. The diurnal trend of $\mathrm{CO}$ can be seen in Figure 20, and the reasoning behind the variation throughout the day may be due to anthropogenic sources, similar to that of $\mathrm{PM}_{10}$ and $\mathrm{NO}_{x}$ as well.

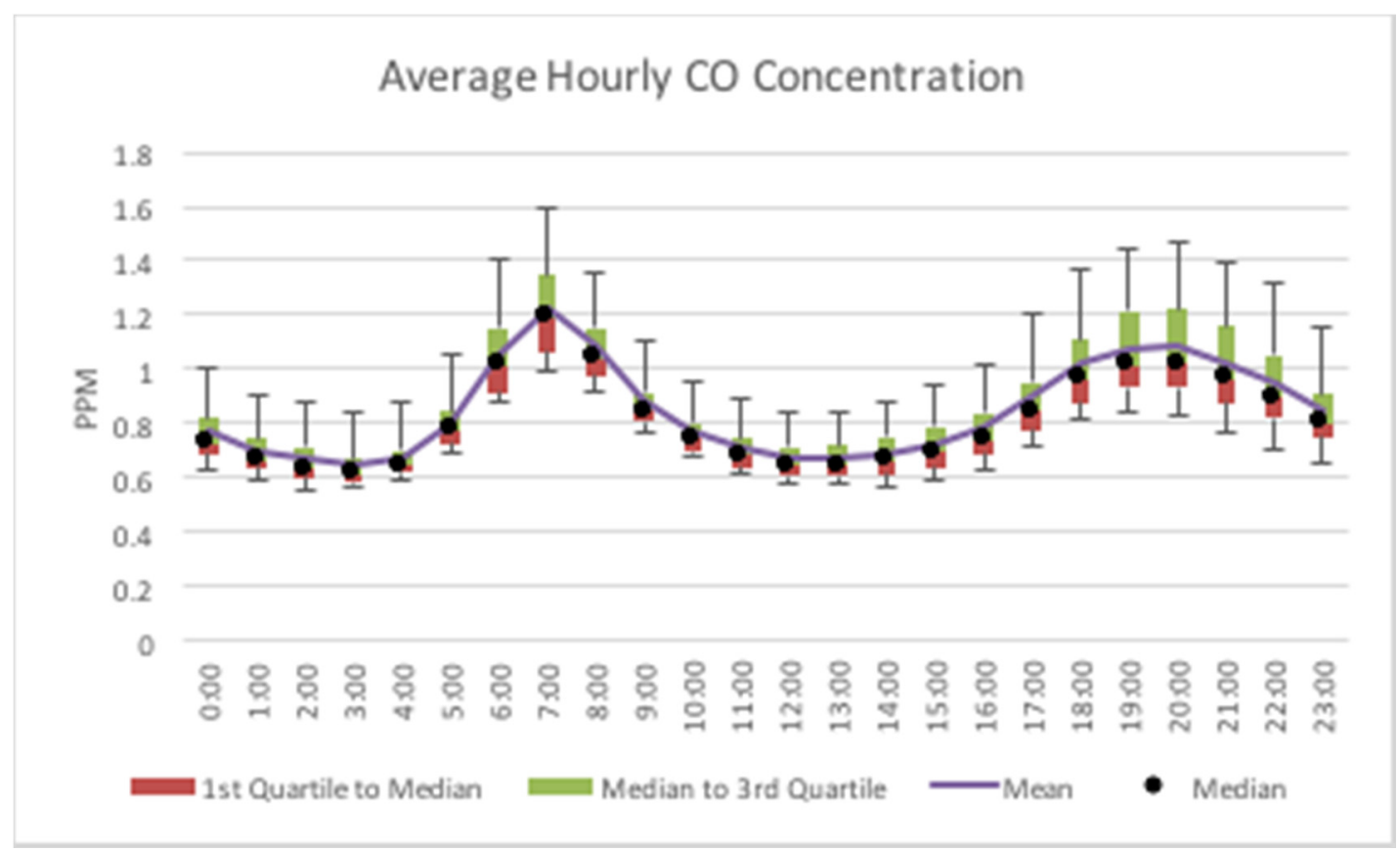

Figure 20. Diurnal CO Trend Graph.

Like $\mathrm{PM}_{10}$ and $\mathrm{NO}_{x}$, higher levels of $\mathrm{CO}$ can be found in the inner city as well as along major roadways, as vehicle emissions play a large role in the production of $\mathrm{CO}$.

Figure 21 displays the spatial distribution of CO in the BMR. Hypothetically this spatial distribution would also correspond with that of VOCs, such as formaldehyde, which could contribute to $\mathrm{O}_{3}$ production and higher $\mathrm{O}_{3}$ levels.



Figure 21. Spatial Distribution of CO Concentration in BMR. 
The 1st International Electronic Conference on Atmospheric Sciences (ECAS 2016), 16-31 July 2016; Sciforum Electronic Conference Series, Vol. 1, 2016

There were no exceedences of the hourly standard concentration set for $\mathrm{CO}$, which not to exceed $30 \mathrm{ppm}$ in an hour [14].

\section{5. $\mathrm{SO}_{2}$}

Figure 22 shows the overall trend of $\mathrm{SO}_{2}$ levels in the $\mathrm{BMR}$, which has drastically decreased since the year 2000. There has been approximately a 70\% decrease in $\mathrm{SO}_{2}$ levels measured in the BMR, with an average annual decrease of about $13.4 \%$ annually. $\mathrm{SO}_{2}$ sources in Thailand are primarily industrial [17]. The improvement in $\mathrm{SO}_{2}$ levels may be attributed to improved technology and industrial practices, as well as an improvement in fuel quality and efficiency for vehicles, which may especially play an important role in the high traffic areas of the BMR.



Figure 22. Long Term Average $\mathrm{SO}_{2}$ Trend.

Figure 23 shows the seasonal trend for $\mathrm{SO}_{2}$, where high concentrations of $\mathrm{SO}_{2}$ were recorded during the dry season, while the rainy season experienced lower levels of $\mathrm{SO}_{2}$ air pollution, largely due to dissolution of $\mathrm{SO}_{2}$ in cloud water and removal by wet deposition [18].



Figure 23. Seasonal $\mathrm{SO}_{2}$ Trend. 
The 1st International Electronic Conference on Atmospheric Sciences (ECAS 2016), 16-31 July 2016; Sciforum Electronic Conference Series, Vol. 1, 2016

Figure 24 displays the diurnal trend in $\mathrm{SO}_{2}$, and suggests that $\mathrm{SO}_{2}$ may be affected by transportation and vehicle emissions at a high rate within BMR. The peaks are very similar to other primary pollutants, including $\mathrm{PM}_{10}, \mathrm{CO}$, and $\mathrm{NO}_{x}$, which are all related closely with vehicle activity.

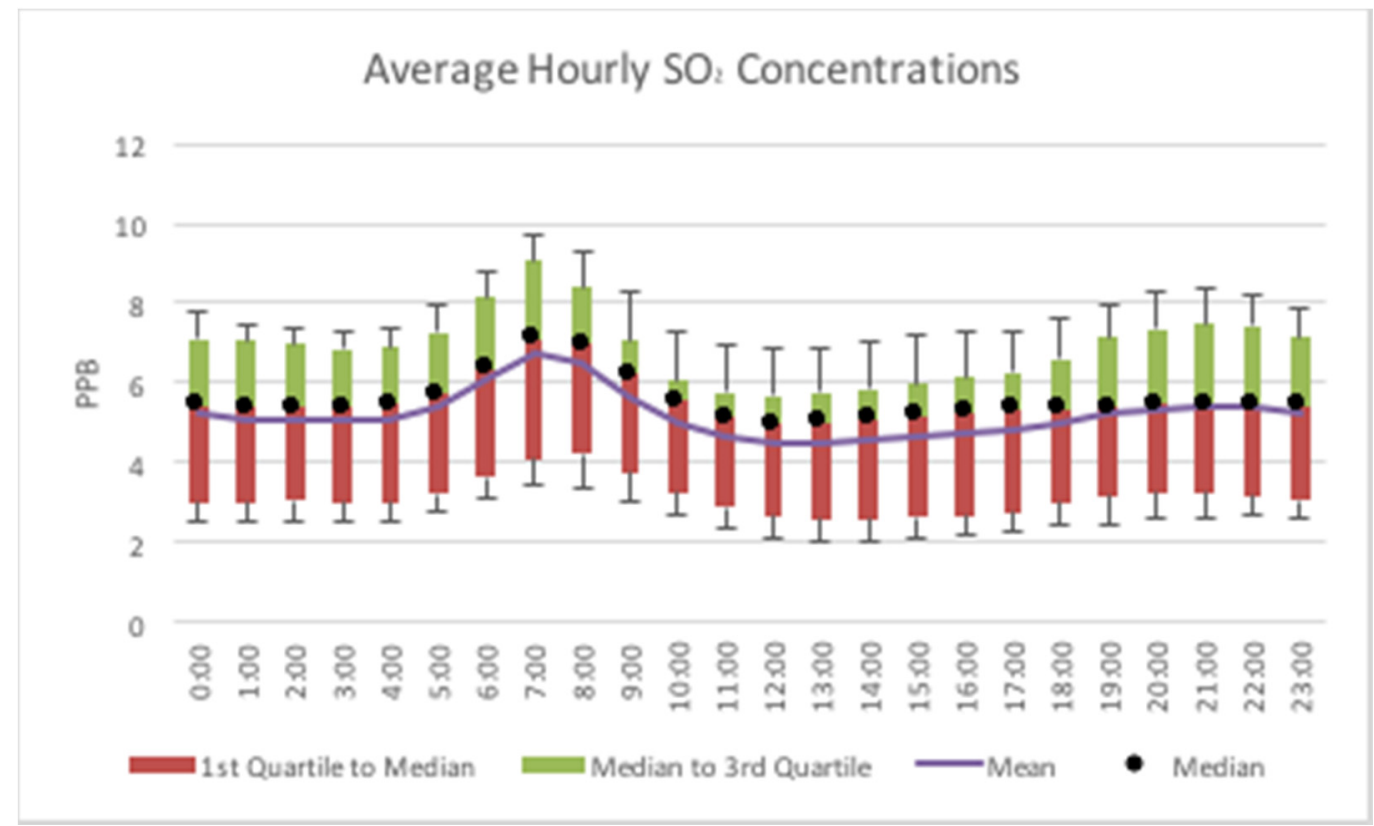

Figure 24. Diurnal $\mathrm{SO}_{2}$ Trend Graph.

Figure 25 shows the spatial trend in $\mathrm{SO}_{2}$, which shows that while there are average to low $\mathrm{SO}_{2}$ concentrations within most of BMR, there are higher levels in Samut Sakhon.



Figure 25. Spatial Distribution of $\mathrm{SO}_{2}$ Concentration in BMR. 
The 1st International Electronic Conference on Atmospheric Sciences (ECAS 2016), 16-31 July 2016; Sciforum Electronic Conference Series, Vol. 1, 2016

There were no exceedences of the $\mathrm{SO}_{2}$ yearly concentration standard, which is not to exceed $0.04 \mathrm{ppm}$ per year [14].

\section{Discussion}

\subsection{Air Quality Change Causes}

In Thailand, the major sources of particulate matter pollution are domestic combustion, industrial processes, vehicles, construction and, re-suspended dust, and biomass open burning, while the major sources of $\mathrm{NOx}, \mathrm{SO}_{2}$ and $\mathrm{CO}$ include power generation, transportation and manufacturing [17]. This study identified a significant decline in $\mathrm{PM}_{10}, \mathrm{NO}_{x}, \mathrm{SO}_{2}$ and $\mathrm{CO}$ over the years of 2000 to 2015, despite an annual increase rate of approximately $22 \%$ in vehicle numbers in Thailand [19] as well as the burgeoning economic and population growth in BMR, and a steadily increase of $\mathrm{O}_{3}$ concentration over time [20].

Thailand has been implementing air quality policies over the past 25 years to manage pollution from motor vehicles, industries and area sources. Considering fuel quality, Thailand has been aimed at a transition from fossil fuels towards bio-fuel, leading to a decrease in emissions for $\mathrm{CO}, \mathrm{HC}$ and $\mathrm{NO}_{\mathrm{x}}$ and an increase in formaldehyde, acetaldehyde and ethanol, which are components of VOC [21]. Thailand has also been working towards gasoline reformulation and diesel fuels to be improved to Euro 4 standard from Euro 3 standard, which brings a considerable decrease in sulfur and CO emissions [20].

Vehicle emission limit in Thailand has transformed from Euro 3 standard and is currently under Euro 4 standard [22]. Such transformation has generated a rise in effectiveness of fuel usage and a reduction in all vehicle pollutants, including $\mathrm{NO}_{x}, \mathrm{PM}_{10}, \mathrm{SO}_{2}, \mathrm{CO}$ that were examined by this study [19].

Decrease in $\mathrm{CO}$ and $\mathrm{NO}_{x}$ are also likely a result of fleet modernization which led to a lower tailpipe emission [23]. Since NO plays a large role in $\mathrm{O}_{3}$ consumption, the above regulations that contributed to $\mathrm{NO}_{x}$ reduction could probably had effect on the gradually increasing trend of $\mathrm{O}_{3}$ over the past 15 years.

\subsection{Air Quality Implications and Improvements}

\subsubsection{Ozone Concentration}

Ozone concentration is a nascent issue which may become the primary source of human health risk from amongst these five criteria pollutants in the future. $\mathrm{O}_{3}$ is a secondary pollutant, and as such, the production of $\mathrm{O}_{3}$ depends on the amount and the type of precursor substances, such as NO and VOCs including formaldehyde and acetaldehyde, as well as the intensity of solar radiation. Generally, $\mathrm{O}_{3}$ concentrations will also increase with increased temperatures, as the rate of photochemical reactions increase at higher temperatures. Thus, global climate change could contribute to an amplified increase in $\mathrm{O}_{3}$ in the near future, along with the continuation of Thailand's commitment to biofuels instead of fossil fuels. This commitment has had myriad benefits, such as allowing Thailand increased energy security, economic benefits, and overall, has increased the air quality.

However, with continued urbanization especially with increased urban sprawl, ozone will remain a critical health risk to the population of the BMR region. It is important to note that many of the areas that are most affected by high ozone levels are the same areas that have high populations (Figures 2 and 8). This means that the health impact of increased ozone levels will be harsher, as it will affect more people who are living in these areas. The improvements necessary to combat this risk lie in the logistics and planning of traffic control, increased infrastructure, specifically public transportation such as the BTS SkyTrain and the Metro, and initiatives to encourage carpooling and the use of public transportation. 
The 1st International Electronic Conference on Atmospheric Sciences (ECAS 2016), 16-31 July 2016; Sciforum Electronic Conference Series, Vol. 1, 2016

\subsection{2. $\mathrm{PM}_{10}$ Concentration}

$\mathrm{PM}_{10}$ has decreased significantly since the turn of the century, however the standards for $\mathrm{PM}_{10}$ are still exceeded consistently. $\mathrm{PM}_{10}$ is the most immediate concern out of the criteria air pollutants analyzed in this study, however there is hope that the shift from fossil fuels to biofuels, along with better industry practices and fleet modernization in the BMR will reduce the impact of $\mathrm{PM}_{10}$ in the very near future, so it will not be of concern. However, as this problem is phased out, new issues arise, and the cleaner burning fuel could still be producing $\mathrm{PM}_{2.5}$ and $\mathrm{PM}_{1}$, which were not measured in this study. These smaller particles are actually even more damaging towards human health, and thus may be an even more urgent problem. The smaller particles are inhaled and lodged deeper into the lungs, and thus may have a more harmful effect on human health [20]. The World Health Organization is thus pushing for all countries to have a standard for $\mathrm{PM}_{2.5}$ concentrations. Thus, as our analysis shows that air quality has improved despite the increased energy usage, there are emerging air quality issues that must be addressed moving forward. These up and coming air quality concerns will require even more proactive and innovative solutions, and will require not only technological advancements, but educational programs and policies in order to protect human health.

\section{Conclusions}

In this study, we analyzed the annual, seasonal, and hourly behaviors of five criteria air pollutants $\left(\mathrm{CO}, \mathrm{NO}_{2}, \mathrm{SO}_{2}, \mathrm{O}_{3}\right.$, and $\left.\mathrm{PM}_{10}\right)$ in the megacity known as the Bangkok Metropolitan Region over the course of 16 years.

Temporally, we found a general decreasing trend for $\mathrm{PM}_{10}, \mathrm{NO}_{x}, \mathrm{CO}$ and $\mathrm{SO}_{2}$, but an increasing trend for $\mathrm{O}_{3}$. Seasonally, we found that all of the criteria air pollutant concentrations were high during the dry season and low during the rainy season. Diurnally we found that $\mathrm{PM}_{10}, \mathrm{NO}_{x}, \mathrm{CO}$ and $\mathrm{SO}_{2}$ had similar trends, and exhibited two peaks during the day, one in the morning and one in the evening, generally associated with traffic activity. We found that $\mathrm{O}_{3}$ exhibited a maximum during the early afternoon, corresponding with high solar radiation levels and low $\mathrm{NO}_{\mathrm{x}}$.

Spatially we found that the inner city and major roadways had higher $\mathrm{PM}_{10}, \mathrm{NO}_{\mathrm{x}}$, and $\mathrm{CO}$ concentrations. We also found that ozone levels were the highest in areas with low vehicular emissions, such as areas away from major roadways and rural areas. This means that as ozone levels rise, these areas will be most affected by the health impact of tropospheric ozone.

This study provided a good overview of the state of the air quality in Bangkok Metropolitan Region, and a glimpse at the issues that remain to be resolved regarding air quality. This study showed that while Bangkok has undergone widespread growth and urbanization over the last 16 years, and increased its energy consumption tremendously, overall it has improved the air quality in the region. Thus Bangkok can serve as a model for other developing and tropical megacities. Further studies may use regression analysis in order to observe clearer long-term trends. Additionally, $\mathrm{PM}_{2.5}$ and VOCs must be monitored and analyzed to fully understand the environmental chemistry behind the observed trends in the studied air pollutants. Finally, although a number of action plans have been implemented regarding the air quality in the BMR, additional policies for improving air quality are needed, especially with respect to ozone and particulate matter.

Acknowledgments: We thank The Joint Graduate School for Energy and Environment (JGSEE), Centre for Energy Technology and Environment (CEE-PERDO), King Mongkut's University of Technology Thonburi (KMUTT), and the UNC-IE (UNC Institute for the Environment) for providing us with this opportunity. We thank the Thailand PCD (Pollution Control Department) for providing us with the source data for this project. We appreciate valuable advice and feedback from Rich Kamens.

Author Contributions: This work has been performed in collaboration among all authors. Towqir Aziz conducted research design, analyzed data, and wrote the paper. Ruozhang $\mathrm{Xu}$ analyzed data and contributed to the writing of the manuscript. Chengliang Fan analyzed data and contributed to the writing of the manuscript. Mansi K. Shah analyzed data and contributed to the writing of the manuscript. Thanonphat Boonman provided GIS expertise, contributed to the writing of the manuscript and analyzed data. Pham Thi Bich Thao contributed 
The 1st International Electronic Conference on Atmospheric Sciences (ECAS 2016), 16-31 July 2016;

Sciforum Electronic Conference Series, Vol. 1, 2016

to the writing of the manuscript and helped organize the paper. Sebastian Bonnet analyzed data, helped organize the structure of the paper, and contributed to the writing of the manuscript. and Savitri Garivait conceived and designed the experiments and helped organize the structure of the paper.

Conflicts of Interest: The authors declare no conflict of interest.

\section{Abbreviations}

The following abbreviations are used in this manuscript:

BMR Bangkok Metropolitan Region

SEA Southeast Asia

PCD Pollution Control Department

BMA Bangkok Metropolitan Administration

\section{Appendix}

Within this appendix we have included the monthly average graphs for each criteria pollutant per each individual air quality monitoring station. 
The 1st International Electronic Conference on Atmospheric Sciences (ECAS 2016), 16-31 July 2016; Sciforum Electronic Conference Series, Vol. 1, 2016

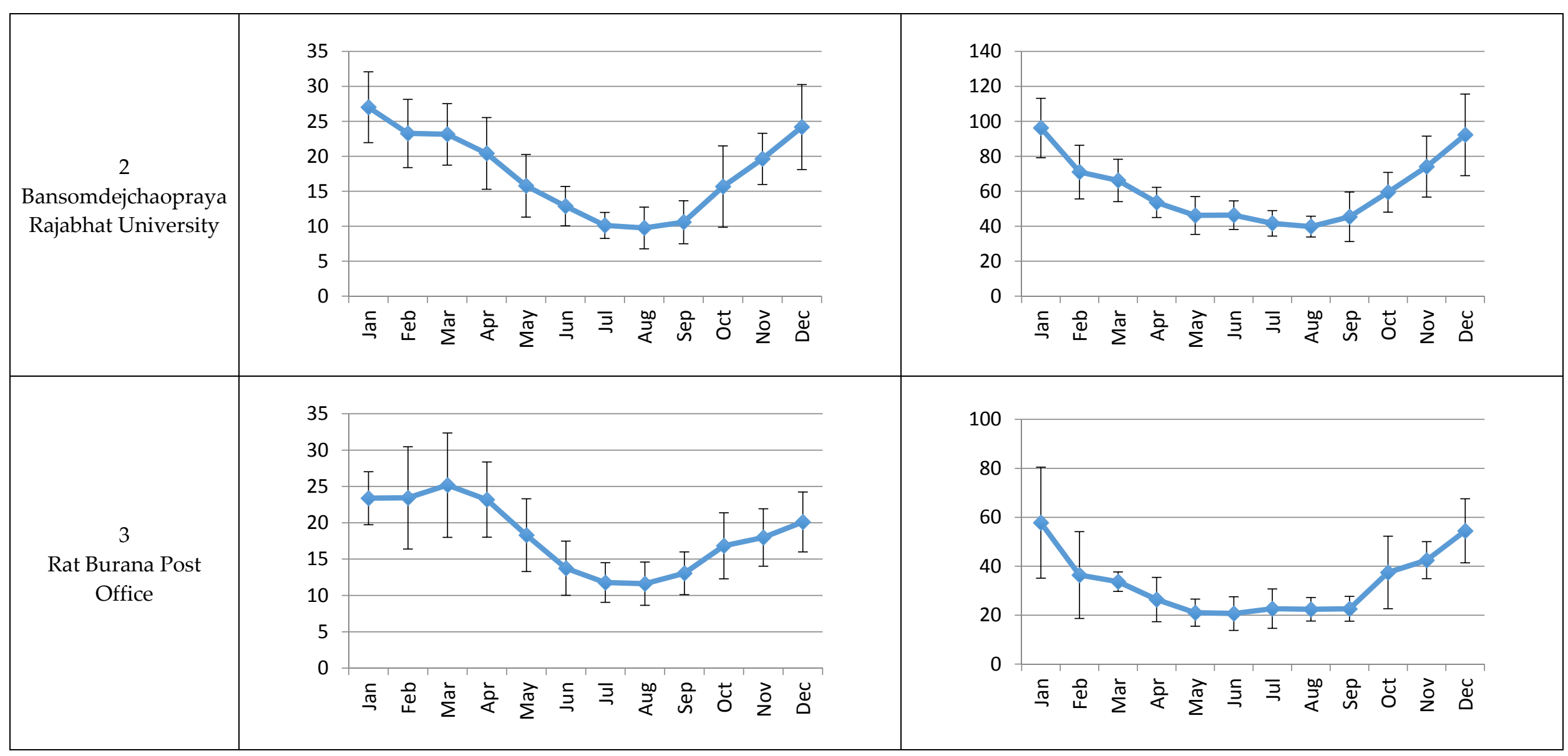


The 1st International Electronic Conference on Atmospheric Sciences (ECAS 2016), 16-31 July 2016; Sciforum Electronic Conference Series, Vol. 1, 2016

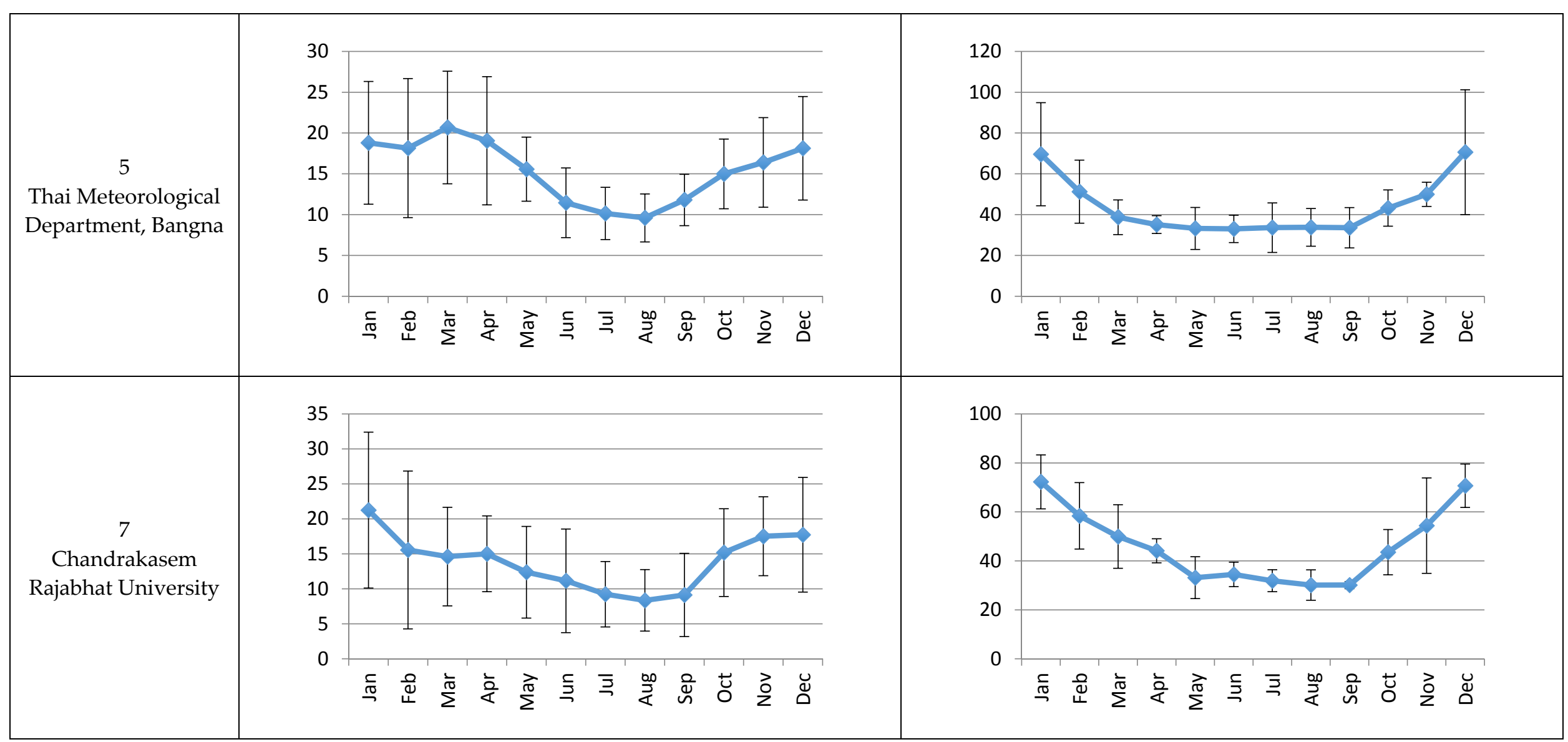


The 1st International Electronic Conference on Atmospheric Sciences (ECAS 2016), 16-31 July 2016; Sciforum Electronic Conference Series, Vol. 1, 2016




The 1st International Electronic Conference on Atmospheric Sciences (ECAS 2016), 16-31 July 2016; Sciforum Electronic Conference Series, Vol. 1, 2016

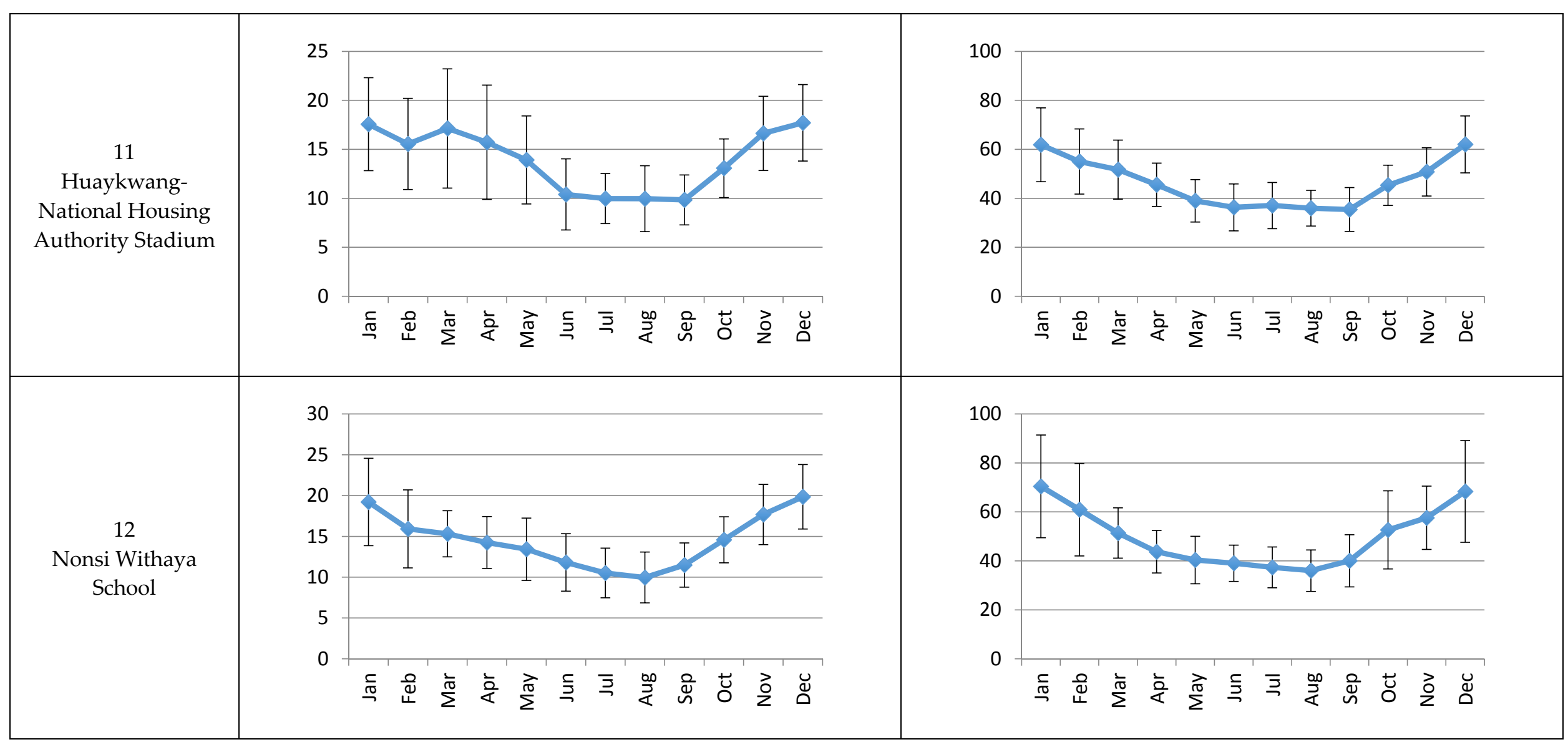


The 1st International Electronic Conference on Atmospheric Sciences (ECAS 2016), 16-31 July 2016; Sciforum Electronic Conference Series, Vol. 1, 2016

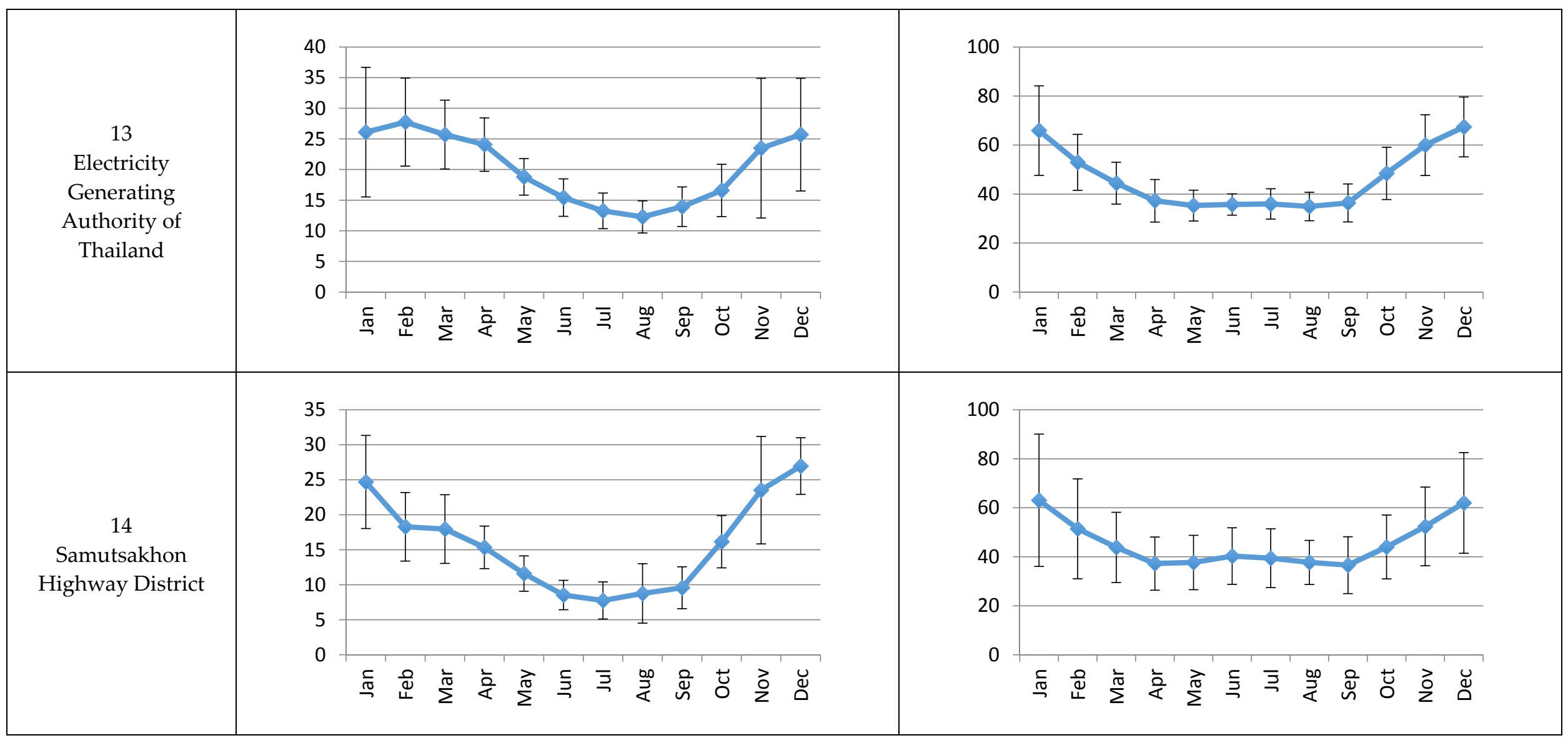


The 1st International Electronic Conference on Atmospheric Sciences (ECAS 2016), 16-31 July 2016; Sciforum Electronic Conference Series, Vol. 1, 2016

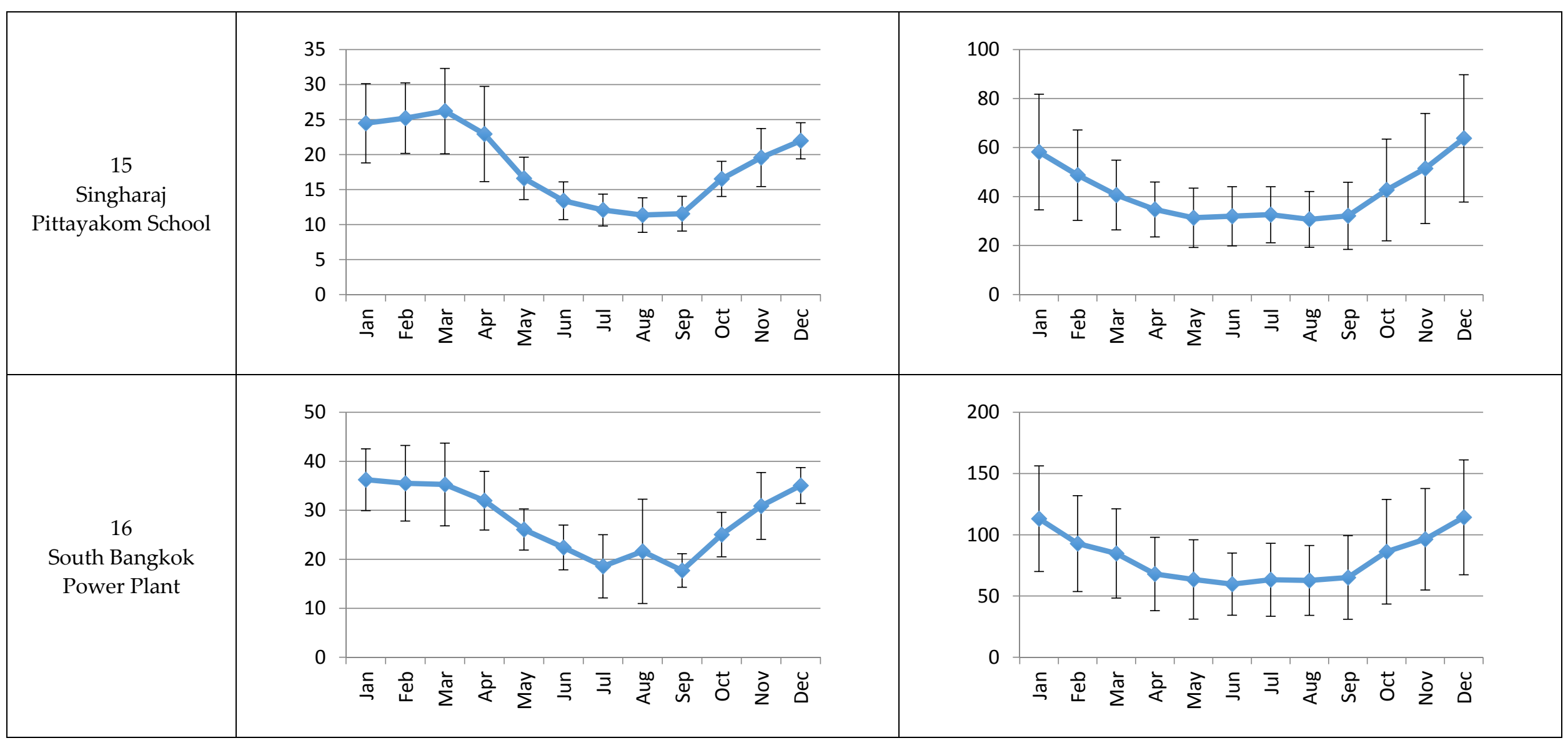


The 1st International Electronic Conference on Atmospheric Sciences (ECAS 2016), 16-31 July 2016; Sciforum Electronic Conference Series, Vol. 1, 2016




The 1st International Electronic Conference on Atmospheric Sciences (ECAS 2016), 16-31 July 2016; Sciforum Electronic Conference Series, Vol. 1, 2016

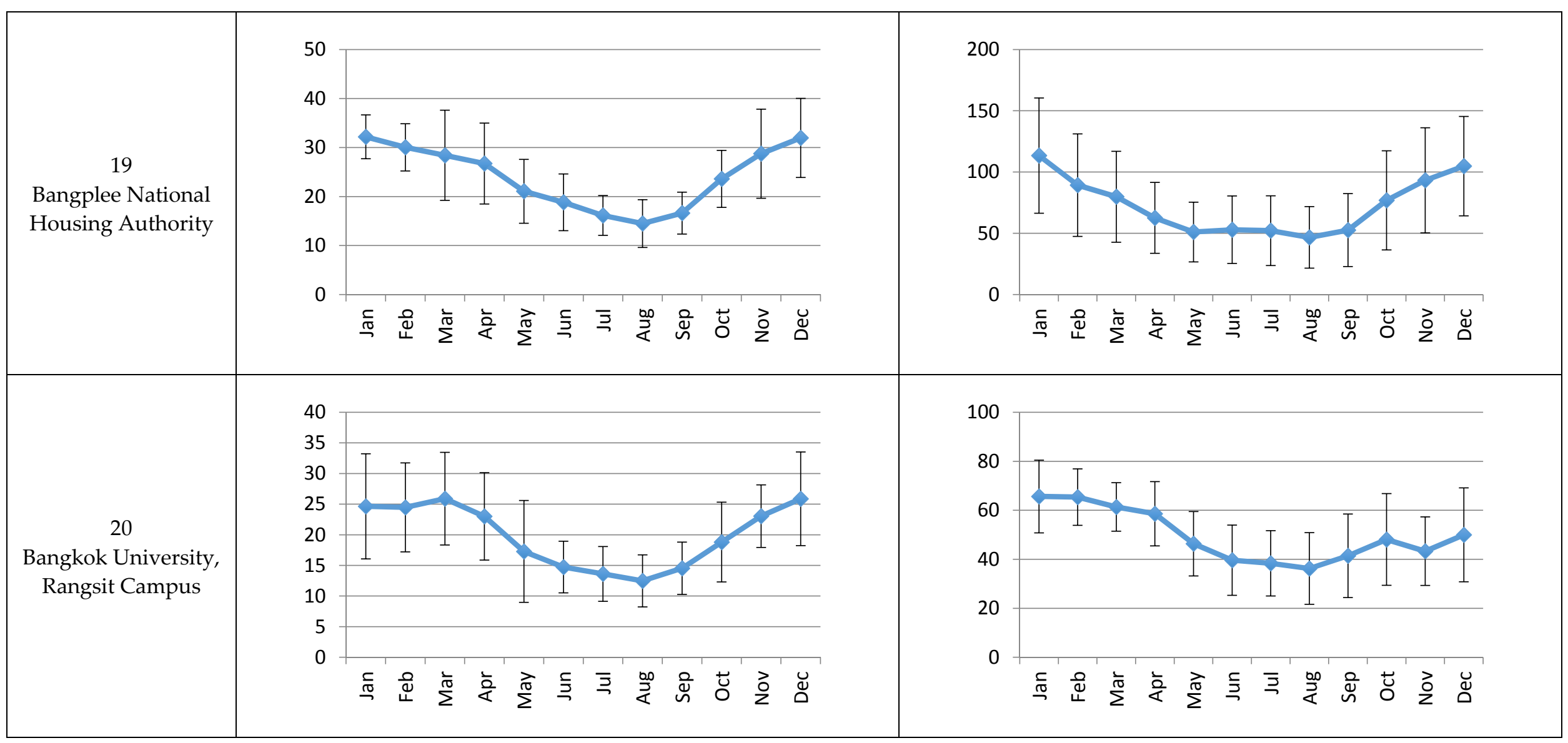


The 1st International Electronic Conference on Atmospheric Sciences (ECAS 2016), 16-31 July 2016; Sciforum Electronic Conference Series, Vol. 1, 2016

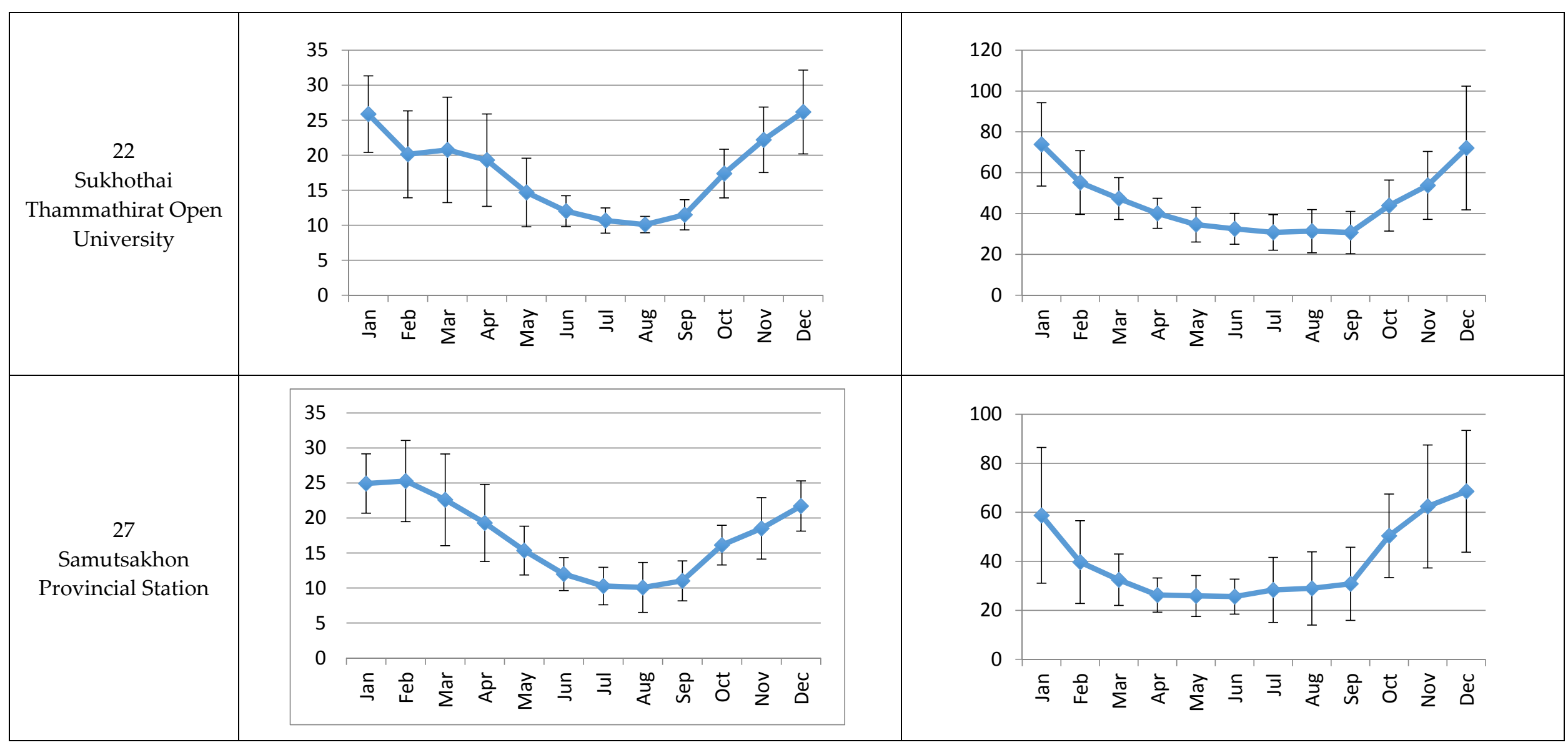


The 1st International Electronic Conference on Atmospheric Sciences (ECAS 2016), 16-31 July 2016; Sciforum Electronic Conference Series, Vol. 1, 2016

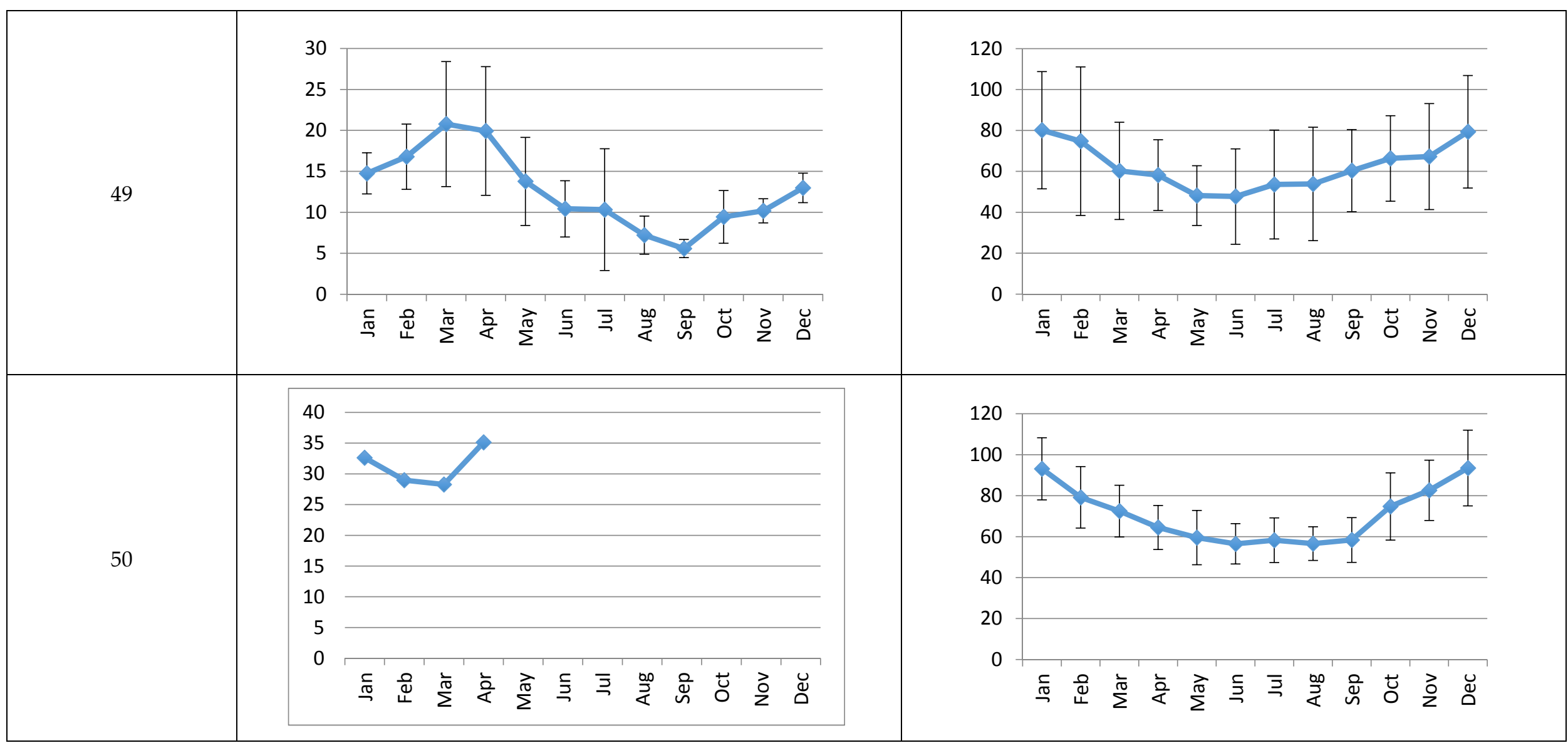


The 1st International Electronic Conference on Atmospheric Sciences (ECAS 2016), 16-31 July 2016; Sciforum Electronic Conference Series, Vol. 1, 2016

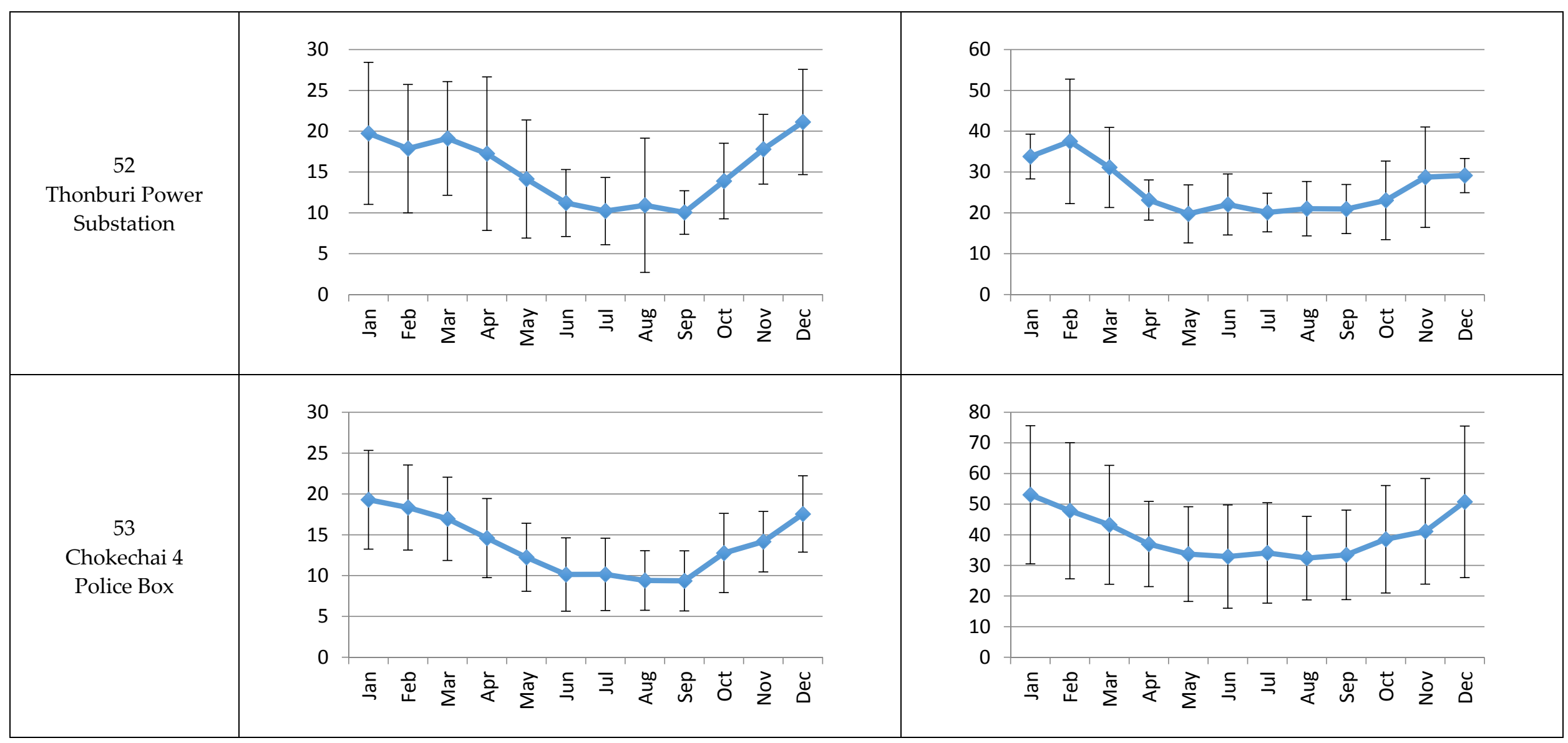


The 1st International Electronic Conference on Atmospheric Sciences (ECAS 2016), 16-31 July 2016; Sciforum Electronic Conference Series, Vol. 1, 2016

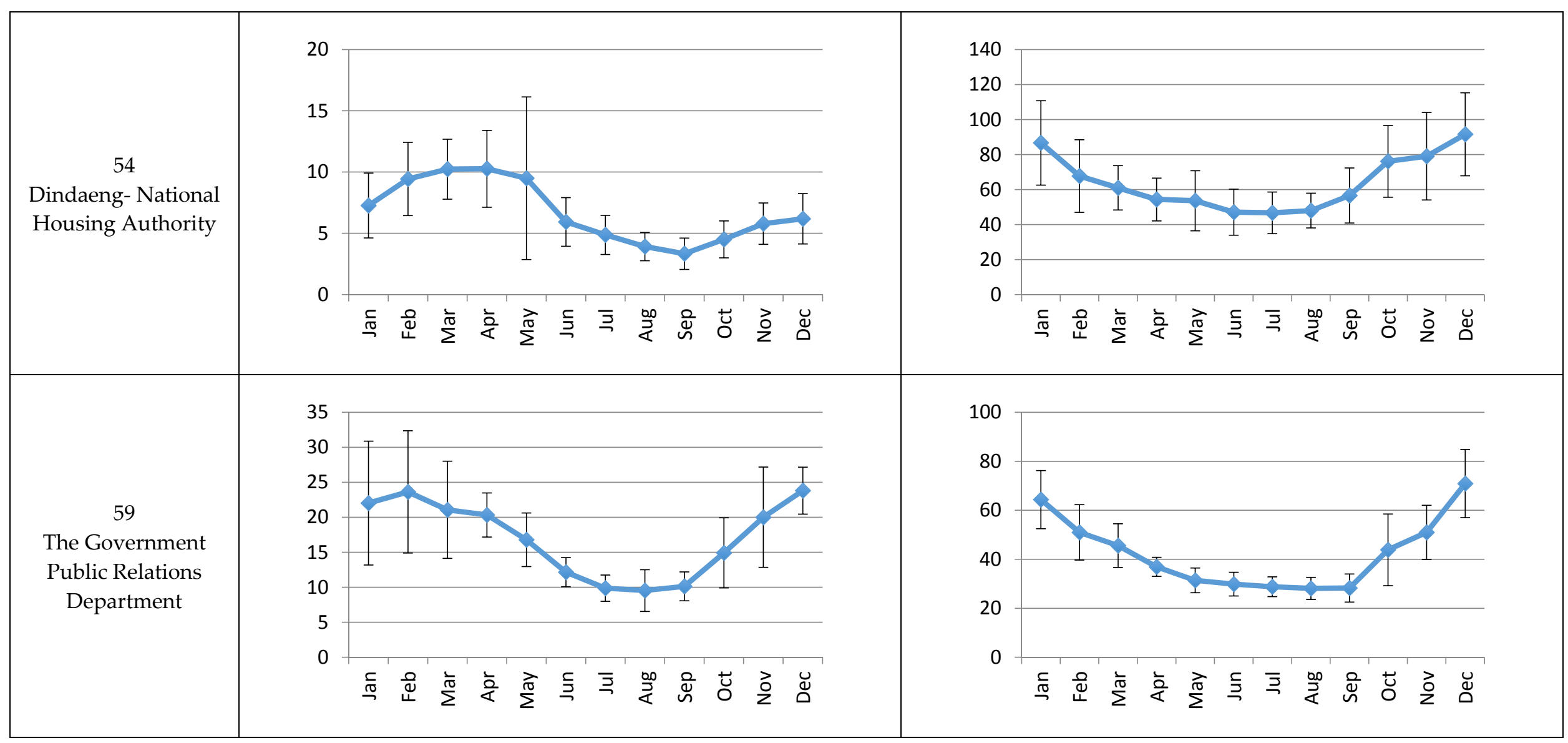


The 1st International Electronic Conference on Atmospheric Sciences (ECAS 2016), 16-31 July 2016; Sciforum Electronic Conference Series, Vol. 1, 2016

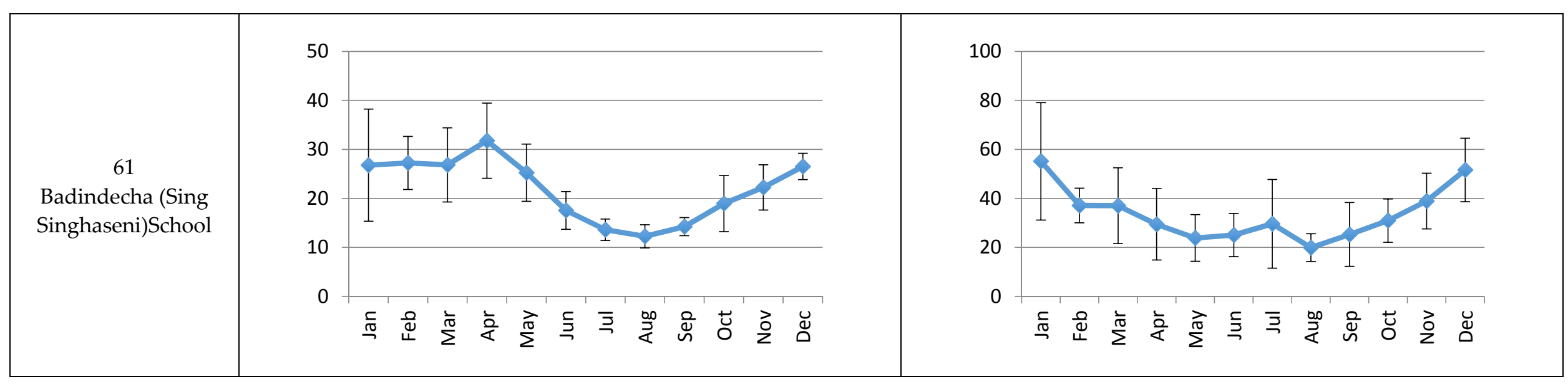


The 1st International Electronic Conference on Atmospheric Sciences (ECAS 2016), 16-31 July 2016; Sciforum Electronic Conference Series, Vol. 1, 2016

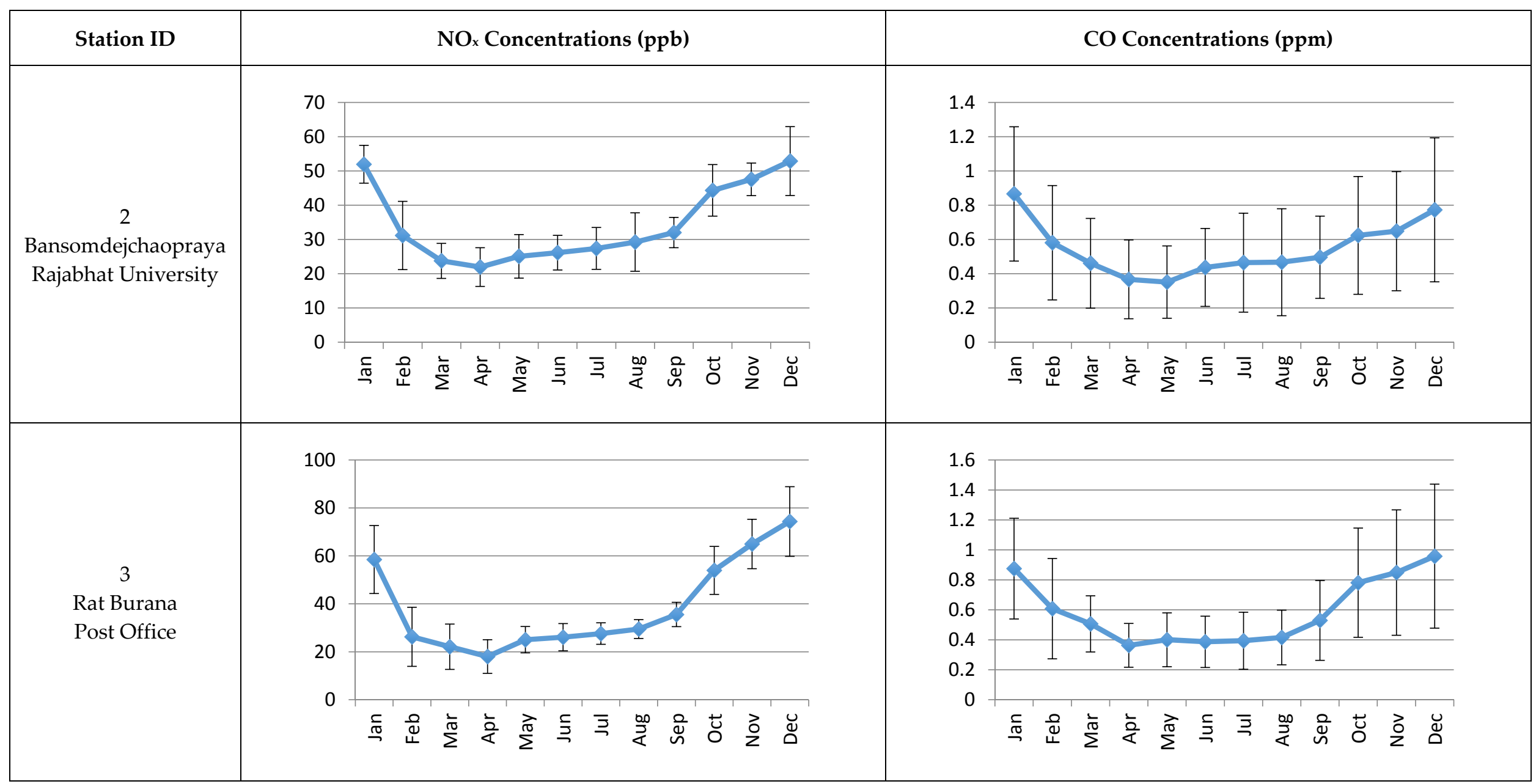


The 1st International Electronic Conference on Atmospheric Sciences (ECAS 2016), 16-31 July 2016; Sciforum Electronic Conference Series, Vol. 1, 2016

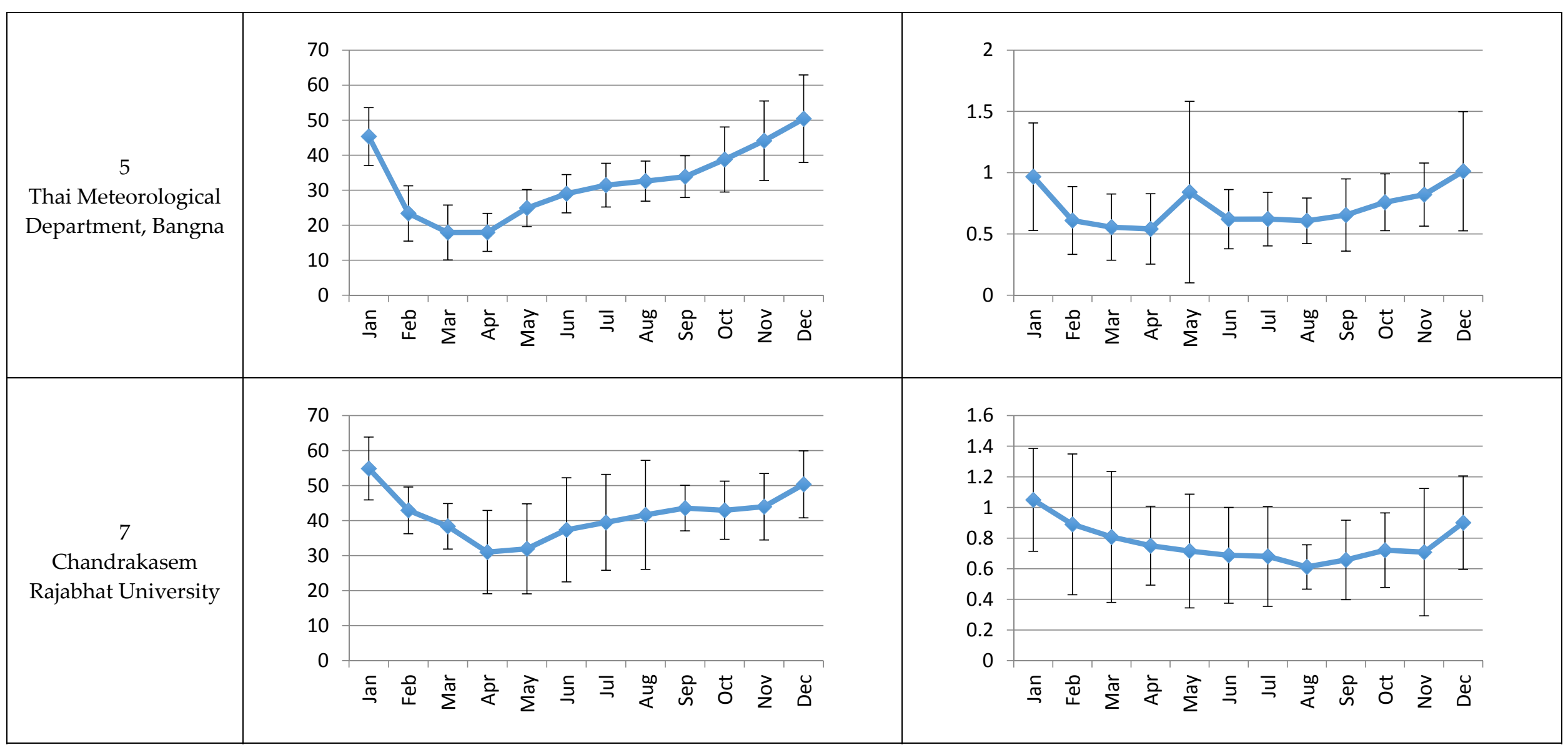


The 1st International Electronic Conference on Atmospheric Sciences (ECAS 2016), 16-31 July 2016; Sciforum Electronic Conference Series, Vol. 1, 2016

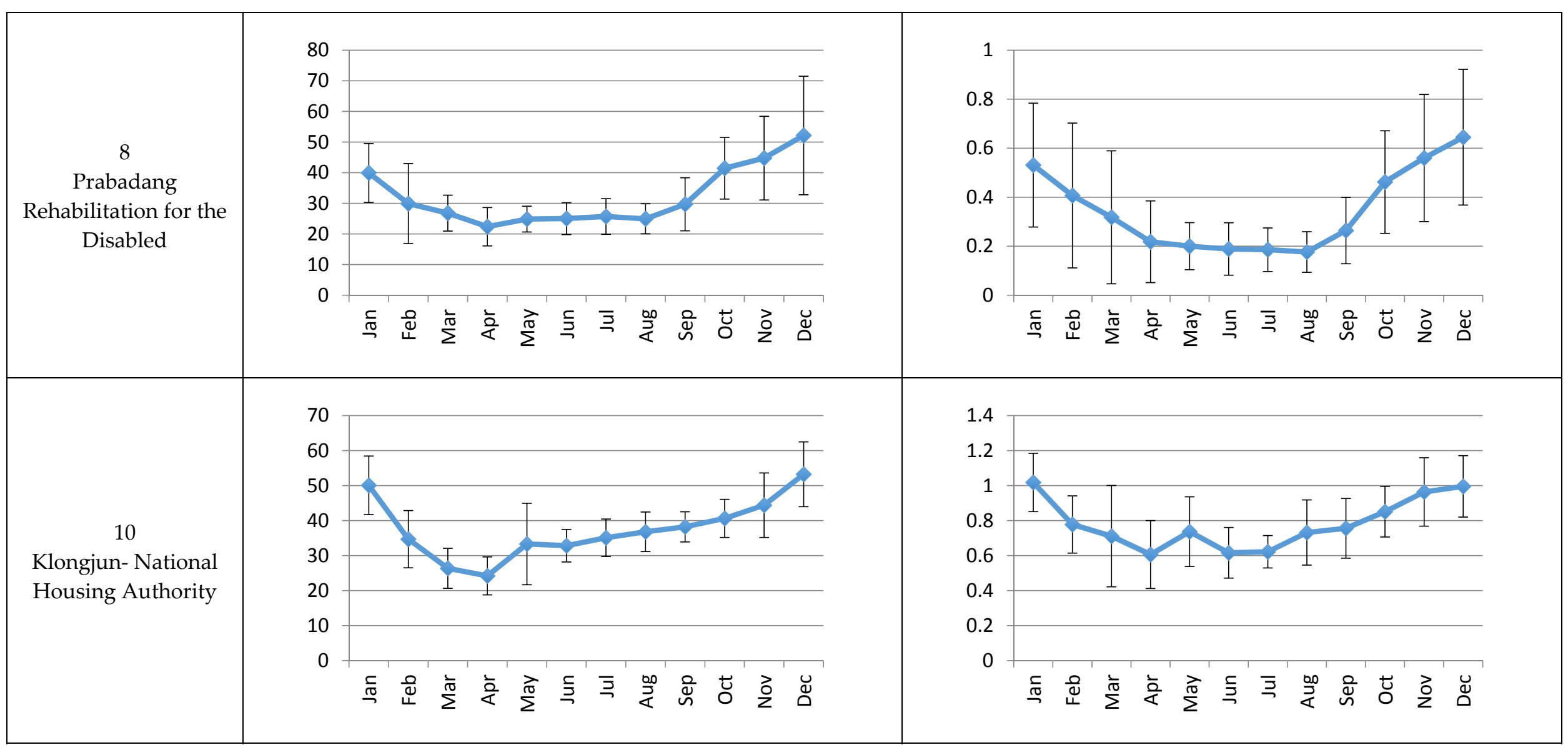


The 1st International Electronic Conference on Atmospheric Sciences (ECAS 2016), 16-31 July 2016; Sciforum Electronic Conference Series, Vol. 1, 2016

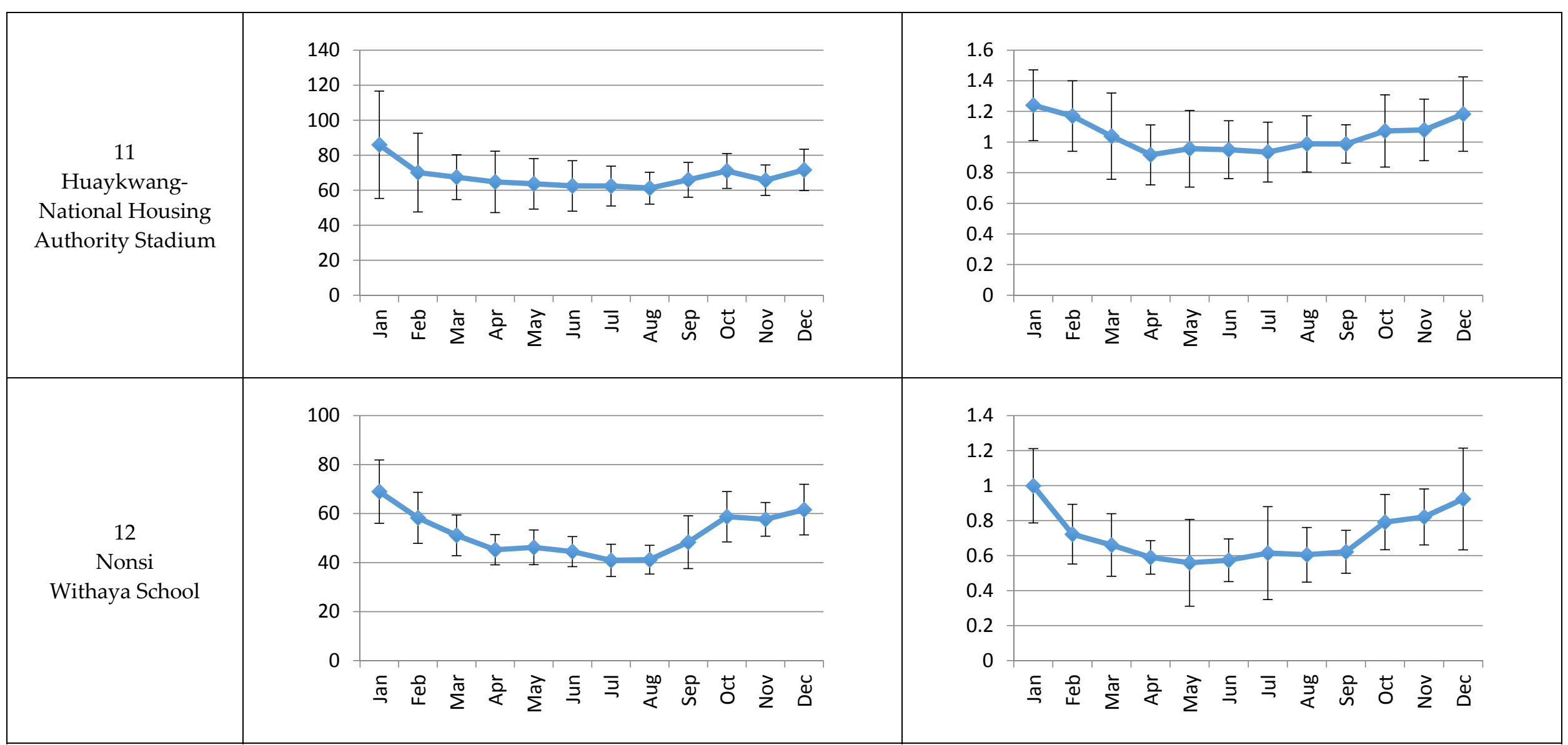


The 1st International Electronic Conference on Atmospheric Sciences (ECAS 2016), 16-31 July 2016; Sciforum Electronic Conference Series, Vol. 1, 2016

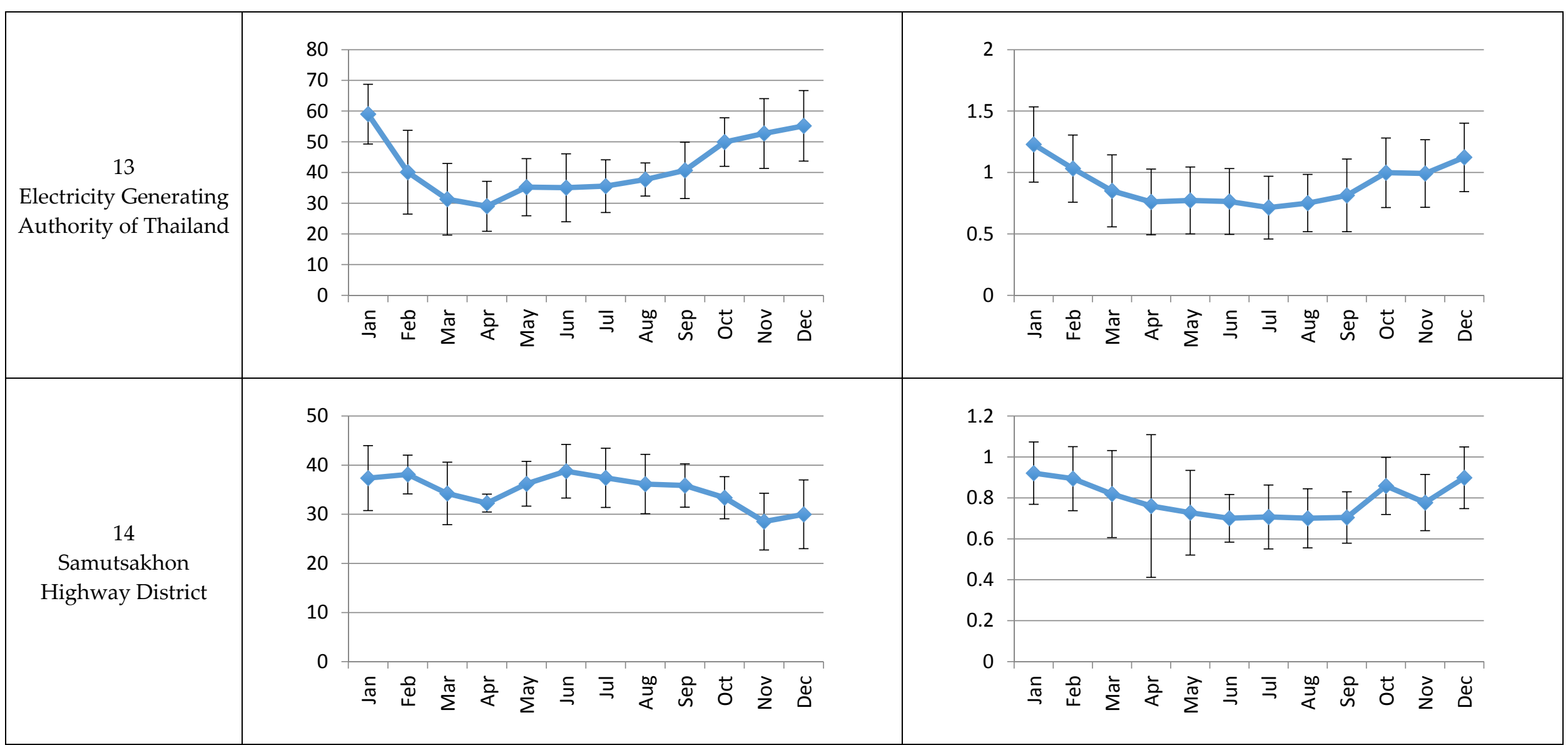


The 1st International Electronic Conference on Atmospheric Sciences (ECAS 2016), 16-31 July 2016; Sciforum Electronic Conference Series, Vol. 1, 2016




The 1st International Electronic Conference on Atmospheric Sciences (ECAS 2016), 16-31 July 2016; Sciforum Electronic Conference Series, Vol. 1, 2016

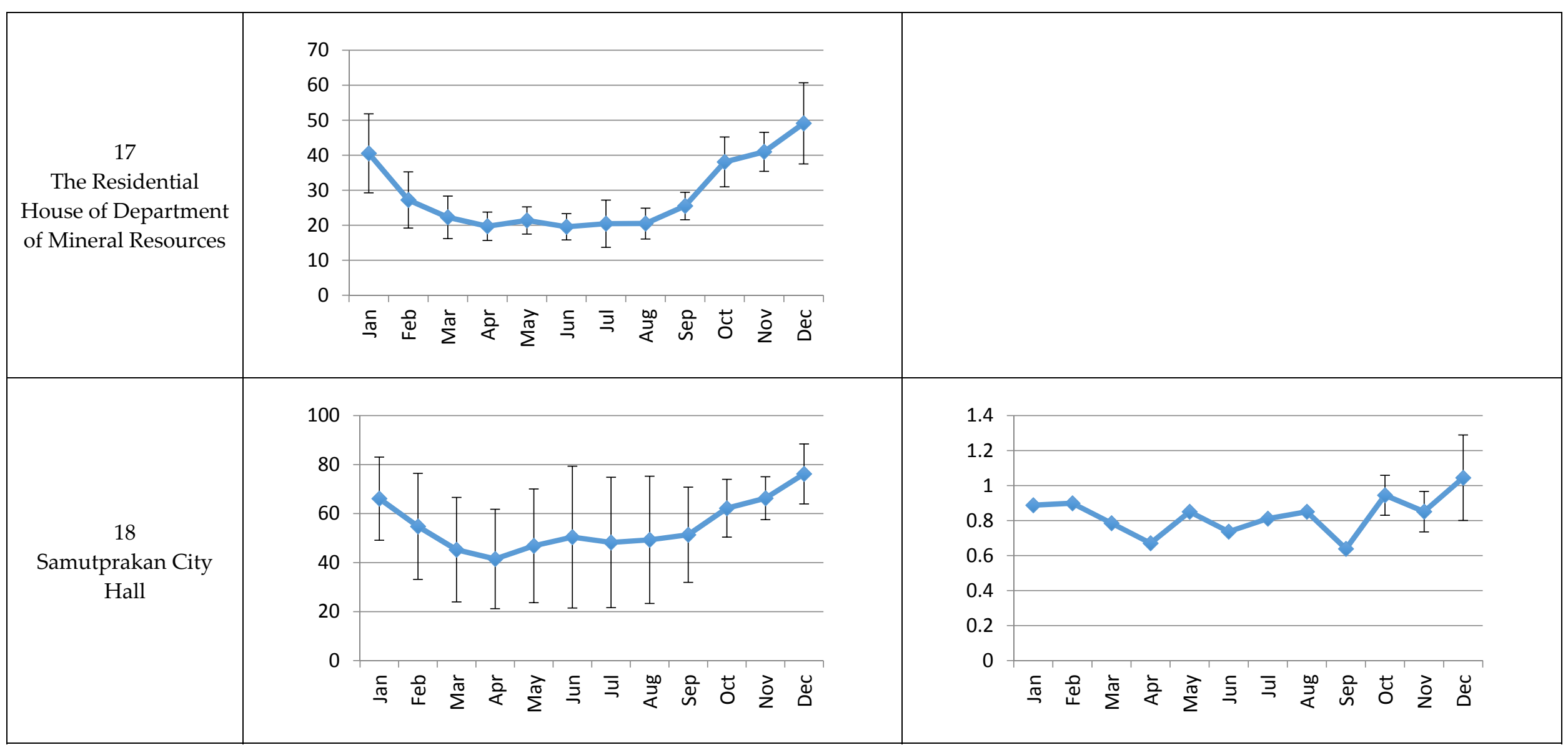


The 1st International Electronic Conference on Atmospheric Sciences (ECAS 2016), 16-31 July 2016; Sciforum Electronic Conference Series, Vol. 1, 2016

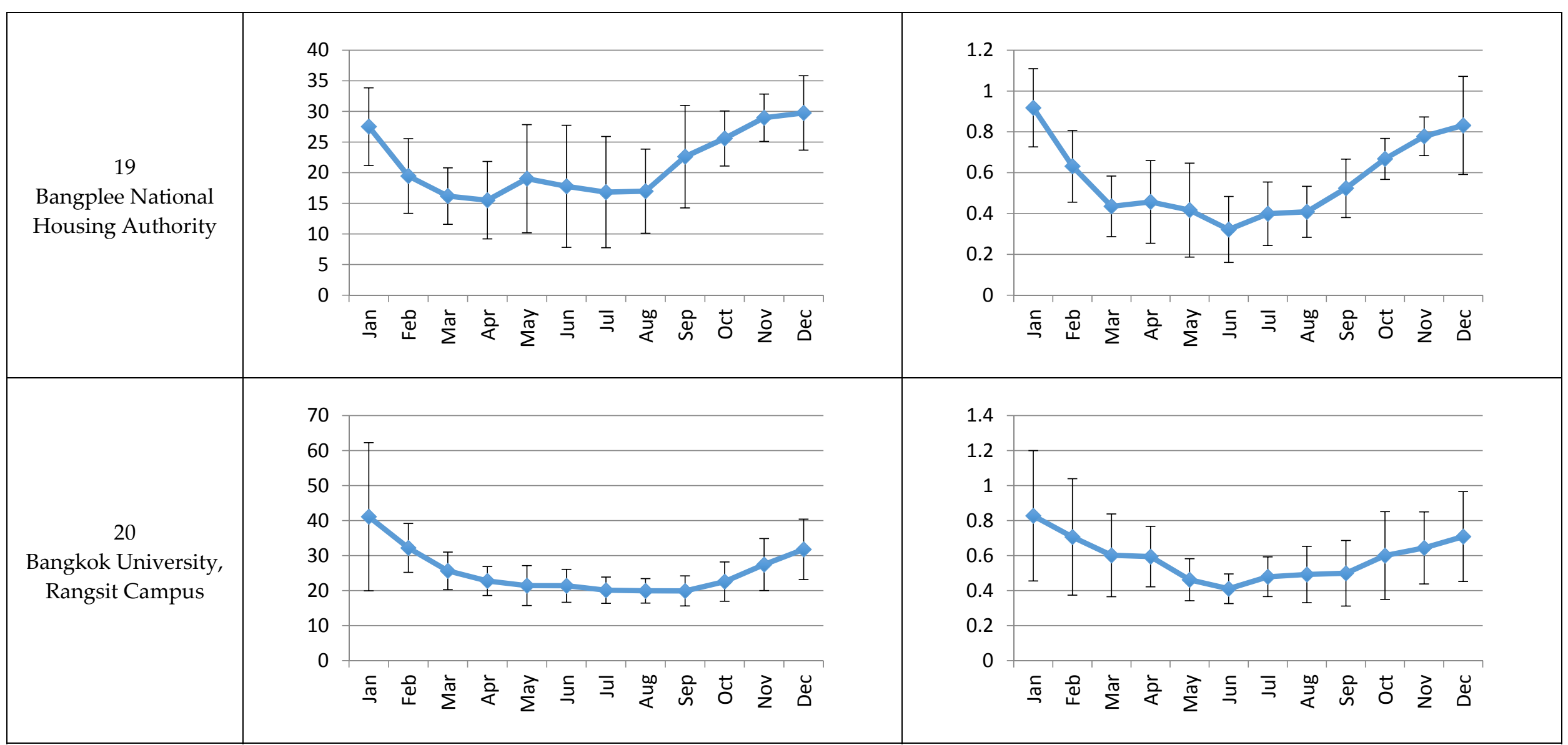


The 1st International Electronic Conference on Atmospheric Sciences (ECAS 2016), 16-31 July 2016; Sciforum Electronic Conference Series, Vol. 1, 2016

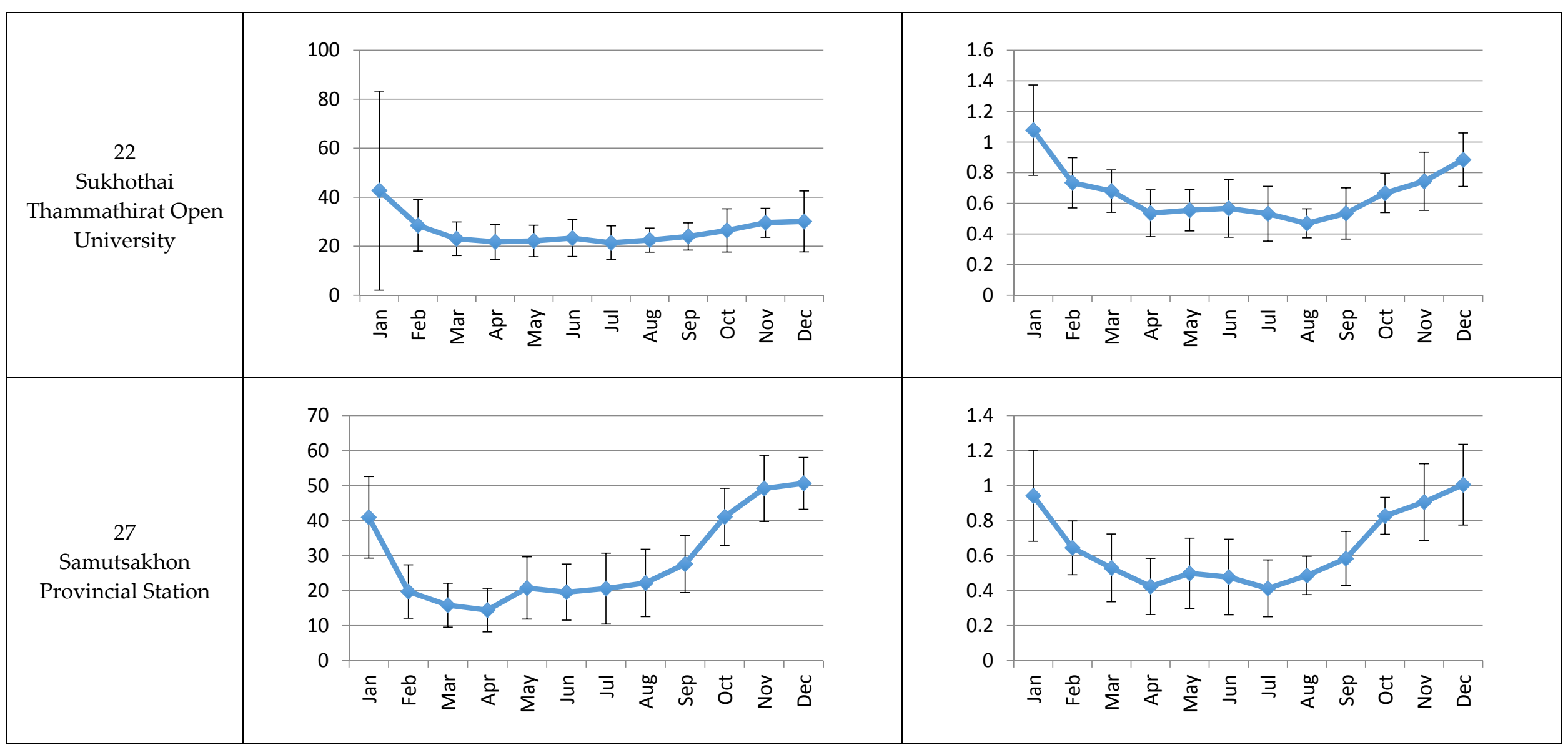


The 1st International Electronic Conference on Atmospheric Sciences (ECAS 2016), 16-31 July 2016; Sciforum Electronic Conference Series, Vol. 1, 2016

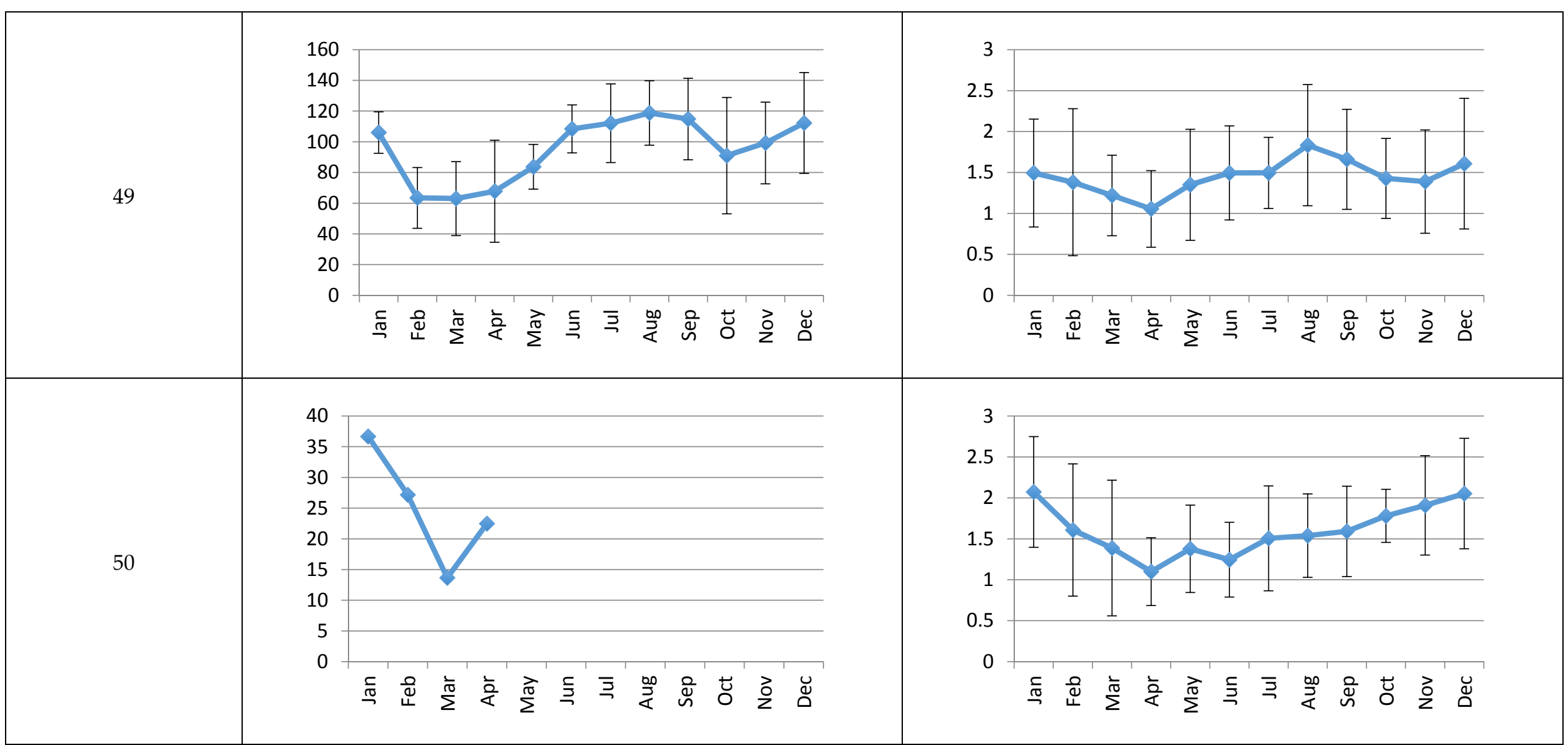


The 1st International Electronic Conference on Atmospheric Sciences (ECAS 2016), 16-31 July 2016; Sciforum Electronic Conference Series, Vol. 1, 2016




The 1st International Electronic Conference on Atmospheric Sciences (ECAS 2016), 16-31 July 2016; Sciforum Electronic Conference Series, Vol. 1, 2016

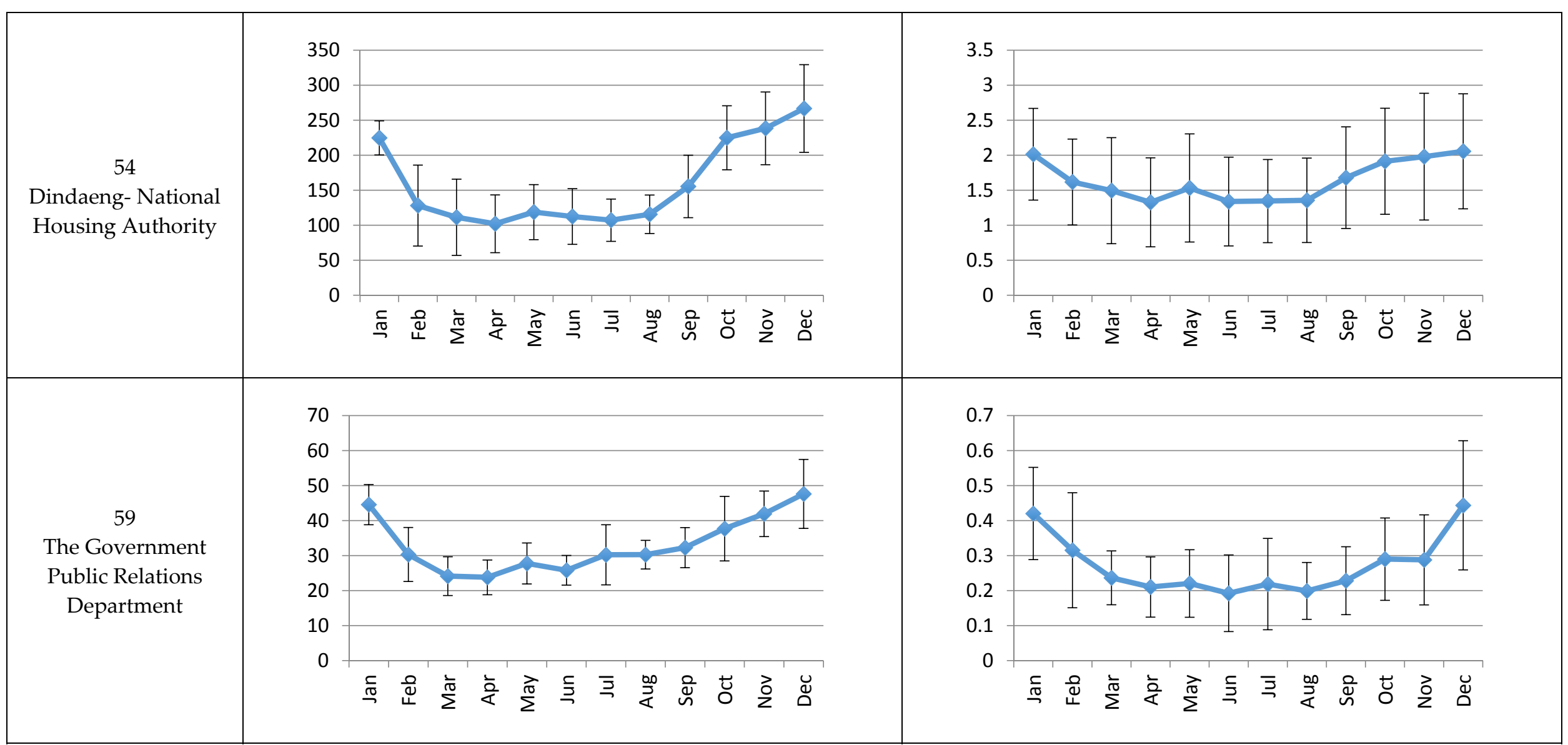


The 1st International Electronic Conference on Atmospheric Sciences (ECAS 2016), 16-31 July 2016; Sciforum Electronic Conference Series, Vol. 1, 2016

61

Badindecha (Sing

Singhaseni)School

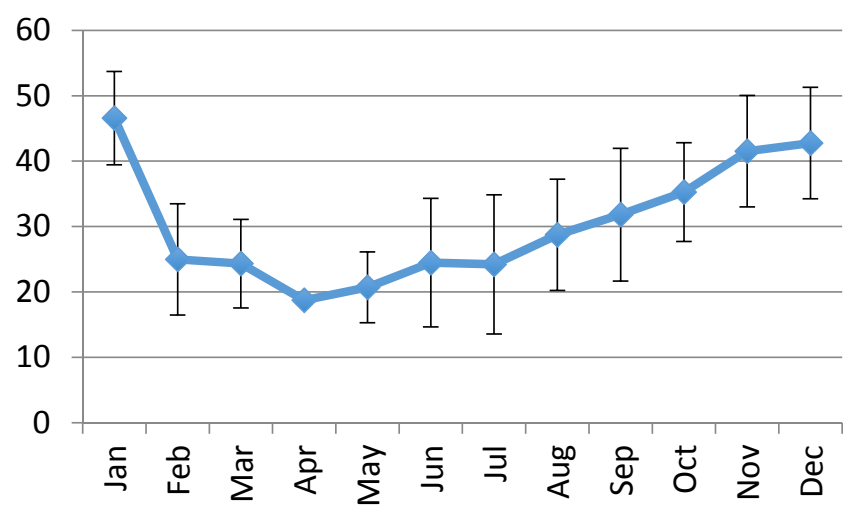

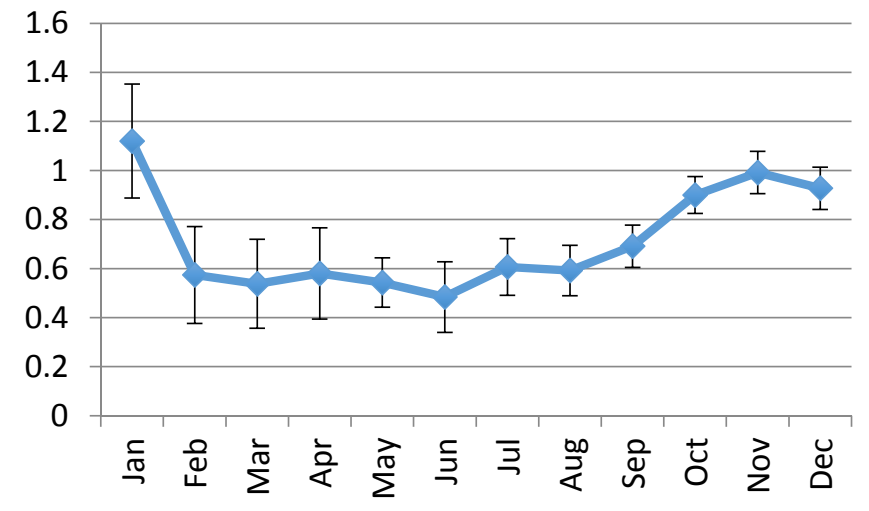


The 1st International Electronic Conference on Atmospheric Sciences (ECAS 2016), 16-31 July 2016; Sciforum Electronic Conference Series, Vol. 1, 2016

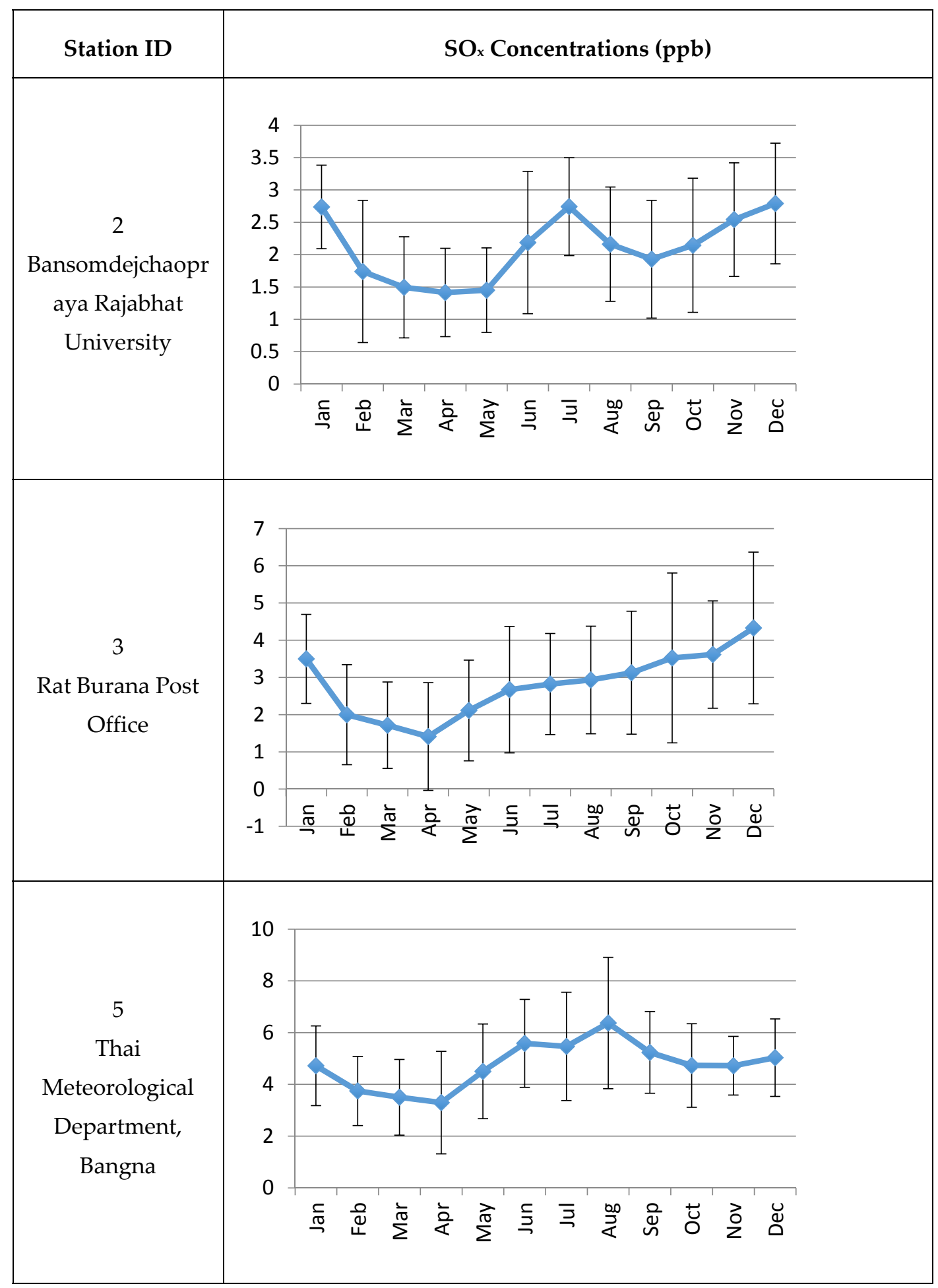


The 1st International Electronic Conference on Atmospheric Sciences (ECAS 2016), 16-31 July 2016; Sciforum Electronic Conference Series, Vol. 1, 2016

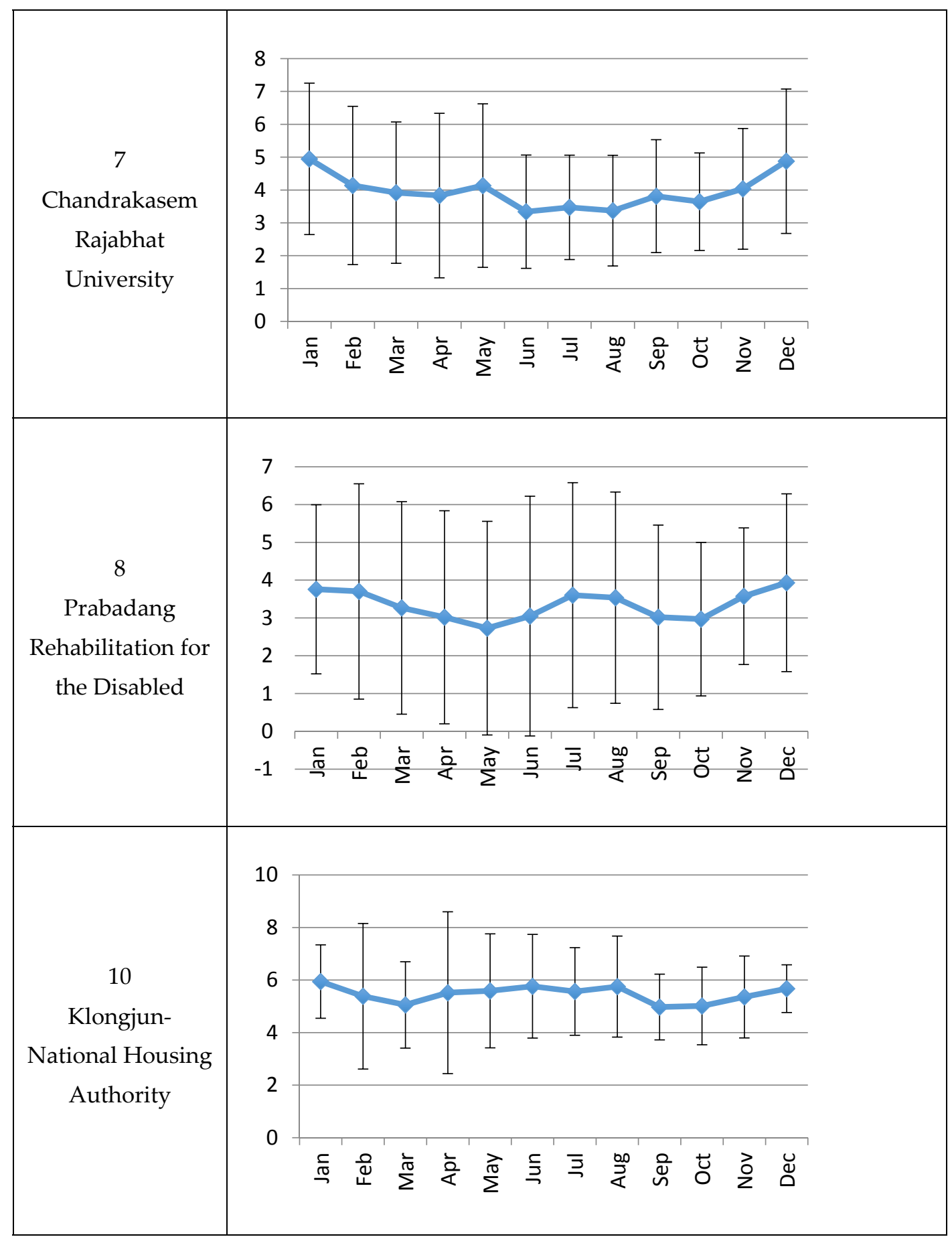


The 1st International Electronic Conference on Atmospheric Sciences (ECAS 2016), 16-31 July 2016; Sciforum Electronic Conference Series, Vol. 1, 2016

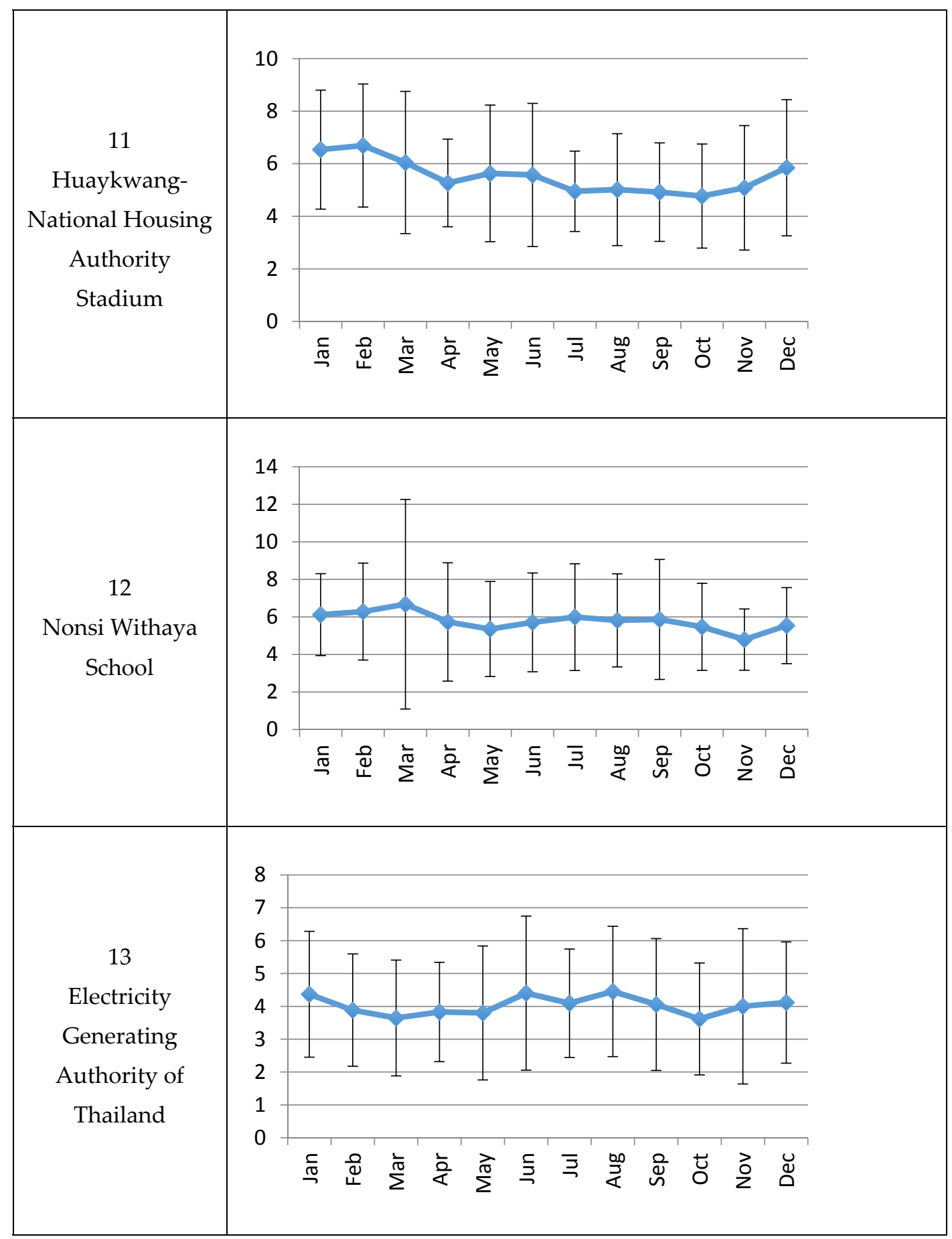


The 1st International Electronic Conference on Atmospheric Sciences (ECAS 2016), 16-31 July 2016; Sciforum Electronic Conference Series, Vol. 1, 2016

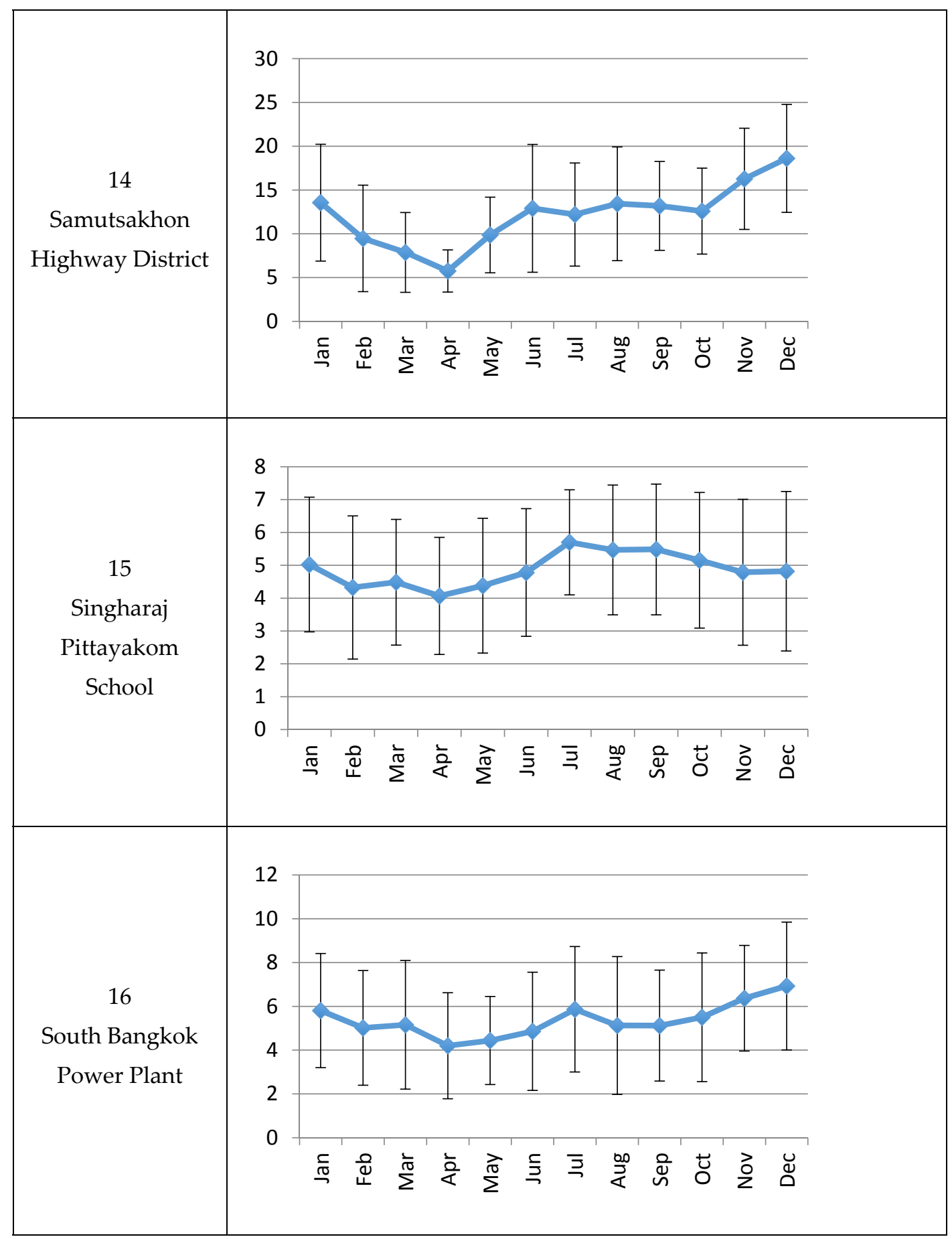


The 1st International Electronic Conference on Atmospheric Sciences (ECAS 2016), 16-31 July 2016; Sciforum Electronic Conference Series, Vol. 1, 2016

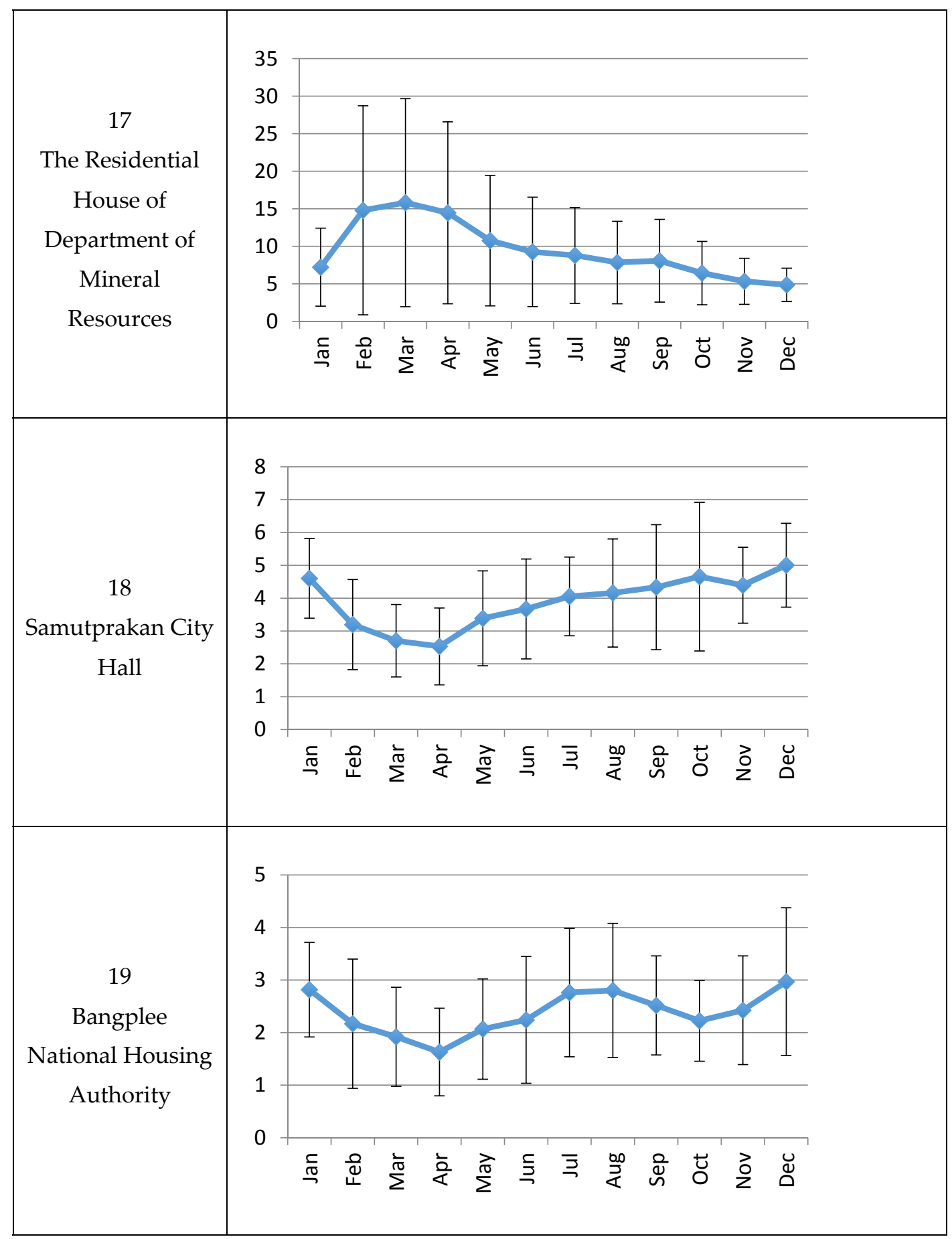


The 1st International Electronic Conference on Atmospheric Sciences (ECAS 2016), 16-31 July 2016; Sciforum Electronic Conference Series, Vol. 1, 2016

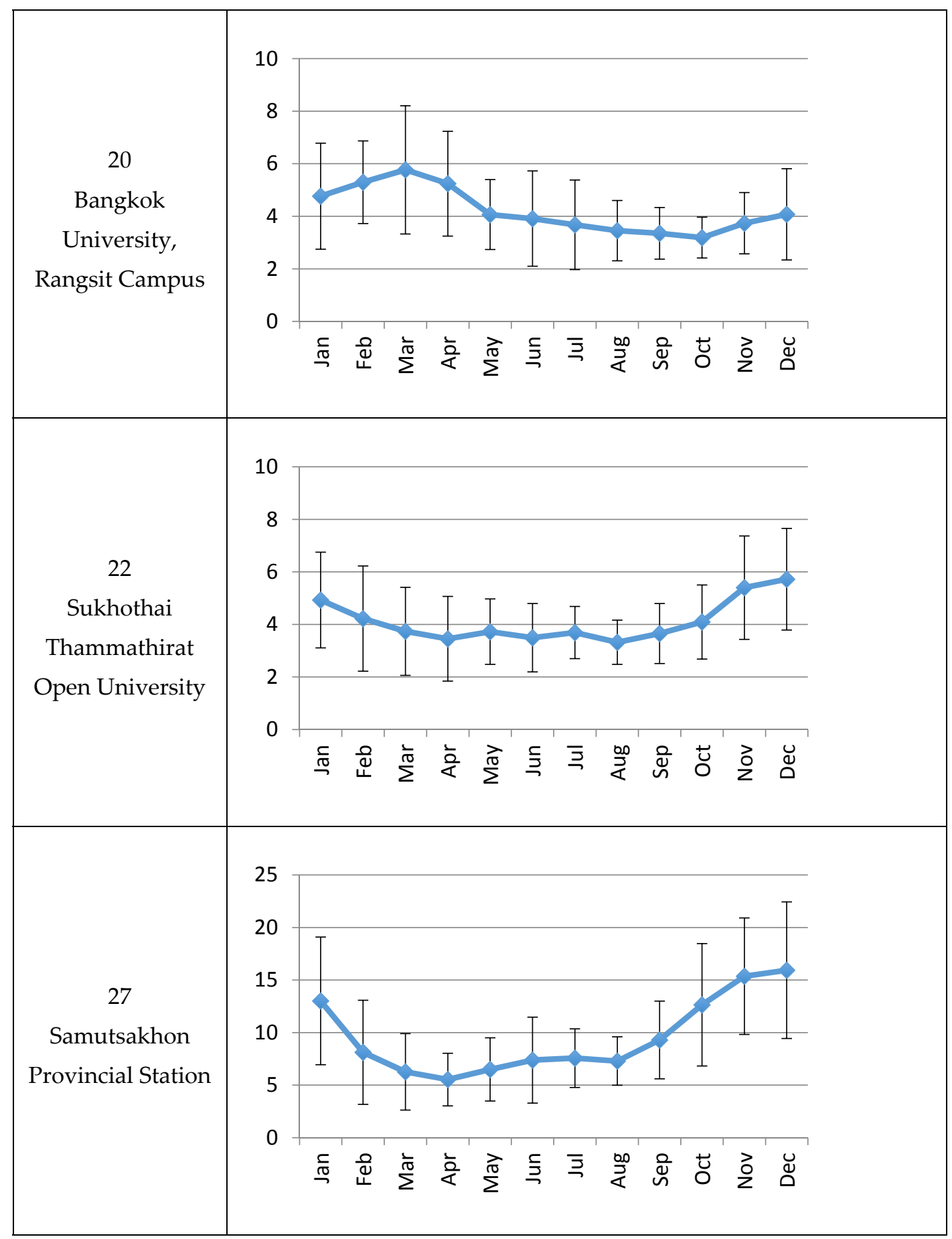


The 1st International Electronic Conference on Atmospheric Sciences (ECAS 2016), 16-31 July 2016; Sciforum Electronic Conference Series, Vol. 1, 2016




The 1st International Electronic Conference on Atmospheric Sciences (ECAS 2016), 16-31 July 2016; Sciforum Electronic Conference Series, Vol. 1, 2016

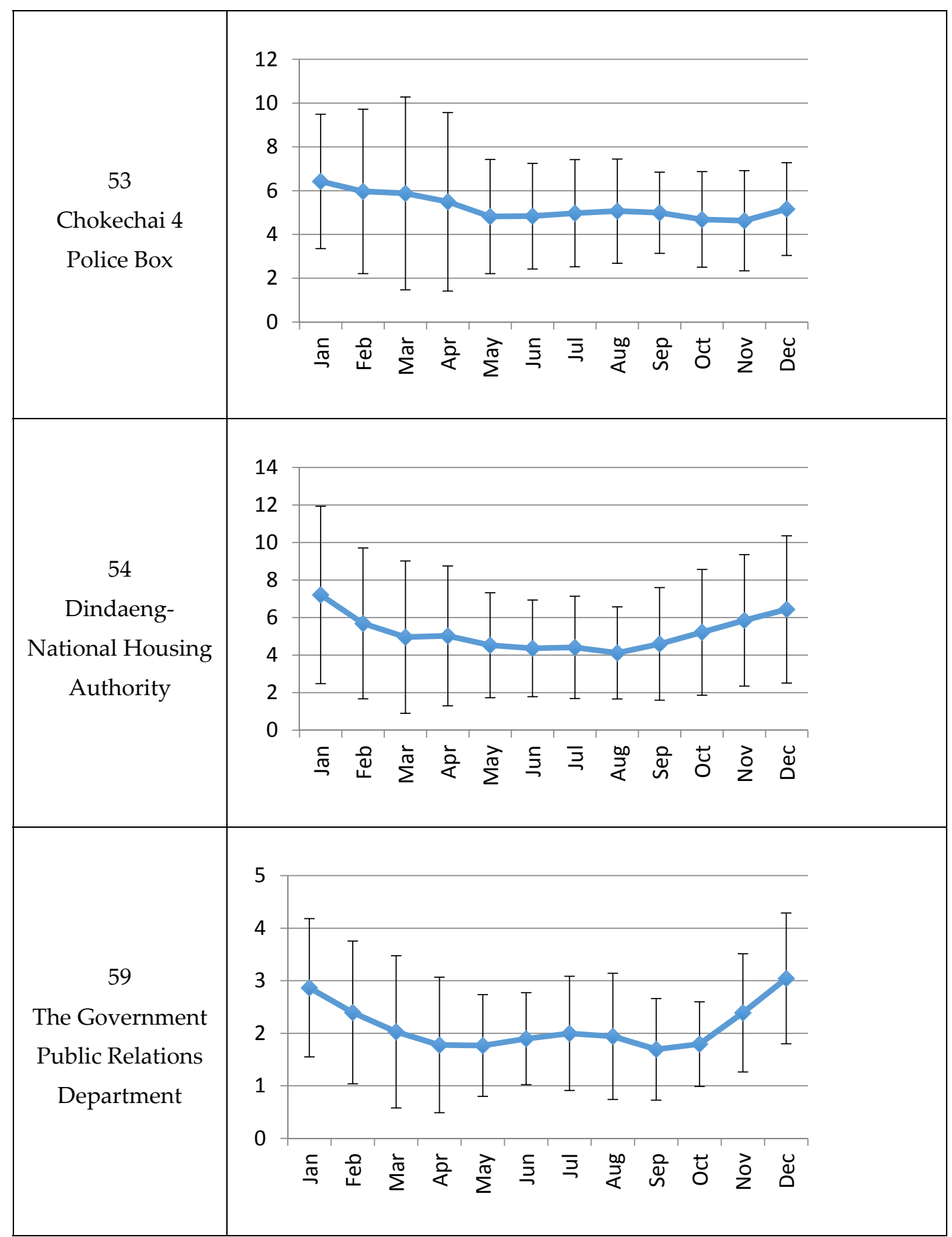


The 1st International Electronic Conference on Atmospheric Sciences (ECAS 2016), 16-31 July 2016; Sciforum Electronic Conference Series, Vol. 1, 2016

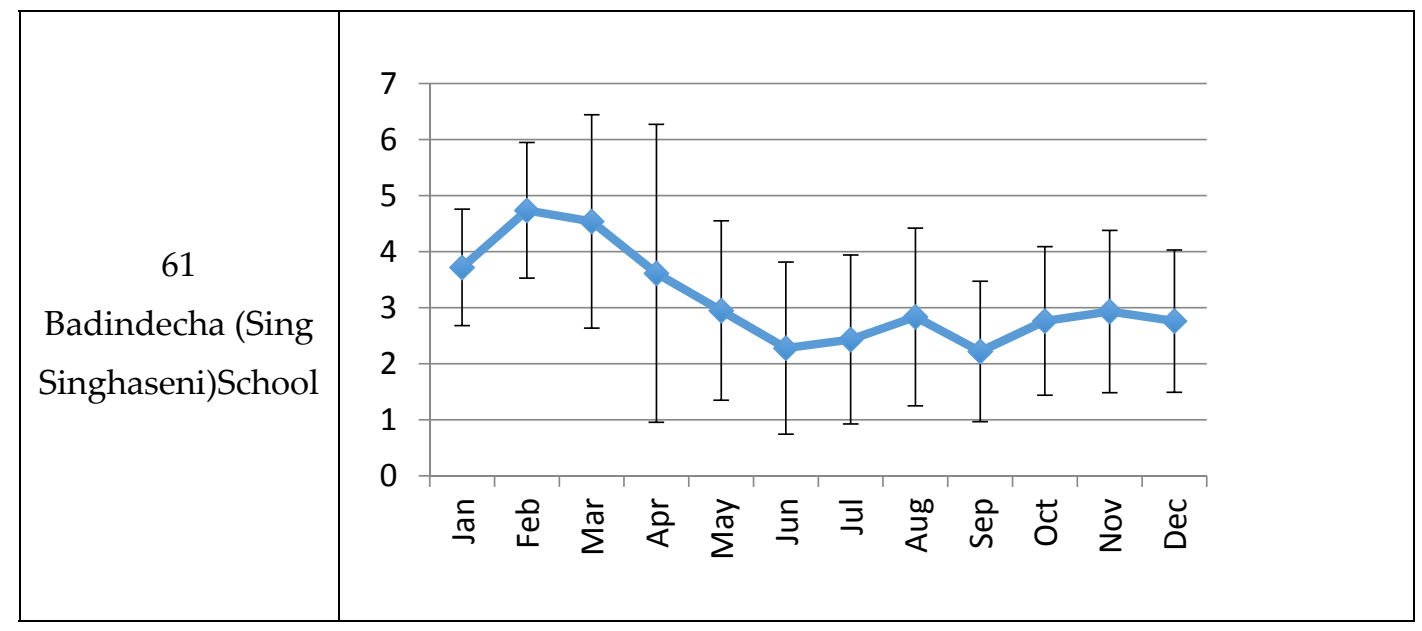

\section{References}

1. Pearce, F. How big can cities get? New Sci. 2006, 190, 10.

2. Boldo, E.; Linares, C.; Aragones, N.; Lumbreras, J.; Borge, R.; de la Paz, D.; Perez-Gomez, B.; Fernandez-Navarro, P.; Garcia-Perez, J.; Pollan M.; et al. Air quality modeling and mortality impact of fine particles reduction policies in Spain. Environ. Res. 2014, 128, 15-26.

3. Wimolwattanapun, W.; Hopke, P.K.; Pongkiatkul, P. Source apportionment and potential source locations of $\mathrm{PM}_{2.5}$ and $\mathrm{PM}_{2.5-10}$ at residential sites in metropolitan Bangkok. Atmos. Pollut. Res. 2011, 2, 172-181, doi:10.5094/APR.2011.022.

4. Machol, B.; Rizk, S. Economic value of U.S. fossil fuel electricity health impacts. Environ. Int. 2013, 52, 75-80, doi:10.1016/j.envint.2012.03.003.

5. Bonnet, S.; Anderson, L.G.; Garivait S. A study of ambient air quality in Bangkok and suburbs: Focus on ozone pollution. In Proceedings of the 15th International Joint Seminar on the Regional Deposition Processes in the Atmosphere and Climate Change, National Taiwan University, Taipei, Taiwan, 12-14 November 2009.

6. The Physics and Chemistry of Ozone. Available online: http://www.fraqmd.org/ozonechemistry.htm (accessed on 6 July 2016).

7. Polichetti, G.; Cocco, S.; Spinali, A.; Trimarco, V.; Nunziata, A. Effects of particulate matter (PM10, PM2.5 and $\mathrm{PM}_{1}$ ) on the cardiovascular system. Toxicology 2009, 261, 1-8, doi:10.1016/j.tox.2009.04.035.

8. Scottish Environment Protection Agency (SEPA). Making the Case for the Environment-the Chemistry of Air Pollution. Available online: https://www.sepa.org.uk/media/120465/mtc_chem_of_air_pollution.pdf (accessed on 6 July 2016).

9. Zhang, B.N.; Kim Oanh, N.T.K. Photochemical smog pollution in the Bangkok Metropolitan Region of Thailand in relation to $\mathrm{O} 3$ precursor concentrations and meteorological conditions. Atmos. Environ. 2002, $36,4211-4222$.

10. Watcharavitoon, P.; Chio, C.-P.; Chan, C.-C. Temporal and spatial variations in ambient air quality during 1996-2009 in Bangkok, Thailand. Aerosol Air Qual. Res. 2013, 13, 1741-1754, doi:10.4209/aaqr.2012.11.0305.

11. Thailand: Bangkok Metropolitan Region. Available online: http://www.citypopulation.de/php/thailandbangkokmetropolitan.php (accessed on 30 June 2016).

12. Urbanization in Thailand Is Dominated by the Bangkok Urban Area. Available online: http://www.worldbank.org/en/news/feature/2015/01/26/urbanization-in-thailand-is-dominated-by-thebangkok-urban-area (accessed on 6 July 2016).

13. The Climate of Thailand. Available online: http://www.tmd.go.th/en/archive/thailand_climate.pdf (accessed on 6 July 2016).

14. Pollution Control Department (PCD). Air Quality and Noise Standards. Available online: http://www.pcd.go.th/info_serv/en_reg_std_airsnd01.html (accessed on 10 July 2016).

15. Finlayson-Pitts, B.J.; Pitts, J.N., Jr. Tropospheric air pollution: Ozone, airborne toxics, polycyclic aromatic hydrocarbons, and particles. Science 1997, 276, 1045-1051. 
16. Kim, S.; Hong, K.-H.; Jun, H.; Park, Y.-J.; Park, M.; Sunwoo, Y. Effect of Precipitation on air pollutant concentration in Seoul, Korea. Asian J. Atmos. Environ. 2014, 8, 202-211, doi:10.5572/ajae.2014.8.4.202.

17. National Statistical Office of Thailand. The 2008 Core Environment Indicators. Available online: http://web.nso.go.th/indicator/environ/air.pdf (accessed on 6 July 2016).

18. Seinfeld J.H.; Pandis, S.N. Atmospheric Chemistry and Physics: From Air Pollution to Climate Changes; John Wiley \& Sons: Hoboken, NJ, USA, 2006.

19. Srisurapanon, V.; Wanichapune, C. Environmental policies in Thailand and their effects. Available online: http://www.un.org/esa/gite/iandm/viroatpaper.pdf (accessed on 10 July 2016).

20. Clean air initiative for Asian Cities (CAI-Asia) Center. Clean Air for Smaller Cities in the ASEAN Region-Thailand Country Profile 2009. Available online: http://www.citiesforcleanair.org/documents/ THAILAND_GTZ_COUNTRY_PROFILE_FINAL.pdf (accessed on 10 July 2016).

21. Anderson, L.G.; Snow, R.; Rasmussen, J.; Garivait, S.; Bonnet, S. Effects of Alternative Fuels on Vehicle Emissions. In Proceedings of the 15th International Joint Seminar on the Regional Deposition Processes in the Atmosphere and Climate Change, National Taiwan University, Taipei, Taiwan, 12-14 November 2009.

22. Thailand: Light-Duty: Emissions. Available online: http://transportpolicy.net/index.php?title= Thailand:_Light-duty:_Emissions (accessed on 10 July 2016).

23. Bonnet, S.; Garivait, S. Trends of Ambient Air Criteria Pollutants in Bangkok during 2000-2006. In Proceedings of the 13th International Joint Seminar on Regional Deposition Processes in the Atmosphere, Tsukuba, Japan, 20-24 January 2008; pp. 99-106.

24. Kim Oanh, N.T.; Upadhyay, N.; Zhuang, Y.-H.; Hao, Z.-P.; Murthy, D.V.S.; Lestari, P.; Villarin, J.T.; Chengchua, K.; Co, H.X.; Duang, N.T.; et al. Particulate air pollution in six Asian cities: Spatial and temporal distributions, and associated sources. Atmos. Environ. 2006, 40, 3367-3380, doi:10.1016/ j.atmosenv.2006.01.050.

(C) 2016 by the authors; licensee MDPI, Basel, Switzerland. This article is an open access article distributed under the terms and conditions of the Creative Commons by Attribution (CC-BY) license (http://creativecommons.org/licenses/by/4.0/). 